\title{
Sandy Gall's Afghanistan Appeal SGAA
}

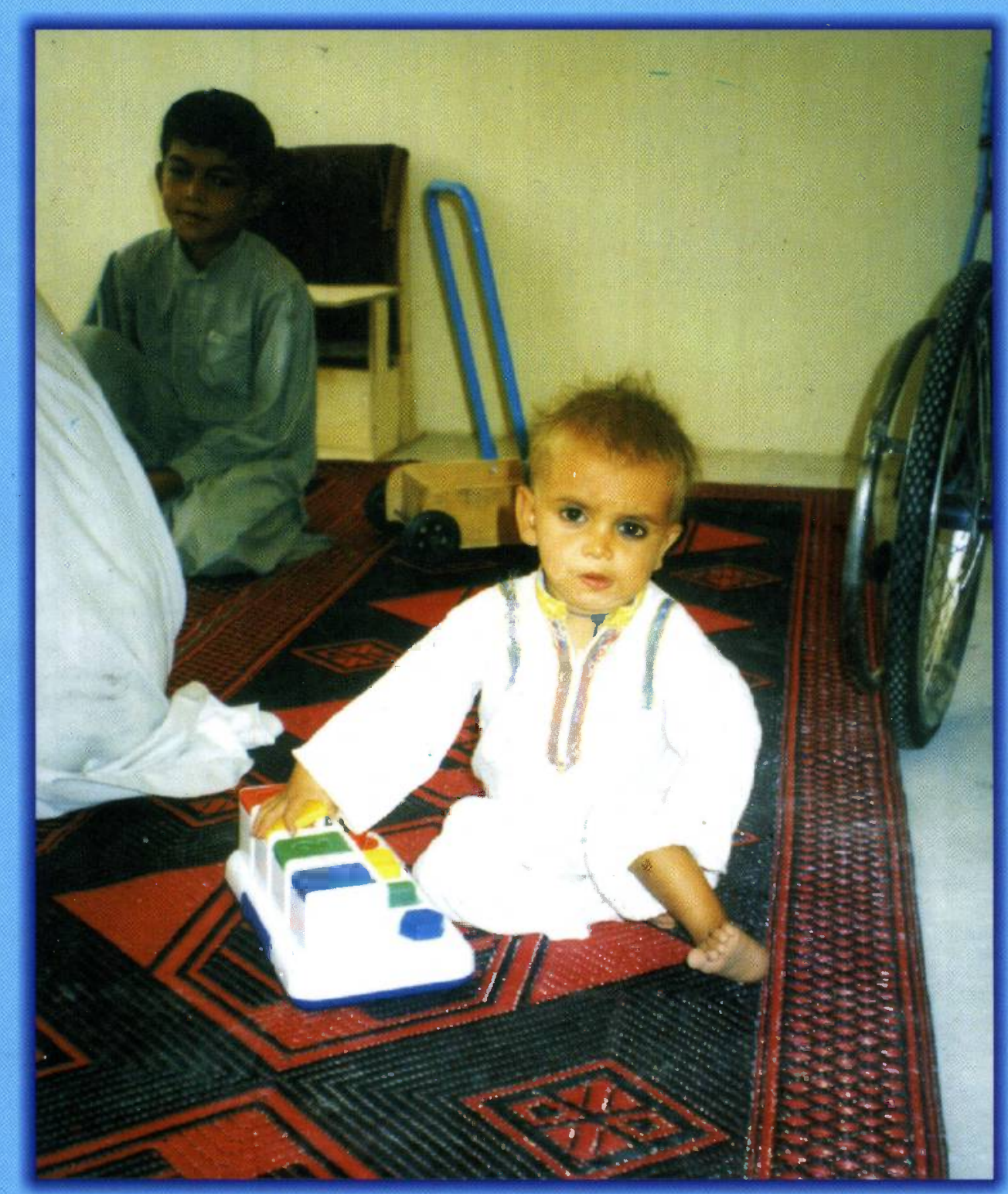

Investigation of the Probable Causes of Specific Childhood Disabilities in Eastern Afghanistan

(May 2000 - March 2001) 


\section{Sandy Gall's Afghanistan Appeal SGAA}

\section{Investigation of the Probable Causes of Specific Childhood Disabilities in Eastern Afghanistan}

(May 2000 - March 2001)

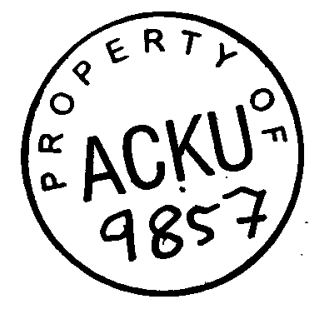

Funded by

United Nation Children's Fund Afghanistan Programme Office 


\section{CONTENTS}

\section{Summary}

Chapter One

Background to the Survey

Extent of Disability in Afghanistan

Page No.

Aims of the Survey

1

Selected Risk Factors from Research

3

Primary Risk Factors

Secondary Risk Factors

3

4

4

Chapter Two Research Methodology and Implementation Literature search for Identification of Risk factors for - causes of cerebral palsy, delayed development and club foot Survey Timetable How questionnaires were administered

Chapter Three Study Findings Summary of statistical findings Comments on findings

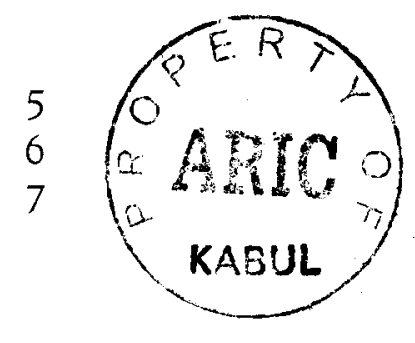
10

Chapter Four Recommendations

General health 13

Prevention of disability 13

Directives for ante-natal care

Ante-natal recommendations

Appendices

1 - Tables of statistical analysis

19

2 - List of research papers

3- Survey questionnaires

73 


\title{
S U M M A R Y
}

\begin{abstract}
Key Words:
Motor Control, Ante-natal, Peri-natal,

Post-natal, Risk Factors, Malnutrition.

\section{Investigation Of The Probable Causes Of Specific Childhood Disabilities In Eastern Afghanistan}

From May 2000 to March 2001 Sandy Gall's Afghanistan Appeal (SGAA) conducted a survey as a result of increasing numbers of patients with cerebral palsy, club foot and other developinental disabilities seen at its physiotherapy clinics in Eastern Afghanistan. SGAA wanted to identify the probable causes of these developmental disabilities in order to plan preventative measures. The study investigated the relation between maternal health factors, socio-economic and environmental variables and the occurrence of cerebral palsy and developmental disabilities.

The study was a case control design and included 633 children registered and treated at SGAA's clinics in the eastern region of Afghanistan between 1993 and 2001. All cases were diagnosed either as: cerebral palsy specific; delayed physical and mental development; clubfoot; or congenital dislocation of the hip. A register has been compiled to monitor the incidence of these disabilities and to provide information for further research.

Afghanistan has meagre resources and inadequate services for the early detection and rehabilitation of children with disabilities. Rehabilitation care for the disabled in Afghanistan is carried out by a handful of humanitarian agencies with minimal input from the naticnal health authorities and is insufficient for the needs. Twenty years of conflict and the continuing displacement of the population inside and outside the country has increased the problem of planning and provision of services for the disabled. In a country where the community faces poverty, war and limited health and education services, the disabled are especially disadvantaged. They have little opportunity to become active members of the community and earn a living unless they can benefit from rehabilitation care.

In all health care systems rehabilitation and medical care, tend to take precedence over prevention. Primary prevention is only possible when the aetiological factors (causes and clinical features) are identified. In order to plan primary preventative health care in Afghanistan it is believed that continued research needs to be done on the needs and wants of the population based on aetiological factors.

The authors hope that this study will serve, at least for some, as a stepping-stone to more advanced epidemiological studies about the disabled population groups in Afghanistan. There is a need to generate scientific data for policy makers to plan better preventive and rehabilitative services for the various disabled population groups in Afghanistan. 


\section{Results}

Analysis of findings against objectives of high and low risk factors.

The statistical significant factors in $C P$ (in order of magnitude) are:

1. Family history of disability 2. Congenital factor (Disability at birth)

3. Anaemia

4. Hyper emesis gravid arum

5. Trauma

6. Consanguinity

7. Too slow delivery

8. Psychological Stress

The statistical significant factors in delayed physical and mental development (in order of magnitude) are:

1. Absence of ante-natal care 2. Urinary tract infection

3. Malnutrition

4. Low birth weight

5. High Fever (12\% possible due to malaria or infection - patients do not take drugs regularly and suffer repeated attacks of malaria).

\section{SANDY GALL'S AFGHANISTAN APPEAL}

London/Afghanistan

\section{Autbors:}

Mrs. P. Chanrnugam M.Ed.H.P., M.C.S.P., P.T. Educational Consultant in Physiotherapy Curriculum in War Zones.

Mr. Ashfaq

Statistician, University of Peshawar, Pakistan.

Dr. Jamal Nasir

Epidemiologist, Environmental Health, Dept. of the National Institute of Health, Islamabad, Pakistan.

Dr. Fazela Shinwari

Survey Co-ordinator, Dept of Obstetrics \& Gynaecology, Ministry of Public Health, Nangarhar, Afghanistan. 


\section{CHAPTER ONE \\ Background to the Survey}

\section{Extent of Disability in Afghanistan}

Even before twenty years of war and its consequences for the population, Afghanistan had one of the highest maternal morbidity and child mortality rates in developing countries (World health Organisation). There are no precise national statistics on the extent of disability in Afghanistan. The estimated international norm is that $3-4 \%$ of the population of a country is physically and mentally disabled. In Afghanistan with a population of twenty million this represents 600,00 to 800,000 individuals, but local surveys indicate that the figure is probably much higher, and that up to $15 \%$ of the population is directly affected by having a disabled family member. While some of these disabilities are a direct result of war injuries, such as traumas inflicted by mine blasts, many others can be attributed to disease and poor health care inside Afghanistan. Due to increasing nuinbers of patients with developmental disabilities SGAA decided to conduct a survey in Eastern Afghanistan with funding from UNICEF.

\section{Brief History of SGAA}

Sandy Gall's Afghanistan Appeal (SGAA) is a British Non-Governmental Organisation (NGO), set up by the journalist Sandy Gall in 1986 to help physically disabled Afghans. The organisation has two goals. Firstly, to treat the physically disabled by providing physiotherapy services and by making good quality artificial limbs, calipers, wheelchairs and walking aids. On average, 900 patients a month are helped with these rehabilitation services. The second aim is to train physiotherapists and orthopaedic technicians to carry out the rehabilitation work. Over 100 physiotherapists and technicians have been trained by SGAA since 1986 and they work all over Afghanistan. The organisation is currently based in Jalalabad, the provincial capital of Nangarhar Province in Eastern Afghanistan where it has run an orthopaedic rehabilitation and physiotherapy programme since 1993.

In its physiotlierapy clinics SGAA sees cases of post-poliomyelitis paralysis, cerebral palsy, head injuries, tuberculosis, congenital deformities and spinal injuries. In 1999 an average of 500 women and children per month (6000 per year) visited the central base in Jalalabad and outreach clinics in Nangarhar. Of these $51 \%$ are children aged 9 years and under and $17 \%$ are aged 10 to 18 years. All patients have treatment files. Amongst patients treated of 18 years and under, 35\% suffer post-poliomyelitis paralysis, $26 \%$ have cerebral palsy and delayed development, 10\% suffer neurological disabilities and 6\% suffer clubfoot. These conditions result in long-term disabilities.

\section{Increasing Trend of Cerebral Palsy Patients}

A comparison of numbers of cerebral palsy, delayed development and club foot patients treated by three programmes providing physiotherapy services for disabled Afghans show an increase in each category (see chart on the next page). These organisations are: the United Nations Comprehensive Disabled Afghans Programme (UNCDAP), which works in Central, Northern and Western Afghanistan and has the largest number of physiotherapy clinics: SGAA which works in Eastern Afghanistan; and the Pakistan Red Crescent Society 
(PRCS) which works in the refugee camps in the North-West Frontier Province of Pakistan. UNCDAP runs a community-based rehabilitation programme and SGAA and PRC run outreach physiotherapy clinics, each services both rural and urban populations. While patients with post-poliomyelitis paralysis and club foot are identified by health workers and medical staff and referred to orthopaedic centres, cerebral palsy and delayed development patients are not normally recognised nor treated by most medical staff except physiotherapy workers who have been specially trained. This means that nothing is done for these patients unless there are physiotherapists working in the local communities alongside other medical staff.

Average increase of patient figures from 1999 to 2000 :

\begin{tabular}{|c|c|c|c|}
\hline & Cerebral Palsy & Delayed Development & Club Foot \\
\hline CDAP & $66 \%$ & $14 \%$ & $38 \%$ \\
\hline SGAA & $24 \%$ & $30 \%$ & $34 \%$ \\
\hline PRCS & $18 \%$ & $56 \%$ & $3 \%$ \\
\hline
\end{tabular}

Due to the increasing incidence of cerebral palsy and developmental disabilities in the past ten years. SGAA and UNCDAP have engaged specialists in paediatric physiotherapy to upgrade the clinical skills of their local staff. In the Eastern region SGAA has a register of every cerebral palsy child treated in the main centre in Jalalabad and in the outreach programme in Nangarhar and Laghman. Currently there are 800 children listed on the register, as well as 4.000 polio patients registered since 1994 in the Eastern region.

Further indications of delayed development have been identified at malnutrition feeding clinics in Jalalabad, Laghman and Kabul. At these centres children with severe malnutrition are showing signs of delayed physical and mental development. Further research would be needed to determine whether it is purely severe malnutrition of mother and child that leads to delayed development or other high risk factors. It is clear to NGOs who are treating disabilities by physiotherapy, that we should be prepared for a further increase in cerebral palsy and delayed development.

\section{Factors Contributing to Disability}

Besides disease and trauma this study has attempted to determine other factors causing developmental disability in the child's socio-economic and environmental background. They include the lifestyle of the child and his or her family, their nutritional needs, and whether the child had access to basic medical services and community services such as those for the blind, deaf and dumb, or severely mentally retarded. These socio-economic and nutritional needs will influence the normal growth and development of the child. Much depends on the good health and care of the mother during the ante-natal, perinatal, and post-natal stages of the pregnancy.

Other factors include cultural attitudes to disabled members of society in Afghanistan. The general attitude of the local community towards the disabled in a country as poor as Afghanistan may not be as negative as it is in a wealthier society. Poverty is a great leveller. On the streets of an Afghan town it is common to see a disabled child being pushed along in a crude cart by other children, with no sense of embarrassment. Male amputees are such a common sight that they are accepted as part of the normal scene, 
but female amputees, because of purdah, are much less visible. Parents do show care and concern for their disabled children, and provide them with basic food and shelter, but usually feel that a child is disabled because of the will of God and that nothing can be done. The main problem is not neglect, but lack of knowledge and ignorance of how to help the child develop. There is a need to educate mothers and local communities on the proper care and management of disabled children.

\section{Aims of the Survey}

The research questions for the survey set out to:

1. Investigate the incidence of selective development disabilities: cerebral palsy (CP), $\mathrm{CP}$ specific, clubfoot, delayed mental and physical development (DD) and congenital displacement of the Hip (CDH) in Afghanistan.

2. Assess the prevalence of risk factors causing developmental disabilities.

3. Establish the difference in the developing world and the developed world's management of the neo-natal period, which can lead to neo-natal sepsis, which in turn causes cerebral palsy? How can this problem be addressed and prevented?

\section{Hypotheses}

1. Need for further study and research of risk factors of these five developmental disabilities during the ante-natal, peri-natal and post-natal periods.

2. The five developmental disabilities will continue to be a growing problem needing preventive care.

3. Safe motherhood can only be achieved by available and accessible ante-natal care for all pregnant women and this needs to be addressed by health actors providing ante-natal care.

4. It may not be feasible to prevent the causes of disabilities in war-torn Afghanistan.

\section{Identification of Risk Factors}

In order to investigate the causes of specific disabilities we needed to identify risk factors and incorporate them into the questionnaire. The following high risk factors for developmental disabilities were identified from research articles:
a) Low birth weight
b) Premature birth
c) Ante partum haemorrhage (APH)
d) Hypertension
e) Antibiotics
f) Forceps delivery
g) Birth asphyxia 
h) Malaria

i) Malnutrition of the mothers

j) Urinary Tract Infection (UTI)

k) Psychological stress

1) Relationship of parents

m) Prolonged labour

n) Infection (Rubella and Toxoplasmosis)

o) Hyperemesis gravidarum

The following risk factors were classified as significant primary and secondary risk factors:

Primary risk factors:

1. Low birth weight

2. Premature delivery

3. Ante partum haemorrhage

4. Essential hypertension

5. Antibiotics with infection

6. Forceps delivery

7. Birth asphyxia
Secondary risk factors:

1. Relationship of patients

2. Malaria (child and mother)

3. Bacterial meningitis

4. Malnutrition of mother and child

5. Rubella

6. Urinary Tract infection

7. Toxoplasmosis

8. Psychological Stress.

A questionnaire was developed to identify these risk factors. 


\section{CHAPTER TWO \\ Research Methodology and Implementation}

\section{Burden of Cerebral Palsy}

Extensive research showed that even in developed countries like the USA, Australia and the UK which provide good antenatal care, there is a growing incidence of cerebral palsy (see Appendix 1, reference 139). Each year about 10,000 babies born in the USA develop cerebral palsy (see Appendix 1, reference 140). These children are generally from poorer ethnic communities: e.g. the Caribbean population in Atlanta, in the USA or the Asian population in Bradford, in Britain. Most of them survive until the age of 18 because of good health-care. This means that the government and taxpayer have to pay a high cost for appropriate services for the disabled - for the specialised homes and institutes for their schooling, for the provision of mobility aids and for appropriate vocational training for income generation. A disabled child is a big psychological and economic burden to the parents. In this study we have not been able to consider the psychological and economic burden on the family and the community in Afghanistan. This will need to be considered in further research.

\section{Literature Search for Identification of Risk Factors}

The literature search was used to identify the primary and secondary risk factors that can contribute to the disabilities under examination (see appendix 1). An initial 10-year (1985 -1995) literature search on causes of cerebral palsy and delayed development only produced three or four studies undertaken in developing countries. The other studies had all taken place in developed countries. A research paper from Columbia University, New York, provided information on the methodology for identifying persons with motor and cognitive (vision, hearing and speech) disabilities from a comparative survey of Pakistan, Bangladesh, and Jamaica. This provided the ten-point model that was used as a guideline for the child questionnaire. A second literature search of the period 1995-2000 produced the gross motor function test, which is currently the most valid test for assessing delayed development for physiotherapists.

\section{Implementation of the Survey}

The survey was originally designed to take six months, but restrictions imposed by the authorities in Jalalabad led to considerable delays. 'The survey team was restricted to carrying out interviews only in Basic Health Units (BHUs) or SGAA centres. This meant a random house to house survey was impossible. SGAA devised an alternative methodology of random sampling in districts and villages where we had addresses of old patients. These patients were tracked down through local health workers. In the same districts local health workers and community leaders were asked to bring disabled patients to be assessed by the survey team. Many disabled came who did not fit the criteria of the survey but they had to be examined and referred. The survey was extended to nine months to collect more data with a monthly target of $80-100$ participants.

Survey Timetable

(See chart over page) 


\section{Survey Research Time Table}

\begin{tabular}{|c|c|c|c|}
\hline Year 2000-01 & Activities & Location & Methodology / Implementation \\
\hline & $\mathrm{PHASP}$ & & \\
\hline \multirow[t]{3}{*}{ May } & Pre-pilot study & Surkhrod, Nangarhar & $\begin{array}{l}21 \text { mothers and } 25 \text { children interviewed from existing } \\
\text { CP patients at Sultanpur clinic }\end{array}$ \\
\hline & $\begin{array}{l}\text { 30th May steering committee } \\
\text { meeting }\end{array}$ & Jalalabad & Review of pre-pilot study and questionnaires \\
\hline & $\mathrm{pnosed}$ & & \\
\hline June & Training of survey staff & Jalalabad & $\begin{array}{l}\text { The survey was halted for one month in June by } \\
\text { MOPH }\end{array}$ \\
\hline July & $\begin{array}{l}\text { Survey sta: is - } 2 \text { teams } \\
\text { (doctor, physio) go to different } \\
\text { locations. Data is entered } \\
\text { weekly into the computer. }\end{array}$ & $\begin{array}{l}\text { Ghanikhel, Jalalabad, } \\
\text { Mehterlam }\end{array}$ & $\begin{array}{l}80-100 \text { patients from SGAA's CP register targeted for } \\
\text { survey. } \\
93 \text { questionnaires completed, (31 included) }\end{array}$ \\
\hline & Otasolit & & 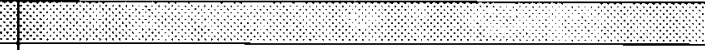 \\
\hline August & $\begin{array}{l}\text { Revision of questionnares to } \\
\text { include further information to } \\
\text { identify risk factors }\end{array}$ & & $\begin{array}{l}\text { 400-500 disabled targeted for further survey. These } \\
\text { disabled were referred by medical staff and local health } \\
\text { workers from NGO and MOPH clinics. } \\
97 \text { questionnaires completed }\end{array}$ \\
\hline September & Survey continues & Laghman. Nangarhar & 97 questionnaires completed \\
\hline \multirow[t]{3}{*}{ October } & Survey continues & & 91 questionnaires completed \\
\hline & $\begin{array}{l}\text { 30th October - Interim report } \\
\text { to steering committee }\end{array}$ & Jalalabad & $\begin{array}{l}\text { To inform steering committee of some of the problems } \\
\text { seen in maternal and child health care in the region. } \\
200 \text { patients were seen }\end{array}$ \\
\hline & Ptased & & \\
\hline November & $\begin{array}{l}\text { Survey extended, monthly } \\
\text { reports }\end{array}$ & $\begin{array}{l}\text { Nangarhar, Northen } \\
\text { Laghman }\end{array}$ & 77 questionnaires completed \\
\hline December & Survey continues & $\begin{array}{l}\text { Nangarhar, Kunar, } \\
\text { Laghman }\end{array}$ & $\begin{array}{l}\text { SGAA started survery in Kunar at the hospital in } \\
\text { Assadabad once a week with a doctor and a physios to } \\
\text { indentify disabled children. } \\
74 \text { questionnaires completed }\end{array}$ \\
\hline January & Survey continues & $\begin{array}{l}\text { Nangarhar, Kunar, } \\
\text { Northern Laghman }\end{array}$ & 95 questionnaires completed \\
\hline February & 29 February - survey finished & $\begin{array}{l}\text { Nangarhar, Kunar, } \\
\text { Laghman }\end{array}$ & $\begin{array}{l}\begin{array}{l}\text { Total of } 633 \text { children and mothers collected from three } \\
\text { provinces. } \\
70 \text { questionnaires completed }\end{array} \\
\text { The }\end{array}$ \\
\hline March & $\begin{array}{l}\text { Data input and statistic } \\
\text { analysis }\end{array}$ & Jalalabad, Peshawar & \\
\hline April & Final report & Jalalabad, Peshawar & Presentations to UNICEF and medical NGOs. \\
\hline
\end{tabular}




\section{Design of the questionnaires}

Two questionnaires were designed for the survey. A questionnaire form asking information about the mother's medical history, and details of her pregnancy leading up to the birth of her disabled child and the peri-natal and post-natal periods. The questionnaire form for the child asked his parents detailed question's about the child's medical history. Each child was also given a physical assessment by an SGAA physiotherapist. A team of 3 Afghan doctors and 1 midwife administered the medical questionnaires. Interviews were conducted at SGAA physiotherapy clinics and patients were provided transport costs to attend the clinics on fixed dates. The medical team was trained to ask a series of questions to ensure the information was accurate. Examples are given below.

\section{How the questionnaires were administered}

* Diseases

For all diseases we explained the clinical feature of each disease separately and then asked the mother if she had had any of the symptoms during the pregnancy or not? For example, we explained the clinical features of toxoplasmosis in details particularly for women who had had more than two abortions. Because of the expense, we were able to test only two mothers who said yes (I had this problem and still I have the same problem). We prescribed the test for toxoplasmosis. The results were positive.

\section{* Bacterial meningitis}

We saw four patients who had had bacterial meningitis and encephalitis and had kept their result cards with them. During our survey we did not find sickle cell anaemia. We asked the mothers about this disease and none of them had had it. But it should be pointed out that the clinical features of sickle cell anaemia are hard to identify and a blood test is necessary. None of the patients had a history of sickle cell anaemia in their family, which is popularly known as $d a$ wene.

\section{* Prolonged labour, birth asphyxia}

By asking one question about slow delivery (prolonged labour) we discovered answers to two other questions about anoxia and a low APGAR score. We would ask the mother to tell us about the duration of the delivery of the disabled child or if she had had any problem with the delivery of her disabled child.

If the mother said that the delivery had been over a long period, then we would ask her to tell us the approximate duration. Several mothers told us that they had regular pain with a leakage of amniotic fluid and no delivery. Then they went to the chemist and bought oxytocin to speed up the delivery process. When even this did not help them, some said they tried to find a dai (traditional birth attendant); in some areas they said they went to the hospital. Those who went to the hospital said the doctor told them it was very late. "Why didn't you come earlier, your child's condition is not good." Some mothers said they asked why the baby was not crying and the doctor told them that the umbilical cord was wrapped around the baby's neck. "That's why your child's condition is not good, and you had a prolonged delivery." Some of them said that with the help of oxytocin and the dai, the delivery was completed and the dai told them that the umbilical cord had been wrapped around the baby's neck. Some of the mothers said that they were sick with irregular pain for two to three days and with regular pain for one complete day. 
Their labour was very difficult, "as if the child was coming out of my eyes" (laka zama da stargo na chi wozi).

\section{* Low APGAR score}

The respiration rate and other signs like pulse rate activity were not easy to obtain from the mothers. For the number of APGAR score we just said low APGAR when the mother explained that the child didn't cry, or the skin colour was blue, ("tak shen"). If the first reflex of the neonate to the external environment was to cry less loudly than normal. they were marked under a low APGAR score. This in itself gave us clues about hypoxia.

\section{* Low birth weight (under peri-natal part 2 questionnaire section I)}

We asked the mother to tell us about the weight of the child at birth. Some of the mothers said: "To tell you the truth in comparison to my other children this child was lighter than the others." Some of the mothers said the baby was just like a worm (chingia). Others said it was like rengare or like nari tota and that old women told them to keep the baby wrapped in cotton otherwise he or she would die. But mothers who had the delivery in hospital, said the doctor would ask them, "Why is your child lower in weight than normal? Did you take any medicine, or did you have any serious disease during pregnancy?"

\section{* Premature labour (question 17 part 2 questionnaire)}

We asked the mothers about the duration of pregnancy - was it a full nine months, or not. They estimated the length of the pregnancy with reference to the timing of their crops. They would say that during the sowing of opium or wheat was last time they had their menses and the same for estimating the length of the pregnancy. They would say, "My actual time was at the wheat harvest". Some who had a premature child would say, "It was not the correct time of the delivery", or "Our child was smaller than normal and was not good at breast feeding". Only a few mothers who said that their baby was delivered prematurely had proof from doctors or midwives.

\section{* Cerebral Palsy at birth (Question under peri-natal)}

To establish if the child had cerebral palsy from birth we asked the mother when she had first noticed that her child had a problem. Some of the mothers told us from birth, others said after six months, and others after one year. For those who said after birth, we asked them how they knew. A typical answer was that from the birth of their child until it was three or four months old, there was no development compared to other children. "After six months I saw that the child was still like a very small child". Some said, "We compared our child to the children of our neighbours and we saw that our child had not developed". Although the child had not had any serious problems or illnesses during its first four or six months, when they took the child to a private clinic or a hospital, the doctor would tell them that the child had a kind of nerve problem, asabi. Others said they waited a year for the child to be able to sit, but when they tried to make it sit or stand, "There was a different reaction in comparison to our other children." (In other words the child could not sit or stand properly).

\section{Constraints}

The methodology used was subjective because answers had to be elicited from the mothers and fathers, as health records are extremely limited. There are no discharge 
records from hospitals and clinics and most dais (traditional birth attendants) are illiterate and not trained to keep patient records. The experienced gynaecologist and the midwife monitoring the administration of the questionnaire for mother and child were fully aware that the majority of families interviewed were illiterate (90\%). It is important, therefore, to understand that Afghan society is large an oral one where women discuss issues, elicit information, answer queries and provide solutions by word of mouth.

Another constraint is the lack of educated midwives, female physicians and gynaecologists to provide ante-natal services. 


\section{CHAPTER THREE \\ Study Findings}

\section{Methodology of Data Analysis}

The data was collected by face to face interviews with disabled children's parents. The study population comprised male and female children up to the age of 15 . The sample consisted of 633 disabled children living in three provinces.

* All questionnaires were coded.

* An experienced statistician examined all completed questionnaires.

* The responses (in the form of codes and numerical figures) were recorded on the computer. Content validity was tested and all those records with impaired validity were deleted.

* The database was tested for validity of data entry by a random checking of records and by making cross tabulation.

* An appropriate programme called SPSS was used to get the required results from the database and these results were transferred to a spread sheet package for further analysis and graphic presentation.

The survey was tested with multi- correlation of risk factors and further for the significance of factors by using Chi-Square distribution. Probability risk factors were also correlated with 2 control groups. For prediction we used the regression analysis.

This system allows the possibility of high risk factors to be identified and a uni-variant correlation can be done with a single other high risk factor. This type of statistical analysis will depend on the nature of the factor identified.

\section{Summary of the Statistical findings}

A cluster sample of 633 parents of the disabled children was interviewed in different villages by trained interviewers with a pre-coded questionnaire to explore the major causative factors of developmental disabilities of all categories in the defined population. This study reveals the following findings.

1. $88 \%$ of the mothers interviewed had delivered at home, only $7 \%$ in hospitals and $5 \%$ at private clinics.

2. $73 \%$ of the children were delivered by relatives, $9 \%$ were delivered by doctors, $8 \%$ were delivered by nurses, $8 \%$ by dais (traditional birth attendants) and $2 \%$ by trained midwives.

3. $37.5 \%$ of the disabilities were identified at birth. Disabilities of congenital origin are more significant.

4. $46 \%$ of the children were born of parents, who were first cousins, which is confirmed by computing chi-square value, which is 10.87 with 1 degree of freedom.

5. $52 \%$ of the children had cerebral palsy specific and mental retardation, $25 \%$ had delayed physical and mental development, $13 \%$ had $\mathrm{CP}$ specific and $10 \%$ had club foot. 
6. $80 \%$ of the children in the defined population had speech problems, $9 \%$ had hearing impairments and $2 \%$ of the children were visually handicapped.

7. $46 \%$ of the children were born of mothers suffering from anaemia, which is confirmed by computing chi-square value. That is 17.3 with 3 degree of freedom.

8. $51.3 \%$ of the disabled children had one parent who suffered from malaria (or high fever).

9. $24 \%$ of the disabled children were born of mothers who suffer from hyper- emesis gravidarum.

10. $58.3 \%$ of the disabled children were born from mothers who had received no antenatal care.

11. $22.4 \%$ of the pregnant women in the defined population had had ante-natal checks before the birth, $77.6 \%$ had not had any.

12. $32 \%$ of the children were born of parents suffering psychological stress, which is confirmed by computing chi-square value. That is 6.948 with 3 degree of freedom.

13. Most families in low-income groups have disabled children. The impact of low income has a positive association with all type of disabilities $\left(\chi^{2}=20.121\right.$. $\left.\mathrm{df}=3\right)$.

14. $19 \%$ of children were found to be malnourished.

15. $31 \%$ of women indicated that they were vaccinated with the Tetanus vaccine.

16. $81 \%$ of children were found to be vaccinated (Triple vaccine) and $86 \%$ of children were vaccinated against polio.

17. There was no significant change in diet during pregnancy. Only $2 \%$ of the mothers could afford to buy fish, $4 \%$ of the mothers could afford to buy chicken, $15 \%$ to buy fruit, $57.5 \%$ to buy meat, $70 \%$ to buy rice, but all could afford dal, vegetable and nan.

18. The average age of the children was 5 years. $56 \%$ of the children were less than 5 . $36 \%$ were between $5-10$, and $8 \%$ above 10 .

19. The average age of the mother was 35, and the average age of the father 42 .

20. $97 \%$ of the mothers in the defined population were illiterate, $2 \%$ had primary education and $1 \%$ were graduates.

\section{Analysis of finding against objective of high and low risks factors}

The statistically significant factors in cerebral palsy in order of magnitude were:

1. Family history of disability

2. Congenital factor (Disability at birth)

3. Anaemia

4. Hyperemesis gravidarum

5. Trauma

6. Consanguinity

7. Too slow delivery

8. Psychological stress

The statistically significant factors in delayed physical and mental development in order of magnitude were:

1. Absence of ante-natal care

2. Urinary tract infection

3. Malnutrition 
4. Low birth weight

5. High fever ( $12 \%$ of mothers surveyed had high fever, possibly due to malaria or infection. Patients did not take drugs regularly and had repeated attacks of malaria).

\section{Comments on the Findings}

The study had identified from international research 15 risk factors likely to cause developmental disabilities. Eight of these were significant in the study. There are some comments to be made:

* Low birth weight was found in delayed development but no cases of premature delivery were found. This was possibly due to the inability of the survey team to get correct information from the mothers. Compare this to the fact that the hospital register in Mehtarlam hospital shows low birth weight and premature births are a factor among cerebral palsy children.

* $6 \%$ of cases took antibiotics during pregnancy, which is low by international standards.

* There were only 5 cases of forceps delivery because the vast majority of women deliver at home with family members assisting.

* $6 \%$ of cases had birth asphyxia which is low by international standards.

* Malaria was not significant (in mothers).

* Malnutrition of the mother was found to be a factor in delayed development ( $75 \%$ of mothers had insufficient breast milk).

* Urinary tract infections were a factor in delayed development, not in cerebral palsy.

* Consanguinity and family history of disability was a factor in cerebral palsy.

* Prolonged labour (too slow delivery) was a factor in cerebral palsy.

* High fever could be due to malaria or infection. Patients did not take anti-malaria drugs regularly and had repeated attacks of malaria. This was significant in delayed development.

* Anaemia was only discovered when antenatal clinics sent the patient for a haemoglobin count and then prescribed iron tablets.

The results of the survey provide important guidance for the Safe Motherhood Initiative being carried nut in Afghanistan to improve ante-natal, peri-natal and post-natal care. For future research it is important to have access to hospital records and all patients should be given discharge summaries.

In addition health practitioners must be aware that a mother with insufficient breast milk is often unable to provide supplementary food and should be encouraged to take her child to a malnutrition clinic. 


\section{CHAPTER FOUR}

\section{Recommendations}

\section{A. General Health}

\section{Publicity Campaign:}

A long-term campaign (radio, newspapers, community leaders, health workers) is needed to inform mothers of the value of ante-natal care and gradually to change the tradition of depending on relatives for help when giving birth.

Discharge summary:

All hospitals should give mothers a discharge summary following birth, so that in the case of disabled children there is better information for the peri-natal period.

Upgrade level of Dais:

Dais (traditional birth attendants) should be trained to record information about labour, if there were signs of foetal distress, or if the child was still-born.

\section{Vaccinations:}

All teenage girls should be given the triple vaccine and rubella vaccine and tested for TB. There are many cases of TB scoliosis.

\section{B. Prevention of Disability}

1. Future Health Planning: A workshop should be organised with NGOs providing ante-natal care, MOPH, WHO and UNICEF to look at strategies of ante-natal care and disability awareness.

2. Further Study: A further study should be made with a control group of normal children to see if the mothers had any high risk factors during the gestation period, and to pinpoint mothers with multiple pregnancies. Do these normal children show any signs of disability up to two years after birth? The study could be carried out in the villages and districts, where SGAA's study showed the highest rate of cerebral palsy and delayed development. Suggested locations are:

\begin{tabular}{llc} 
Province & District & Population \\
\cline { 2 - 2 } & Alinger & 75,000 \\
& Mehtarlam & 120.547 \\
Alishan & 63,607 \\
& Qarghaie & 97,639 \\
& & \\
Nangarhar & Surkhrod & 115,246 \\
& Shinwary & 36,695 \\
& Ghani Khail & 11,223 \\
& Khughyani & 111,223 \\
& Batikote & 58,463 \\
& Kama & 79,853 \\
& Mahsud & ------
\end{tabular}


The study could investigate other risk factors among mothers in these districts. All patients with poliomyelitis, cerebral palsy and delayed development would be followedup to ensure that they benefit from their physiotherapy treatment. A health educator worker could visit their homes to examine that the children were progressing and achieving their goals.

3. Surveillance of Malnourished Children: A surveillance plan should be set up to monitor delayed development in children following severe malnutrition in all regions of Afghanistan in conjunction with other organisations providing physiotherapy services. These children would have to be monitored until they are two years old to verify that there is a delayed development in malnourished children.

4. Delayed Development: All physiotherapists should be trained in the use of the gross motor function questionnaire which recent research shows is the most valid instrument for assessing delayed development.

\section{Some Directives for Ante-natal Care}

The Aims of Ante-natal Care should ensure that:

* The mother reaches the end of the pregnancy as healthy as, or even healthier than she was before pregnancy.

* Any physical or psychological problems arising during the pregnancy are detected and treated.

* Any complication of pregnancy is either prevented or detected early and managed adequately.

* The mother gives birth to a healthy baby.

* The mother has the opportunity to discuss her anxieties and fears about pregnancy.

* The mother is informed about any proposed procedures, the reasons for the procedure and the probable outcome.

* The parents are prepared for the birth and for child bearing including receiving information about diet, child care and family planning.

* Diet during Pregnancy: To a large extent this will depend on the mother's cultural background, eating habits and income level. But as a general principle, mothers should be advised to eat more fruit and vegetables and less fatty foods.

\section{General Advice}

Women who have a history of illnesses like diabetes or hypertension should make sure that they are under control.

\section{Care of Pregnant Women}

* Laboratory Tests:

a) Blood $\mathrm{Hb}$ ( 12-16 gr/L ) first antenatal visit.

b) Urine.

* All Women in Subsequent Antenatal Visits:

Rh factor

* Frequency of Antenatal Visits:

Every 4 weeks until the $28^{\text {th }}$ weeks of pregnancy.

Every 2 weeks until the $36^{\text {th }}$ week of pregnancy.

Foetal heart sounds by sound machine or Fetascope. 


\section{Preparation for Breast Feeding}

The person responsible for the ante-natal visit should inform the mother atout the importance and effectiveness of breast feeding.

\section{Growth of the Foetus during Pregnancy}

It is important to ensure that the foetus is not in any abnormal position. This is done by a trained gynaecologist, midwife or dai.

Ante-natal Screening

* Screening frr congenital defects, such as Down's Syndrome, neural tube defects and single gene defects, should be carried out on women over 35 or who have had a previous Down's Syndrome baby. Screening for genetic defects carried out by examining chorionic villus from 9-11 weeks, and amniocentesis at the $15^{\text {th }}$ or $16^{\text {th }}$ week of pregnancy.

* Ultrasound images will detect any congenital defects of the child.

\section{Problems in Peri-natal Care:}

\section{a. Birth Asphyxia}

Definition: Failure to initiate breathing in the newborn as a result of lack of oxygen. Apgar score of less than 5 minutes is accepted as evidence of asphyxia and is defined as a 5-minute Apgar of 3 or less.

b) Etiol ogy

a) Maternal - Hypertension (including pre-eclampsia)

- Diabetes Mellitus

- Nephritis

- Hypertension

- Infection

b) Placental - Abruptio Placenta

- Maternal hypoxia (from pulmonary or cardiac diseases)

- Infarction

c) Foetal - Cord Prolapse or Compression

- Anaemia

- Infection

- Intrauterine growth retardation (malnutrition)

\section{Clinical Features of Birth Asphyxia}

The infants are stuporous or comatose with generalised hypotonia. Breathing may be irregular with periods of Apnoea. Seizures usually occur in severely affected infants. generally in the first 12 hours. Besides the brain, other organs may be affected.

The incidence of neurological sequelae in survivors is $20-45 \%$ :

- prolonged coma,

- protracted seizures.

- generalized and persistent hypotonia.

Neo-natal Sepsis

Bacterial infection in a neonate (in the first four weeks of life) can be documented by positive blood culture. Incidence varies from 1-10/1000 live births. 
Predisposing Factors:

* Host factor (the newborn):

Impaired cellular responses - the leukocytes have defects in their response to chemotactic stimuli and show impaired bactericidal capacity.

Response - Impaired Humeral only Ig G is passively transferred from the mother to the newborn, while IgM and IgA is not. This leaves the newborn with weak defences.

Maternal Factors

* Poor socio-economic status.

* Maternal illness at the time of labour and delivery.

* Premature rupture of membranes (more than 18 hours)

* Maternal amniotensis.

* Prolonged labour.

* Maternal colonization (of cervix) with infections. Agents (E.coli group B streptococcal).

\section{Environmental Factors}

* Bacterial contamination at the time of labour and delivery.

* No infection control - unclean hospital and nursery environment and practices, e.g. hands are not washed properly, improper care.

* Bottle-feeding.

\section{Problems and Recommendations for Ante-natal Care}

\section{Poor History Recording}

During the survey SGAA found that the following information was not elicited from the patients during their ante-natal care:

* How many abortions have you had in your childbearing period?

* How many disabled children do you already have?

No proper history was taken from the patient. They were asked general questions like what problems do you have? If the answer was a headache, the doctor simply prescribed different kinds of analgesics and sent the patient away.

Example of poor ante-natal care: Mother Gulab Zari, age 40. SGAA card number 697, total pregnancies -9 , abortions -7 , only 2 living children. Of these two, one has cerebral palsy. No one had ever asked this mother about her many cases of abortion. If the health staff had asked her then they might have found the reason why.

\section{Training of Dais (Traditional Birth Attendants)}

There is a serious need to upgrade the training of dais so that they can take oral or written history from the patient and give them proper advice.

\section{Over-crowded MCH Clinics}

Some of the reasons for poor history recording are due to over-crowded clinics. The $\mathrm{MCH}$ clinics in the regions that we visited were very crowded and too many patients were waiting to be examined in a short time. The doctors just asked them a few questions and then prescribed them medicine.

To solve this problem we need to increase the working hours of the MCH clinics or increase the number of $\mathrm{MCH}$ clinics. We also need to train more qualified female staff.

\section{Promotion of Ante-natal Care}

There is a need to establish a good network of health workers to convince women that ante-natal care is very important. Most BHUs have health workers attached but more 
then half the women surveyed had never had ante-natal care. Why? Because these women have no idea about the importance of ante-natal care. Health workers together with dais should try to convince women to have regular ante-natal care.

Example of lack of ante-natal care: Mother Mohbibi, age 30, child's name Gulab, 8 pregnancies, 4 abortions, 4 children alive. One of the 4 has CP. She has never had antenatal care during pregnancy.

\section{Better Access to MCH and Paediatric Facilities in Eastern Afganistan}

In Rodat district in Nangarhar the survey assessed some disabled children. When we asked their mothers about ante-natal care during pregnancy. they said that they have no $\mathrm{MCH}$ clinic in Rodat and had to come to Jalalabad several times during each pregnancy which was very expensive.

Example: Mother Zaiagul, age 30, child Fahima age 18 months, total pregnancies -4 . Of four children alive one has cerebral palsy. The child developed fever and fell into a deep coma. There is no local government clinic to take the child to, only a paediatric clinic open for a short period in the mornings until 12 noon. There is nowhere for night emergencies and no $\mathrm{MCH}$ clinic in Rodat.

Action: All health actors involved in Safe Motherhood Initiative to discuss better coverage of the population with additional facilities in Nangarhar, Laghman and Kunar (including Nuristan).

\section{A Widespread Family Planning Programme in Eastern Afghanistan}

Doctors and health workers in the field should spend more time with mothers to explain the importance of family planning. The survey found some of the families had 2 or 3 children with delayed development and malnutrition. The mother has too many young children to feed at the same time and has difficulty in coping.

Example of no family planning: Mother Khan Bibi, (SCAA card number A 2102), 9

pregnancies, 3 still births. 6 children alive. Of the 6,3 suffer from delayed development. The reasons for this is that is no family planning, no information about preparing nutritional food and low family income.

\section{Urgent Problem of Oxytocin}

This drug is easily available in the bazaar and widely used, every family is equipped with the injection of oxytocin for women in labour. Why? Most women and their families want labour to finish quickly. No one tells the community that this injection can be harmful to the mother.

Recommendation: No Sale of Oxytocin without a doctor's prescription.

\section{Lack of Toxoplasmosis Tests}

Some mothers had toxoplasmosis tests prescribed by doctors in private clinics, but none had been referred by doctors during ante-natal care in $\mathrm{MCH}$ clinics. This is proof of poor ante-natal care.

Example: Mother Nasema, age 30, total pregnancies - 3, one still birth. two alive. Of the two living children one has cerebral palsy. Her toxoplasmosis test was + . We also prescribed toxoplasmosis tests for two other mothers with clinical signs and they also had + tests. Their records are in the survey documents. 


\section{Lack of Advice on Causes of Disability}

No one prevented the mothers of children with cerebral palsy from delivering more disabled children, or gave them proper advice on how to stop having more disabled children. Nor were they told what kinds of laboratory examinations were necessary.

\section{Correct Diet}

None of the mothers of children with cerebral palsy had been told about correct diet during pregnancy. Again, dais need to be trained to advise mothers on the importance of a nutritious diet and the need to gain weight during pregnancy.

\section{Need for Neonatal Wards in all Hospitals}

The survey saw many cases of disabled children who have had fever due to neonatal sepsis such as infection from the umbilical cord, eyes, jaundice and pneumonia. The establishment of a neonatal ward in each hospital should be a priority as well as the upgrading and training of midwives and dais.

\section{Regular Follow-up of Children Delivered by Forceps}

The survey saw some cases of disabled children with C.P. who were delivered by forceps. No one had asked the family to bring their children for a check, particularly those with trauma to the head.

Example: Child's name Mena, age 2 1/2, (SGAA card number 4292). She has cerebral palsy due to trauma of the head during forceps delivery.

\section{E. General Prevention}

For the last two years UNICEF's mandate has focused on Child Protection (2000) and Safe Motherhood (2001), issues which are closely related. Children need to be protected against cerebral malaria and tuberculosis, as well as polio, so polio re-vaccination campaigns could well be expanded to take in TB and malaria prevention.

Plans to prevent further malnutrition this winter, and safe water and drainage to prevent cholera in the summer must also be considered by all concerned UN and NGO agencies.

\section{GENERAL CONCLUSION}

This survey sets out the scale of the problems facing mother and child in the Eastern Province of Afghanistan. Implementation of the survey's recommendations; improved ante-natal care, a concerted effort to improve nutrition, prevention of malaria, TB and polio, and above all a better awareness of sound hygiene in rural societies, will do much to improve and, it is to be hoped, eventually transform the present dire state of health care in Afghanistan.

We strongly believe that despite all the constraints, including poverty, conflict, lack of access to health care and a shortage of experienced staff, it will be possible to effect, over the next five years, a considerable reduction in the number of physically and mentally impaired children, leading to a healthier and happier society, if there is better and more widespread ante-natal care. However, if malnutrition is not addressed in children under 5 years, the number of cases of delayed development will increase. Physiotherapy services must be ready to work in hospitals and clinics to treat children suffering from delayed development and to counsel their families and the community. 


\section{TABLE 01}

$\mathrm{CP}$ and Anaemia

\begin{tabular}{|ll|r|r|r|}
\hline \multirow{2}{*}{ Count } & \multicolumn{2}{|c|}{ Anaemia } & \multicolumn{2}{c|}{} \\
\cline { 3 - 5 } & & \multicolumn{2}{|c|}{ Yes } & \multicolumn{2}{c|}{ No } & \multicolumn{2}{c|}{ Total } \\
\hline Diagnosis & CP Specific & 54 & 31 & \multicolumn{2}{c|}{85} \\
& CP Specific \& Mental Ret & 153 & 173 & 326 \\
Total & & 207 & 204 & 411 \\
\hline
\end{tabular}

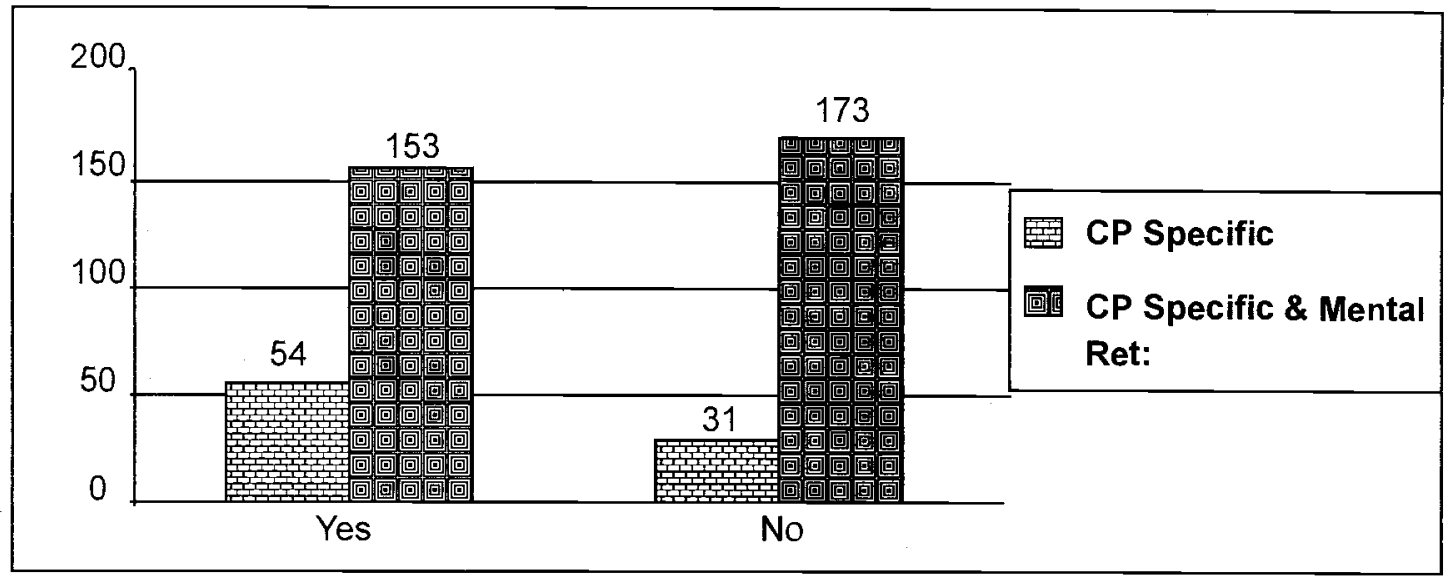

Chi-Square Tests

\begin{tabular}{|c|c|c|c|c|c|}
\hline & Value & df & $\begin{array}{l}\text { Asymp. Sig. } \\
\text { (2-sided) }\end{array}$ & $\begin{array}{l}\text { Exact Sig. } \\
\text { (2-sided) }\end{array}$ & $\begin{array}{l}\text { Exact Sig. } \\
\text { (1-sided })\end{array}$ \\
\hline Pearson Chi-Square & 7.429 & 1 & .006 & \multirow{6}{*}{.007} & \multirow{6}{*}{.004} \\
\hline Continuity Correction & 6.780 & 1 & .009 & & \\
\hline Likelihood Ratio & 7.508 & 1 & .006 & & \\
\hline Fisher's Exact Test & & & & & \\
\hline $\begin{array}{l}\text { Linear-by-Linear } \\
\text { Association }\end{array}$ & 7.411 & 1 & .006 & & \\
\hline$N$ of Valid Cases & 411 & & & & \\
\hline
\end{tabular}

$50.4 \%$ of mothers are anaemic during pregnancy, $13.1 \%$ of these mothers have a disabled child with "CP specific" and $37.2 \%$ of mothers have a disabled child with "CP specific and mental retardation".

The Probability ratio of a mother is 0.5 and the probability of that disabled child (CP specific) is 0.63 . The probability of the disabled child (CP specific and mental retardation) is 0.47 .

The Odds Ratio showed that the mother with a "CP specific" disabled child is 1.26 time higher than a mother with a "CP Specific \& Mental Retarded" child.

The chi-square test showed the value $=7.429$ with 1 degree of freedom and p-value is 0.004 . By comparing the p-value $=0.004$ with $5 \%$ level of significant shows association between disability and anaemia. 


\section{TABLE 02}

$\mathrm{CP}$ and Hyper Emesis Gravidarum

\begin{tabular}{|c|c|c|c|c|}
\hline & \multicolumn{2}{|c|}{$\begin{array}{c}\text { hyper emesis } \\
\text { gravidarum }\end{array}$} & \multirow[b]{2}{*}{ Total } \\
\hline & & Yes & No & \\
\hline $\begin{array}{l}\text { Diagnosis } \\
\text { Total }\end{array}$ & $\begin{array}{l}\text { CP Specific } \\
\text { CP Specific \& Mental Ret }\end{array}$ & $\begin{array}{l}12 \\
77 \\
89\end{array}$ & $\begin{array}{c}73 \\
249 \\
322\end{array}$ & $\begin{array}{r}85 \\
326 \\
411\end{array}$ \\
\hline
\end{tabular}

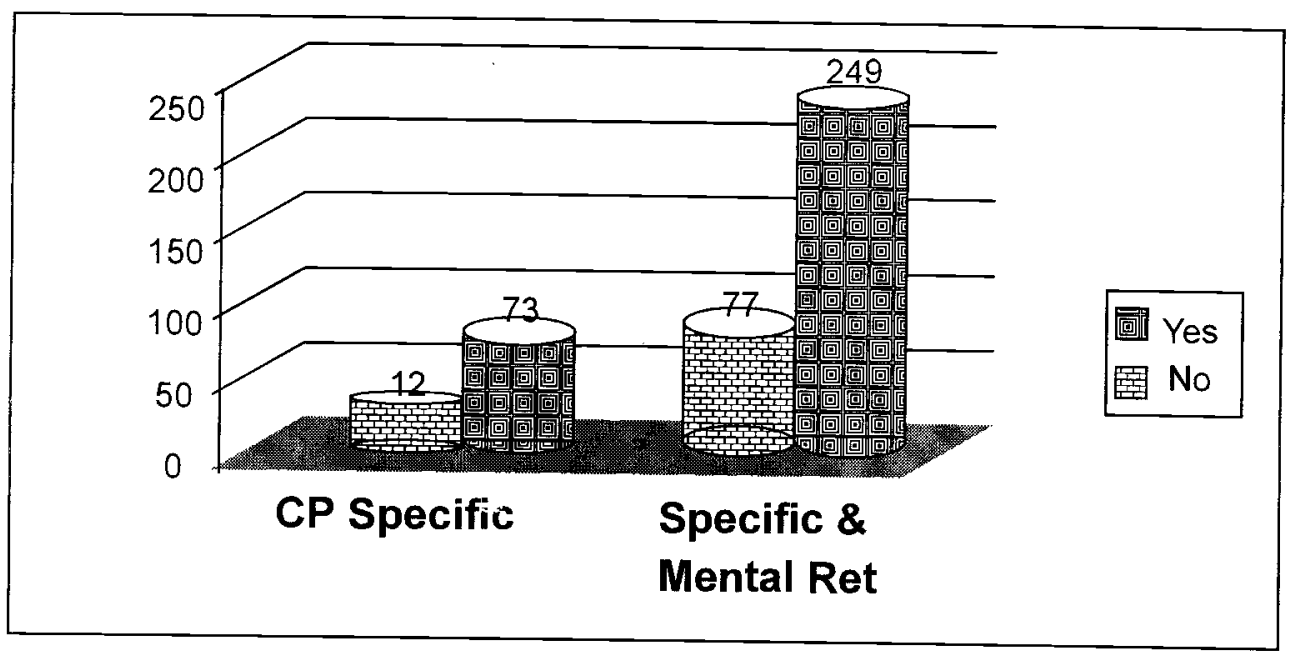

Chi-Square Tests

\begin{tabular}{|c|c|c|c|c|c|}
\hline & Value & df & $\begin{array}{l}\text { Asymp. Sig. } \\
\text { (2-sided) }\end{array}$ & $\begin{array}{l}\text { Exact Sig. } \\
\text { (2-sided })\end{array}$ & $\begin{array}{l}\text { Exact Sig } \\
\text { (1-sided) }\end{array}$ \\
\hline Pearson Chi-Square & 3.588 & 1 & .058 & \multirow{6}{*}{.075} & \multirow{6}{*}{.037} \\
\hline Continuity Correction & 3.050 & 1 & 081 & & \\
\hline Likelihood Ratio & 3.870 & 1 & 049 & & \\
\hline Fisher's Exact Test & & & & & \\
\hline $\begin{array}{l}\text { Linear-by-Linear } \\
\text { Association }\end{array}$ & 3.579 & 1 & 059 & & \\
\hline $\mathrm{N}$ of Valid Cases & 411 & & & & \\
\hline
\end{tabular}

$21.7 \%$ of mothers had Hyperemesis Gravidarum (HEG) during pregnancy. $3 \%$ of mothers had a "CP specific" disabled child and $19 \%$ of mothers had a "CP specific and mentally retarded" disabled child.

The Odds Ratio showed that mothers with HEG during pregnancy who had a child suffering from $\mathrm{CP}$ specific and mental retardation was almost 2 times higher compared to mothers with HEG with a $\mathrm{CP}$ specific child.

The Probability of having disability with HEG during pregnancy is 0.217 .

The chi-square test value $=7.429$ with 1 degree of freedom, where P-value (two sided) is 0.006 . By comparing the P-value with $5 \%$ level of significant association with disability and HEG. 


\section{TABLE 03}

\section{CP and Trauma}

Count

\begin{tabular}{|ll|r|r|r|}
\hline & & \multicolumn{2}{|c|}{ Trauma } & \multirow{2}{*}{ Total } \\
\cline { 3 - 5 } & & Yes & No & \multicolumn{1}{|c|}{. } \\
\hline Diagnosis & CP Specific & 3 & 82 & 326 \\
& CP Specific \& Mental Ret: & 29 & 297 & 326 \\
Total & & 32 & 379 & 411 \\
\hline
\end{tabular}

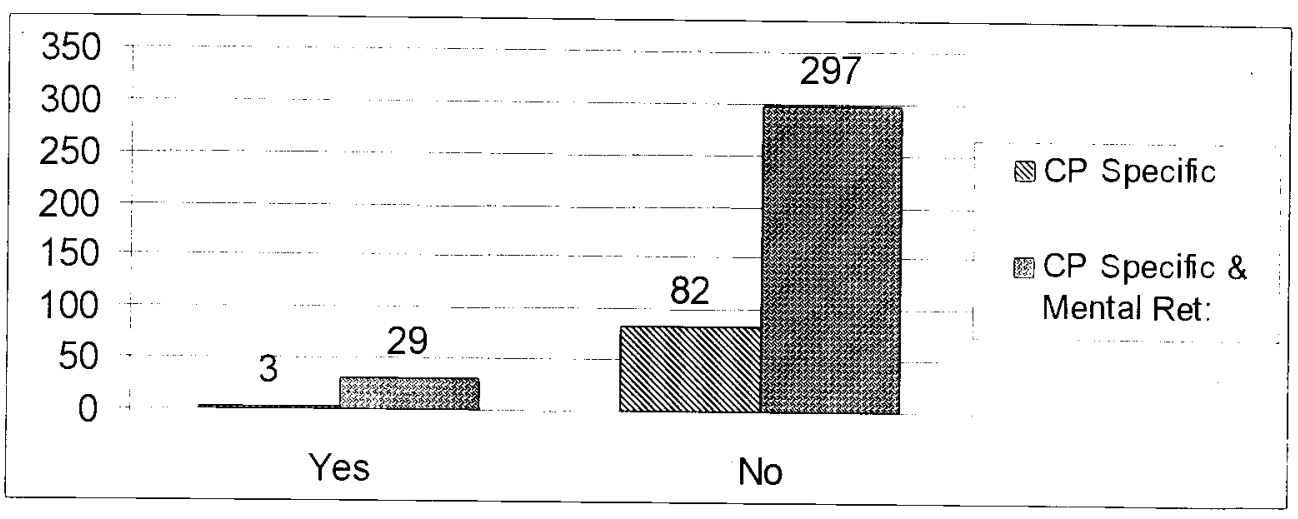

Chi-Square Tests

\begin{tabular}{|c|c|c|c|c|c|}
\hline & Value & df & $\begin{array}{l}\text { Asymp. Sig. } \\
\text { (2-sided) }\end{array}$ & $\begin{array}{l}\text { Exact Sig. } \\
\text { (2-sided) }\end{array}$ & $\begin{array}{l}\text { Exact Sig } \\
\text { (1-sided) }\end{array}$ \\
\hline Pearson Chi-Square & 2.704 & 1 & 100 & \multirow{6}{*}{115} & \multirow{6}{*}{.071} \\
\hline Continuity Correction & 2.008 & 1 & .156 & & \\
\hline Likelihood Ratio & 3.190 & 1 & .074 & & \\
\hline Fisher's Exact Test & & \multirow{3}{*}{1} & \multirow{3}{*}{.100} & & \\
\hline $\begin{array}{l}\text { Linear-by-Linear } \\
\text { Association }\end{array}$ & 2.698 & & & & \\
\hline$N$ of Valid Cases & 411 & & & & \\
\hline
\end{tabular}

Out of 411 samples. $7.8 \%$ mothers suffered trauma during pregnancy. So the probability that a mother suffers trauma during pregnancy is 0.073 .

The Odds Ratio showed that trauma during pregnancy leading to a child with CP specific and mental retardation is 2.69 times higher then the CP Specific. The chi-square test value is 2.704 with 1 degree of freedom. Where the P-value $=0.71$. By comparing P-value with $10 \%$ level significant.

This indicates that there is significant association between disability and trauma. 


\section{TABLE 04}

$\mathrm{CP}$ and Too slow delivery

\begin{tabular}{|c|c|c|c|c|}
\hline & & Too slow & very & \\
\hline & & Yes & No & Total \\
\hline Diagnosis & CP Specific & 12 & 73 & 85 \\
\hline Total & CP Specific \& Mental Ret: & $\begin{array}{l}26 \\
38\end{array}$ & $\begin{array}{l}300 \\
373\end{array}$ & $\begin{array}{l}326 \\
411\end{array}$ \\
\hline
\end{tabular}

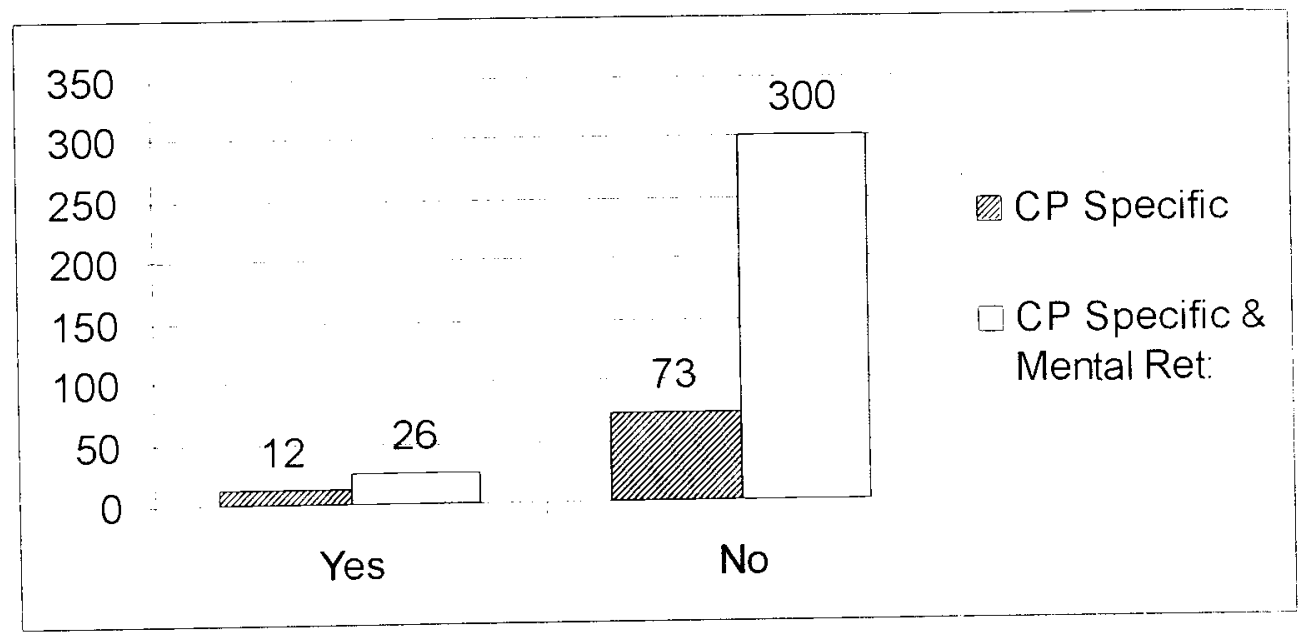

Chi-Square Tests

\begin{tabular}{|c|c|c|c|c|c|}
\hline & Value & $\mathrm{df}$ & $\begin{array}{c}\text { Asymp. Sig. } \\
\text { (2-sided) }\end{array}$ & $\begin{array}{l}\text { Exact Sig. } \\
\text { (2-sided) }\end{array}$ & $\begin{array}{l}\text { Exact Sig } \\
\text { (1-sided) }\end{array}$ \\
\hline Pearson Chi-Square & 3.031 & 1 & .082 & & \\
\hline Continuity Correction & 2.344 & 1 & .126 & & \\
\hline Likelihood Ratio & 2.757 & 1 & .097 & .093 & .067 \\
\hline $\begin{array}{l}\text { Linear-by-Linear } \\
\text { Association }\end{array}$ & 3.024 & 1 & .082 & & \\
\hline$N$ of Valid Cases & 411 & & & & \\
\hline
\end{tabular}

Out of 411 cases. $38(9.2 \%)$ mothers suffered from prolonged labour or "too slow delivery". The Odds Ratio showed that mothers of CP specific children are almost twice as likely to suffer prolonged labour compared to mothers of children with CP specific and mental retardation. The chi-square test at 1 degree of freedom is 7.429 . Where $P$ - value $=$ 0.041 one sided. By comparing the P-value with $5 \%$ level of significant. It indicates that there is a significant association between the disability and too slow delivery. 


\section{TABLE 05}

Disability and Psychologicai Stress

Count

\begin{tabular}{|ll|r|r|r|}
\hline & & \multicolumn{2}{|c|}{ psychological stress } & \multirow{2}{*}{} \\
\cline { 3 - 4 } & & Yes & \multicolumn{1}{|c|}{ No } & \multicolumn{1}{|c|}{ Total } \\
\hline Diägnosis & CP Specific & 35 & 50 & 85 \\
& CP Specific \& Mental Ret: & 107 & 219 & 326 \\
Total & & 142 & 269 & 411 \\
\hline
\end{tabular}

250

200

150

100

50

0
107

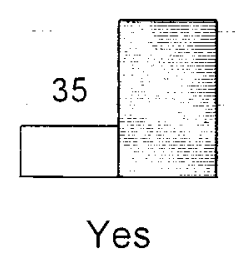

219

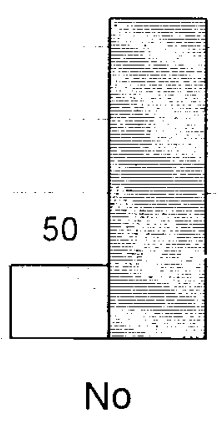

$\square$ CP Specific

CP Specific \& Mental Ret:

Chi-Square Tests

\begin{tabular}{|c|c|c|c|c|c|}
\hline & Value & df & $\begin{array}{c}\text { Asymp. Sig. } \\
\text { (2-sided) }\end{array}$ & $\begin{array}{l}\text { Exact Sig. } \\
\text { (2-sided) }\end{array}$ & $\begin{array}{c}\text { Exact Sig. } \\
\text { (1-sided) }\end{array}$ \\
\hline Pearson Chi-Square & 2.081 & 1 & .149 & & \\
\hline Continuity Correction & 1.728 & 1 & 189 & & \\
\hline Likelihood Ratio & 2.042 & 1 & .153 & & \\
\hline Fisher's Exact Test & & & & 160 & .095 \\
\hline $\begin{array}{l}\text { Linear-by-Linear } \\
\text { Association }\end{array}$ & 2.076 & 1 & 150 & & \\
\hline $\mathrm{N}$ of Valid Cases & 411 & & & & \\
\hline
\end{tabular}

Out of 411 mothers $34.5 \%$ mothers suffered psychological stress during pregnancy. Among these, $8.5 \%$ mothers with $\mathrm{CP}$ specific child had suffered psychological stress and $26 \%$ of the mothers had suffered psychological stress with children with CP specific and mental retardation. The Probability is 0.345 .

Odds Ratio showed that $\mathrm{CP}$ specific is 1.43 times higher as compared to $\mathrm{CP}$ specific and mental retardation. The chi-square test value is 2.081 with 1 degree of freedom and the Pvalue is 0.095 . There is significant association between disability and psychological stress.

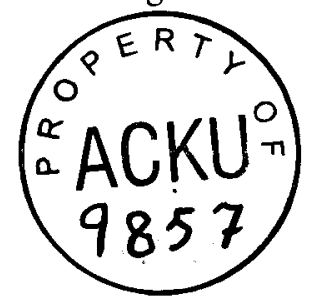




\section{TABLE 06}

\section{$\mathrm{CP}$ and Relationship of parents}

Count

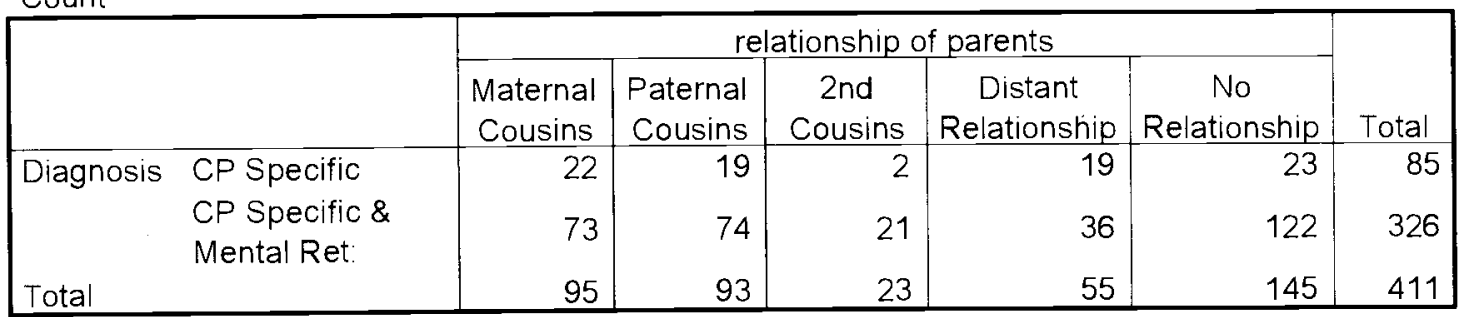

\section{$\square$ CP Specific 7 CP Specific \& Mental Ret:}

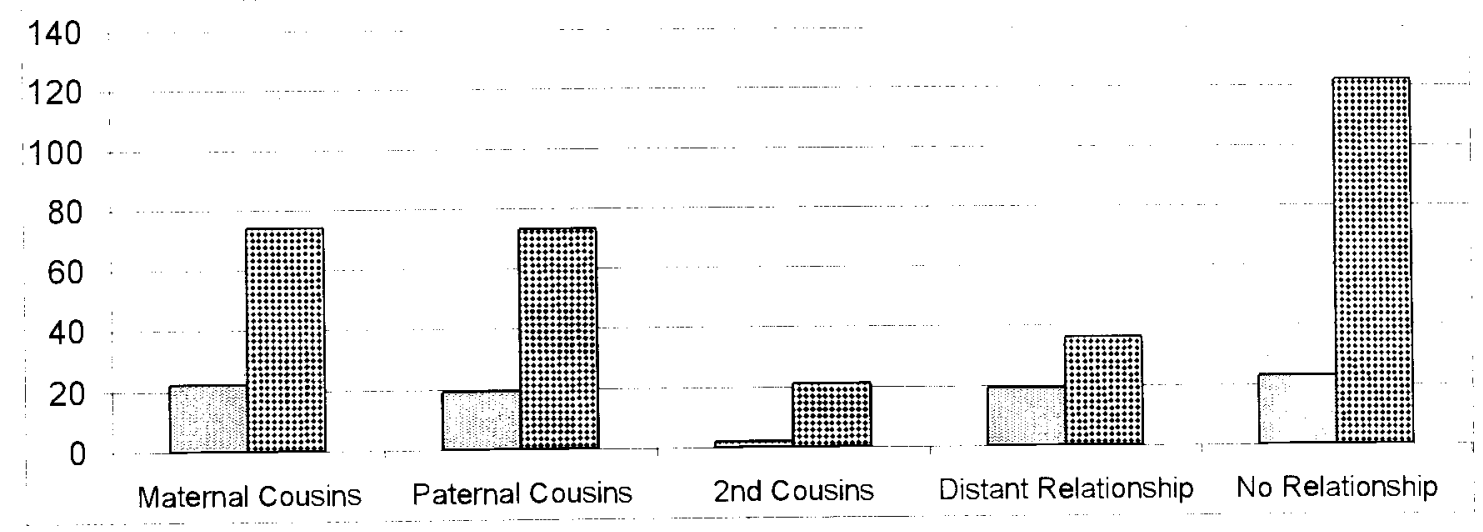

Chi-Square Tests

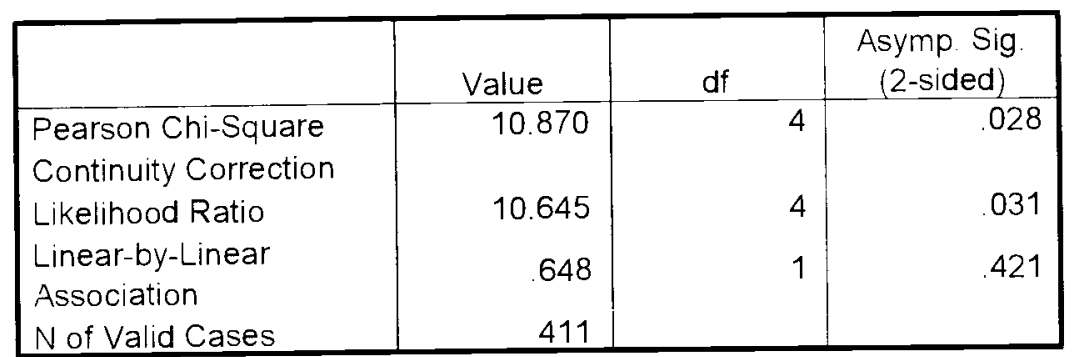

Out of 411 disabled children, 188 (46\%) had parents who were first cousins.

The probability of disability is 0.46 (Reference 34 ). $5.6 \%$ were second cousin parents while $13.4 \%$ were distantly related parents and $35.3 \%$ were parents with no relations. The chi-square test value is 10.87 with 1 degree of freedom showed that there is significant association between disability and the consanguinity of the parents. 


\section{TABLE 07}

\section{CP and Disability at birth}

Count

\begin{tabular}{|ll|r|r|r|}
\hline & & \multicolumn{2}{|c|}{ Disability at birth } & \multirow{2}{*}{ Total } \\
\cline { 3 - 5 } & \multicolumn{2}{|c|}{ Yes } & No & \multicolumn{1}{c|}{85} \\
Diagnosis & CP Specific & 44 & 41 & 326 \\
& CP Specific \& Mental Ret: & 108 & 218 & 411 \\
\hline
\end{tabular}

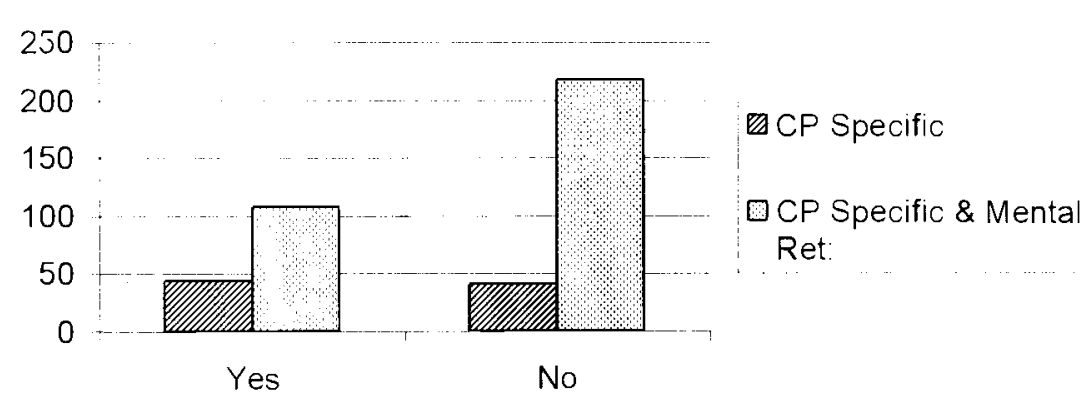

Chi-Square Tests

\begin{tabular}{|c|c|c|c|c|c|}
\hline & Value & df & $\begin{array}{l}\text { Asymp. Sig. } \\
\text { (2-sided) }\end{array}$ & $\begin{array}{l}\text { Exact Sig. } \\
\text { (2-sided) }\end{array}$ & $\begin{array}{l}\text { Exact Sig. } \\
\text { (1-sided })\end{array}$ \\
\hline Pearson Chi-Square & 10.047 & 1 & .002 & & \\
\hline Continuity Correction & 9.263 & 1 & .002 & & \\
\hline Likelihood Ratio & 9.781 & 1 & .002 & & \\
\hline Fisher's Exact Test & & & & .002 & 001 \\
\hline $\begin{array}{l}\text { Linear-by-Linear } \\
\text { Association }\end{array}$ & 10.023 & 1 & .002 & & \\
\hline $\mathrm{N}$ of Valid Cases & 411 & & & & \\
\hline
\end{tabular}

The study reveals that about $37 \%$ disability has a congenital origin. About $51.8 \% \mathrm{CP}$ specific and $33.1 \%$ CP specific and mental retardation are congenital.

The Odds Ratio showed that the Odds of disability at birth in CP Specific is 2.17 times higher compared to disability at birth in CP specific and mental retardation.

The $\chi^{2}$-value is 10.047 with 1 degree of freedom. This showed that there is a significant association between disability and disability at birth. 


\section{TABLE 08}

\section{CP and Family history of disability}

Count

\begin{tabular}{|ll|r|r|r|}
\hline & & \multicolumn{2}{|c|}{ family history disability } & \multirow{2}{*}{ Total } \\
\cline { 3 - 4 } & & Yes & No & \multicolumn{2}{|c|}{ Total } \\
Diágnosis & CP Specific & 12 & 73 & 35 \\
& CP Specific \& Mental Ret: & 16 & 310 & 326 \\
Total & & 28 & 383 & 411 \\
\hline
\end{tabular}

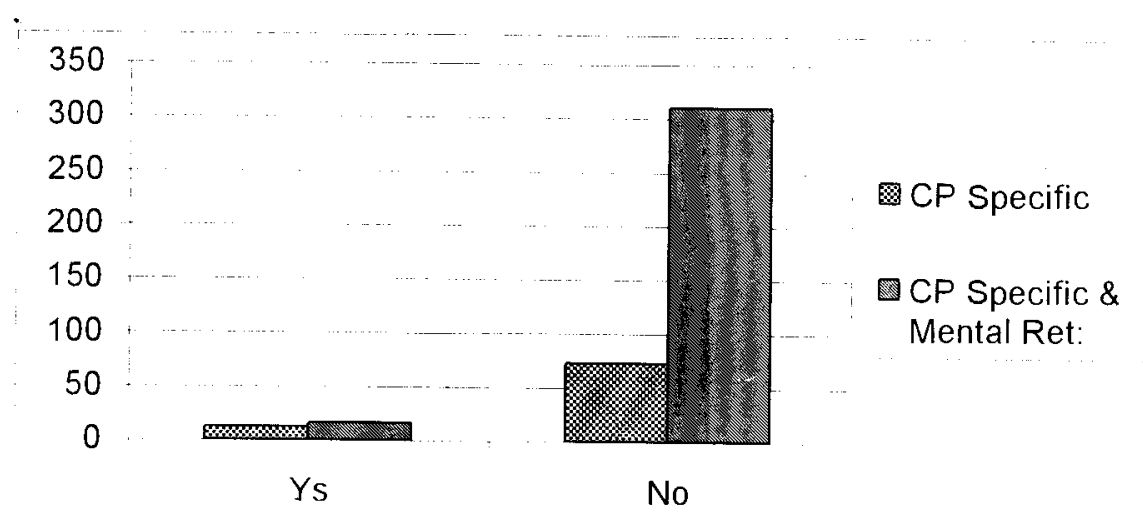

Chi-Square Tests

\begin{tabular}{|c|c|c|c|c|c|}
\hline & Value & df & $\begin{array}{l}\text { Asymp. Sig. } \\
\text { (2-sided) }\end{array}$ & $\begin{array}{l}\text { Exact Sig. } \\
\text { (2-sided) }\end{array}$ & $\begin{array}{l}\text { Exact Sig. } \\
\text { (1-sided })\end{array}$ \\
\hline Pearson Chi-Square & 9.008 & 1 & 003 & \multirow{6}{*}{006} & \multirow{6}{*}{.005} \\
\hline Continuity Correction & 7.615 & 1 & .006 & & \\
\hline Likelihood Ratio & 7.620 & 1 & .006 & & \\
\hline Fisher's Exact Test & & & & & \\
\hline $\begin{array}{l}\text { Linear-by-Linear } \\
\text { Association }\end{array}$ & 8.986 & 1 & .003 & & \\
\hline$N$ of Valid Cases & 411 & & & & \\
\hline
\end{tabular}

Out of 411 cases, 28 cases had disability with family history, among these $14 \%$ were CP Specific and 5\% had CP Specific and mental retardation.

Odds Ratio showed that disability with family history CP Specific is 3.18 times higher then the family history of disability in CP Specific \& mental retardation. The $\chi^{2}$ - value is 9.008 with 1 degree of freedom and the P-value is 0.003 (two sided). This indicates that there is a significant association between disability and family history of disability. 


\section{TABLE 09}

CP amd Malaria

\begin{tabular}{|c|c|c|c|c|}
\hline & & \multicolumn{2}{|c|}{ Malaria } & \multirow[b]{2}{*}{ Total } \\
\hline & & Yes & No & \\
\hline Diagnosis & CP Specific & 47 & 38 & 85 \\
\hline & CP Specific \& Mental Ret: & 172 & 154 & 326 \\
\hline Total & & 219 & 192 & 411 \\
\hline
\end{tabular}
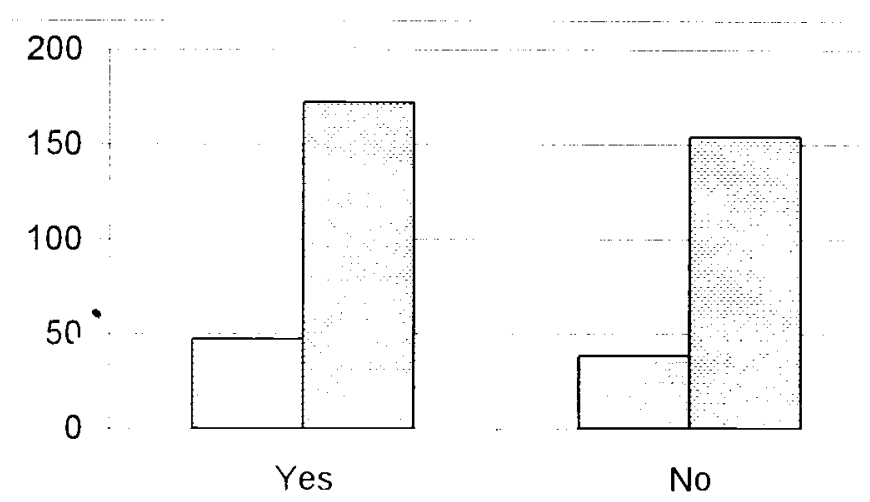

$\square C P$ Specific

$\square$ CP Specific

\& Mental

Ret:

Chi-Square Tests

\begin{tabular}{|c|c|c|c|c|c|}
\hline & Value & df & $\begin{array}{c}\text { Asymp. Sig. } \\
\text { (2-sided) }\end{array}$ & $\begin{array}{l}\text { Exact Sig. } \\
\text { (2-sided) }\end{array}$ & $\begin{array}{l}\text { Exact Sig. } \\
\text { (1-sided) }\end{array}$ \\
\hline Pearson Chi-Square & 174 & 1 & .677 & & \\
\hline Continuity Correction & .087 & 1 & .768 & & \\
\hline Likelihood Ratio & 174 & 1 & 676 & & \\
\hline Fisher's Exact Test & & & & 715 & 385 \\
\hline $\begin{array}{l}\text { Linear-by-Linear } \\
\text { Association }\end{array}$ & 173 & 1 & 677 & & \\
\hline $\mathrm{N}$ of Valid Cases & 411 & & & & \\
\hline
\end{tabular}

Out of 411 cases, 53.3\% mothers had Malaria during pregnancy, among these $21 \%$ were CP Specific and $79 \%$ had CP Specific \& mental Retardation. The Probability that a mother had Malaria during pregnancy is 0.53

Odds Ratio showed that CP Specific is 1.11 times higher as compare to CP Specific and mental retardation. The $\chi^{2}$ - value is 0.174 with 1 degree of freedom and the P-value is 0.677 (two sided). This indicates that there is an insignificant association between disability and Malaria. 


\section{TABLE 10}

CP and Absence of Pre-natal Care

\begin{tabular}{|ll|r|r|r|}
\hline \multirow{2}{*}{} & \multicolumn{2}{|c|}{$\begin{array}{c}\text { Absence of Pre-natal } \\
\text { Count }\end{array}$} & \multirow{2}{*}{ Care } \\
\cline { 3 - 4 } & \multicolumn{2}{|c|}{ Yes } & \multicolumn{1}{|c|}{ No } & \multicolumn{1}{|c|}{ Total } \\
\hline Diagnosis & CP Specific & 48 & 37 & 85 \\
& CP Specific \& Mental Ret: & 188 & 138 & 326 \\
Total & & 236 & 175 & 411 \\
\hline
\end{tabular}

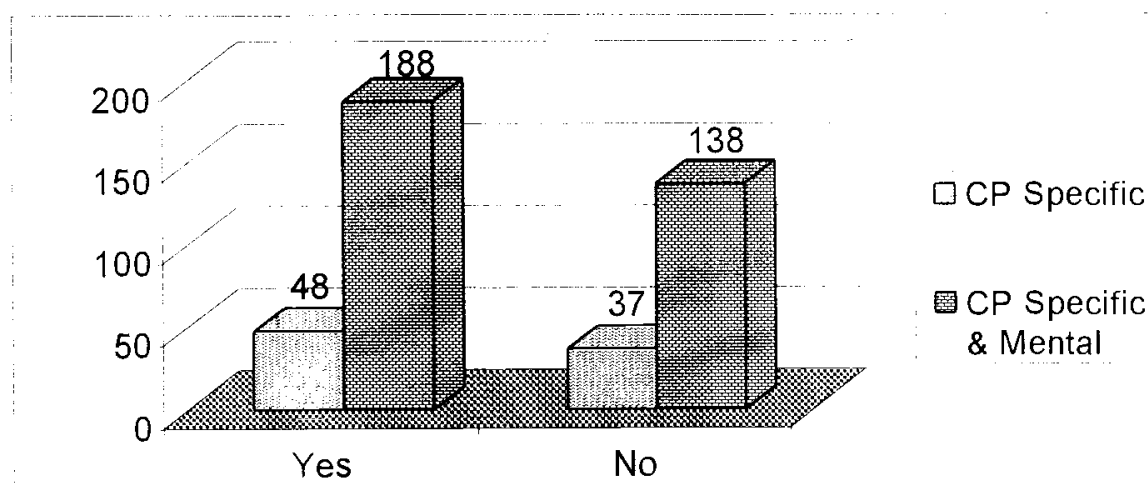

Chi-Square Tests

\begin{tabular}{|c|c|c|c|c|c|}
\hline & Value & df & $\begin{array}{c}\text { Asymp. Sig. } \\
\text { (2-sided) }\end{array}$ & $\begin{array}{l}\text { Exact Sig } \\
\text { (2-sided) }\end{array}$ & $\begin{array}{l}\text { Exact Sig. } \\
\text { (1-sided) }\end{array}$ \\
\hline Pearson Chi-Square & .040 & 1 & .842 & & \\
\hline Continuity Correction & .006 & 1 & 940 & & \\
\hline Likelihood Ratio & .040 & 1 & 842 & & \\
\hline Fisher's Exact Test & & & & .902 & 468 \\
\hline $\begin{array}{l}\text { Linear-by-Linear } \\
\text { Association }\end{array}$ & .039 & 1 & .842 & & \\
\hline$N$ of Valid Cases & 411 & & & & \\
\hline
\end{tabular}

Out of 411 cases, $236(57.4 \%)$ mothers had no ante-natal care, of these $11.67 \%$ had CP Specific children and $45.7 \%$ had children who were CP Specific with mental Retardation. The Probability that a mother had no ante-natal care is 0.57 .

Odds Ratio showed that no ante-natal care in CP Specific and mental retardation is 1.05 times higher in comparison to CP Specific. The $\chi^{2}$ - value is 0.04 with 1 degree of freedom and the P-value is 0.842 (two sided). This indicates that there is an insignificant association between disability and absence of ante-natal care. 


\section{TABLE 11}

\section{Contingency table (Sex amd Malnutrition) of Delayed Physical \&Mental Development}

\begin{tabular}{|c|c|c|c|c|}
\hline & & \multicolumn{2}{|c|}{ malnutrition } & \multirow[b]{2}{*}{ Total } \\
\hline & & Yes & No & \\
\hline \multirow[t]{2}{*}{ Sex } & Male & 21 & 64 & 85 \\
\hline & Female & 30 & 41 & 71 \\
\hline Total & & 51 & 105 & 156 \\
\hline
\end{tabular}

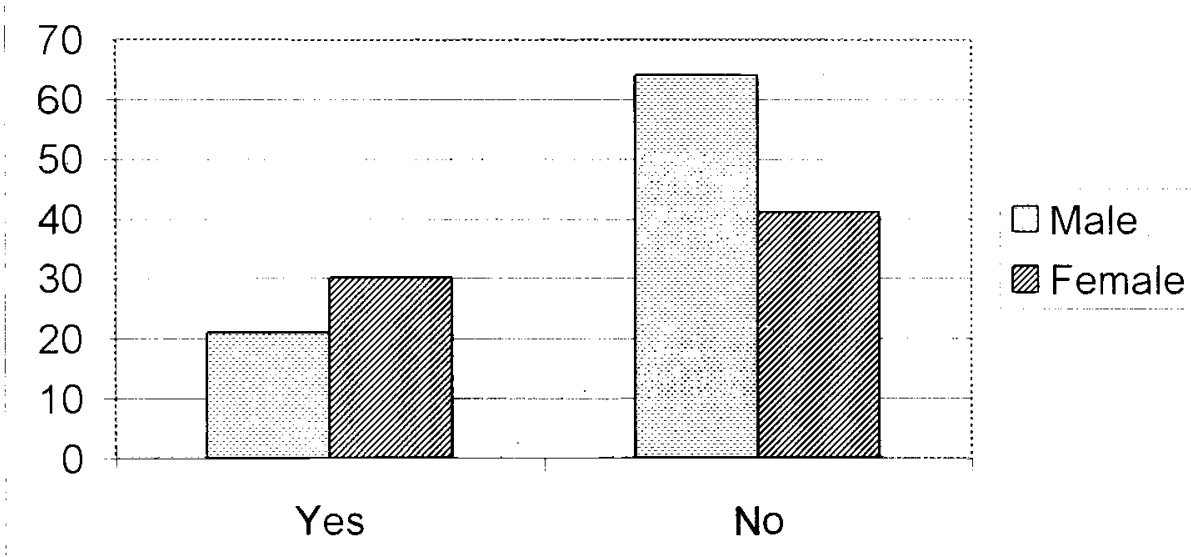

Chi-Square Tests

\begin{tabular}{|c|c|c|c|c|c|}
\hline & Value & df & $\begin{array}{c}\text { Asymp. Sig. } \\
\text { (2-sided) }\end{array}$ & $\begin{array}{l}\text { Exact Sig. } \\
\text { (2-sided) }\end{array}$ & $\begin{array}{l}\text { Exact Sig. } \\
\text { (1-sided) }\end{array}$ \\
\hline Pearson Chi-Square & 5.414 & 1 & .020 & & \\
\hline Continuity Correction & 4.645 & 1 & .031 & & \\
\hline Likelihood Ratio & 5418 & 1 & .020 & & \\
\hline Fisher's Exact Test & & & & 026 & 016 \\
\hline $\begin{array}{l}\text { Linear-by-Linear } \\
\text { Association }\end{array}$ & 5.379 & 1 & .020 & & \\
\hline $\mathrm{N}$ of Valid Cases & 156 & & & & \\
\hline
\end{tabular}

Out of 156 children, $85(54.5 \%)$ were male and 71 (45\%) were female. 21 male and 30 female were malnourished. The probability of disability in males is 0.13 and disability in females is 0.19 .

Odds Ratio showed that female (malnutrition) two times higher in comparison to male (malnutrition). The $\chi^{2}$-value is 5.414 with 1 degree of freedom and the P-value is 0.020 (two sided). This indicates that there is a significant association between malnutrition and the sex of the child. 


\section{TABLE 12}

Contingency table (Sex and Absence of Pre-natal Care) of Delayed Physical \& Mental Development

Count

\begin{tabular}{|c|c|c|c|c|}
\hline & & \multicolumn{2}{|c|}{$\begin{array}{c}\text { Absence of Pre-natal } \\
\text { Care }\end{array}$} & \multirow[b]{2}{*}{ Total } \\
\hline & & Yes & No & \\
\hline \multirow[t]{2}{*}{ Sex } & Male & 40 & 45 & 85 \\
\hline & Female & 50 & 21 & 71 \\
\hline Total & & 90 & 66 & 156 \\
\hline
\end{tabular}

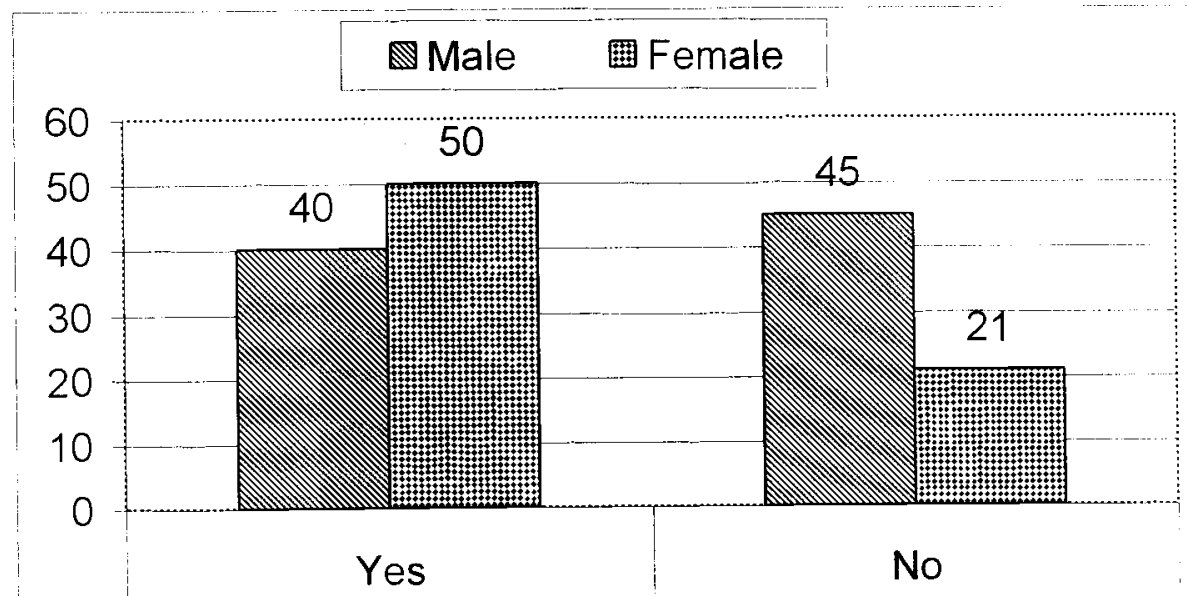

Absence Of Prenatal

Chi-Square Tests

\begin{tabular}{|c|c|c|c|c|c|}
\hline & Value & $d f$ & $\begin{array}{l}\text { Asymp. Sig. } \\
\text { (2-sided) }\end{array}$ & $\begin{array}{l}\text { Exact Sig. } \\
\text { (2-sided) }\end{array}$ & $\begin{array}{c}\text { Exact Sig. } \\
\text { (1-sided) }\end{array}$ \\
\hline Pearson Chi-Square & 8.652 & $\overline{1}$ & .003 & & \\
\hline Continuity Correction & 7.721 & 1 & .005 & & \\
\hline Likelihood Ratio & 8.786 & 1 & .003 & & \\
\hline Fisher's Exact Test & & & & .004 & .003 \\
\hline $\begin{array}{l}\text { Linear-by-Linear } \\
\text { Association }\end{array}$ & 8.596 & 1 & .003 & & \\
\hline N of Valid Cases & 156 & & & & \\
\hline
\end{tabular}

Out of 156 cases, 90 mothers had no ante-natal care (58\%). The probability that a mother having no ante-natal care is 0.58 . The probability of disability in males is 0.26 and in females is 0.32 .

Odds Ratio showed that female is 2.68 times higher as compare to male. The $\chi^{2}$ - value is 8.652 with 1 degree of freedom and the P-value is 0.003 (two sided). This indicates that there is a significant association between sex and absence of ante-natal care. 


\section{TABLE 13}

\section{Contingency table (Sex and Urinary tract infection) of Delayed Physical and Mental Development}

Count

\begin{tabular}{|ll|r|r|r|}
\hline & & \multicolumn{2}{|c|}{ Urinary tract infection } & \multicolumn{2}{c|}{} \\
\cline { 3 - 4 } & Yes & No & \multicolumn{2}{|c|}{ Total } \\
\hline Sex & Male & 4 & 81 & 85 \\
& Female & 14 & 57 & 71 \\
Total & & 18 & 138 & 156 \\
\hline
\end{tabular}

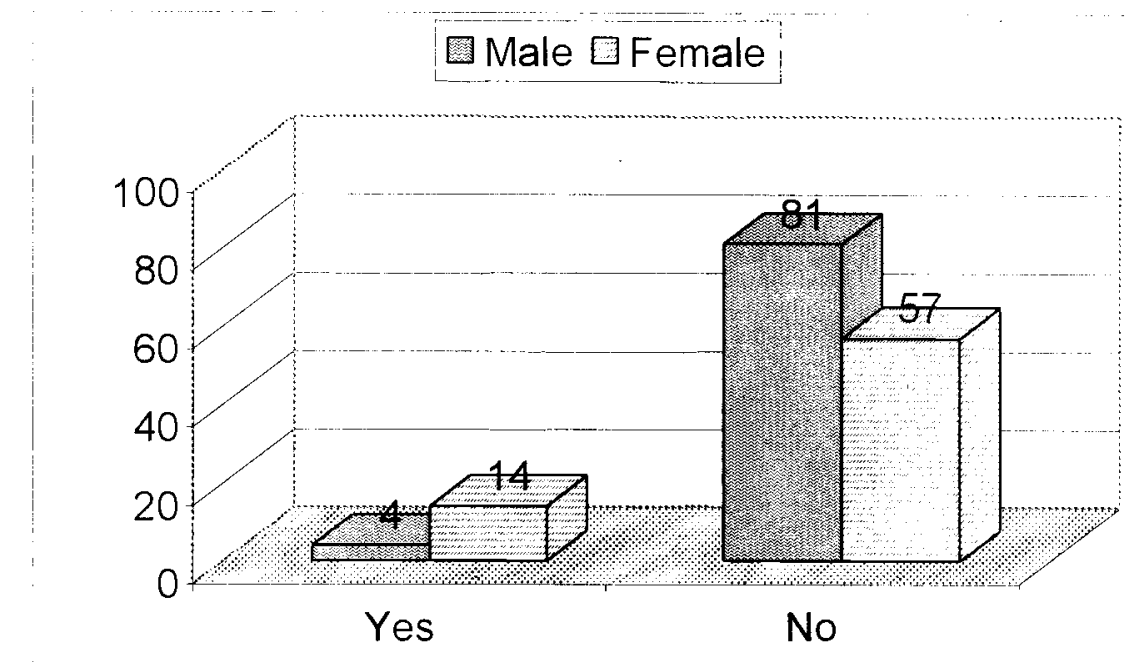

Chi-Square Tests

\begin{tabular}{|c|c|c|c|c|c|}
\hline & Value & df & $\begin{array}{c}\text { Asymp. Sig. } \\
\text { (2-sided) }\end{array}$ & $\begin{array}{l}\text { Exact Sig. } \\
\text { (2-sided) }\end{array}$ & $\begin{array}{l}\text { Exact Sig } \\
\text { (1-sided) }\end{array}$ \\
\hline Pearson Chi-Square & 8.542 & $\overline{1}$ & .003 & & \\
\hline Continuity Correction & 7.134 & 1 & .008 & & \\
\hline Likelihood Ratio & 8.821 & 1 & .003 & & \\
\hline Fisher's Exact Test & & & & .005 & .003 \\
\hline $\begin{array}{l}\text { Linear-by-Linear } \\
\text { Association }\end{array}$ & 8.487 & 1 & .004 & & \\
\hline $\mathrm{N}$ of Valid Cases & 156 & & & & \\
\hline
\end{tabular}

Out of 156 cases. $11.5 \%$ of mothers had urinary tract infection during pregnancy. The Probability that a mother having Urinary tract infection during pregnancy is 0.115 Odds Ratio showed that females are almost five times higher in comparison to males. The $\chi^{2}$-value is 8.54 with 1 degree of freedom and the P-value is 0.003 . This indicates that there is a significant association between gender and urinary tract infection. 


\section{TABLE 12}

Contingency table (Sex and Absence of Pre-natal

Care) of Delayed Physical \& Mental Development

Count

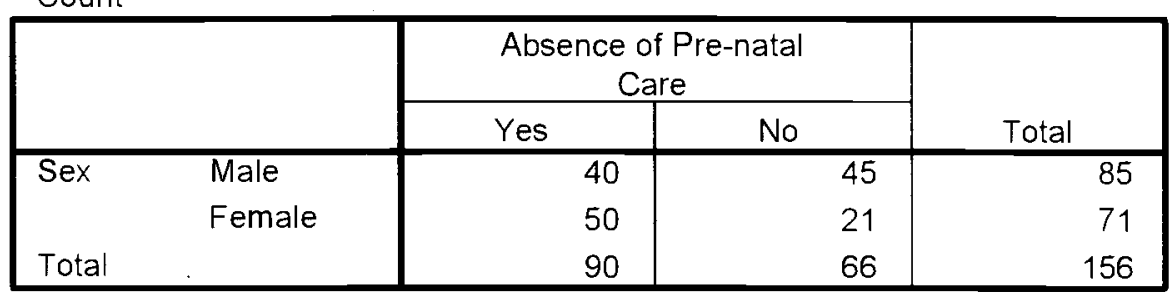

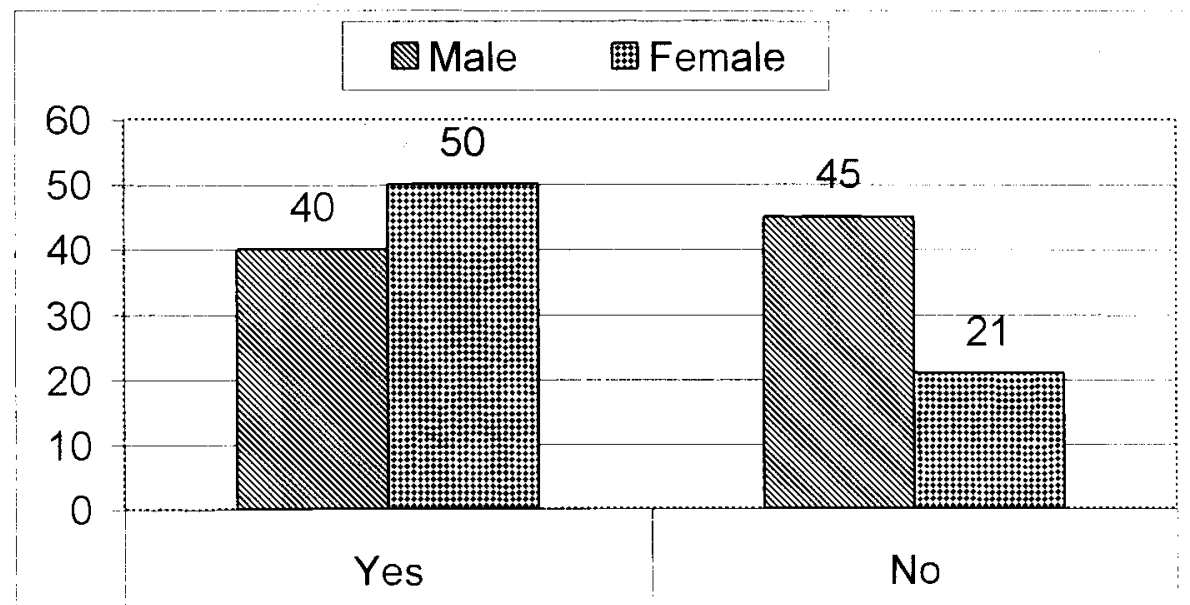

Absence Of Prenatal

Chi-Square Tests

\begin{tabular}{|c|c|c|c|c|c|}
\hline & Value & df & $\begin{array}{l}\text { Asymp. Sig. } \\
\text { (2-sided) }\end{array}$ & $\begin{array}{l}\text { Exact Sig. } \\
\text { (2-sided) }\end{array}$ & $\begin{array}{l}\text { Exact Sig. } \\
\text { (1-sided) }\end{array}$ \\
\hline Pearson Chi-Square & 8.652 & 1 & .003 & & \\
\hline Continuity Correction & 7.721 & 1 & .005 & & \\
\hline Likelihood Ratio & 8.786 & 1 & .003 & & \\
\hline Fisher's Exact Test & & & & .004 & .003 \\
\hline $\begin{array}{l}\text { Linear-by-Linear } \\
\text { Association }\end{array}$ & 8.596 & 1 & .003 & & \\
\hline$N$ of Valid Cases & 156 & & & & \\
\hline
\end{tabular}

Out of 156 cases, 90 mothers had no ante-natal care (58\%). The probability that a mother having no ante-natal care is 0.58 . The probability of disability in males is 0.26 and in females is 0.32 .

Odds Ratio showed that female is 2.68 times higher as compare to male. The $\chi^{2}$ - value is 8.652 with 1 degree of freedom and the P-value is 0.003 (two sided). This indicates that there is a significant association between sex and absence of ante-natal care. 


\section{TABLE 15}

\section{Contingency table (Sex and High Fever) of Delayed}

Physical \&Mental Development

Count

\begin{tabular}{|ll|r|r|r|}
\hline & & \multicolumn{2}{|c|}{ High fever } & \multicolumn{2}{|c|}{} \\
\cline { 3 - 4 } & & Yes & \multicolumn{2}{|c|}{ No } \\
\hline Sex & Male & 14 & 71 & 85 \\
& Female & 5 & 66 & 71 \\
Total & 19 & 137 & 156 \\
\hline
\end{tabular}

\section{$\square$ Male $\square$ Female}

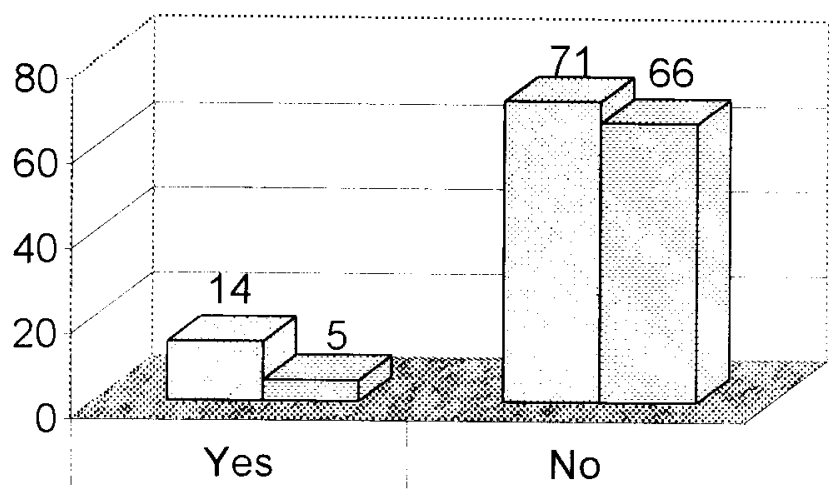

High fever

Chi-Square Tests

\begin{tabular}{|c|c|c|c|c|c|}
\hline & Value & $\mathrm{df}$ & $\begin{array}{l}\text { Asymp. Sig. } \\
\text { (2-sided) }\end{array}$ & $\begin{array}{l}\text { Exact Sig. } \\
\text { (2-sided) }\end{array}$ & $\begin{array}{l}\text { Exact Sig. } \\
\text { (1-sided) }\end{array}$ \\
\hline Pearson Chi-Square & 3.215 & $\overline{1}$ & .073 & \multirow{6}{*}{.088} & \multirow{6}{*}{.059} \\
\hline Continuity Correction & 2.394 & 1 & .122 & & \\
\hline Likelihood Ratio & 3.363 & 1 & .067 & & \\
\hline Fisher's Exact Test & & & & & \\
\hline $\begin{array}{l}\text { Linear-by-Linear } \\
\text { Association }\end{array}$ & 3.195 & 1 & .074 & & \\
\hline $\mathrm{N}$ of Valia Cases & 156 & & & & \\
\hline
\end{tabular}

Out of 156 cases, 19 children had high fever. The Probability that a child might have high fever is 0.12 . The probability of males having high fever is 0.09 and in females is 0.03 Odds Ratio showed that Males are 2.6 times higher than Females. The $\chi^{2}$ - value is 3.215 with 1 degree of freedom and the P-value is 0.073 (two sided). This indicates that there is a significant association between high fever and gender. 


\section{TABLE 16}

PERCENTAGES OF PROVINCE ACCORDING TO DIAGNOSIS

\begin{tabular}{|c|c|c|c|c|c|c|c|c|c|}
\hline & \multicolumn{8}{|c|}{ DIAGNOSIS } & \multirow[b]{2}{*}{ Total } \\
\hline Province & $\begin{array}{l}\text { Cercbral } \\
\text { Palsy } \\
\text { Specific }\end{array}$ & $\%$ & $\begin{array}{l}\text { CP Specific \& } \\
\text { Mental Ret: }\end{array}$ & $\%$ & $\begin{array}{l}\text { Delayed Physical \& } \\
\text { Mental Development }\end{array}$ & $\%$ & Club Foot & $\%$ & \\
\hline Nangarhar & 42 & 11 & 198 & 51 & 117 & 30 & 31 & 8 & 388 \\
\hline Laghman & 22 & 14 & 86 & 55 & 27 & 17 & 22 & 14 & 157 \\
\hline Kunar & 21 & 24 & 42 & 48 & 12 & 14 & 13 & 15 & 88 \\
\hline Total & 85 & & 326 & & 156 & & 66 & & 633 \\
\hline
\end{tabular}

250 $\quad$ Nangarhar Laghman $\quad$ Kunar

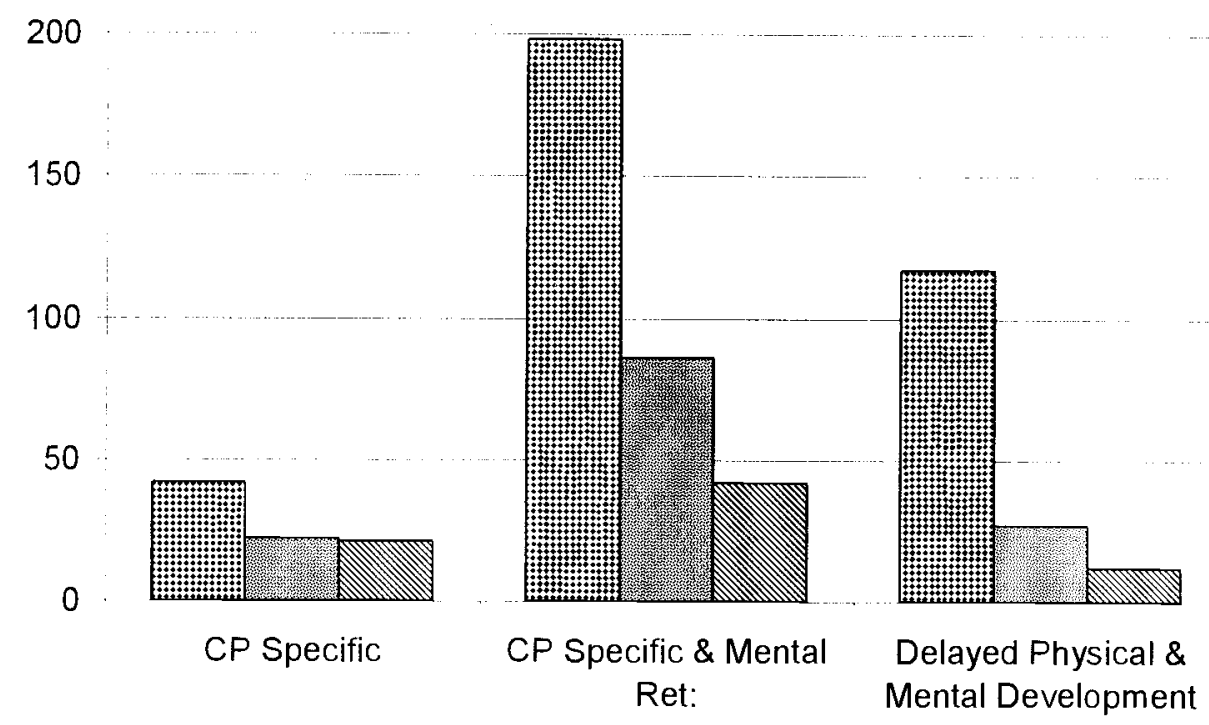

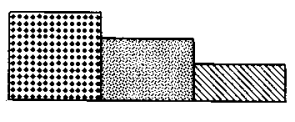

Club Foot

Note: The proportion of cases is higher from Nangharhar province because the majority of SGAA's regular clinics are based in Nangarhar. There is one regular clinic in Laghman and no clinics in Kunar. 
TABLE 17

Ratio Between Different Terrain

\begin{tabular}{|l|c|c|c|c|c|c|}
\hline \multicolumn{1}{|c|}{ DIAGNOSIS } & \multicolumn{7}{c|}{ TERRAIN } & \\
\hline CP Specific & U & V & W & X & Y & Total \\
CP Specific \& Mental retardation & 2 & 0 & 64 & 4 & 15 & 85 \\
Delayed Physical \& Mental Development & 6 & 10 & 199 & 30 & 81 & 326 \\
Club Foot & 4 & 5 & 98 & 8 & 41 & 156 \\
\hline Total & 3 & & 40 & 9 & 14 & 66 \\
\hline
\end{tabular}

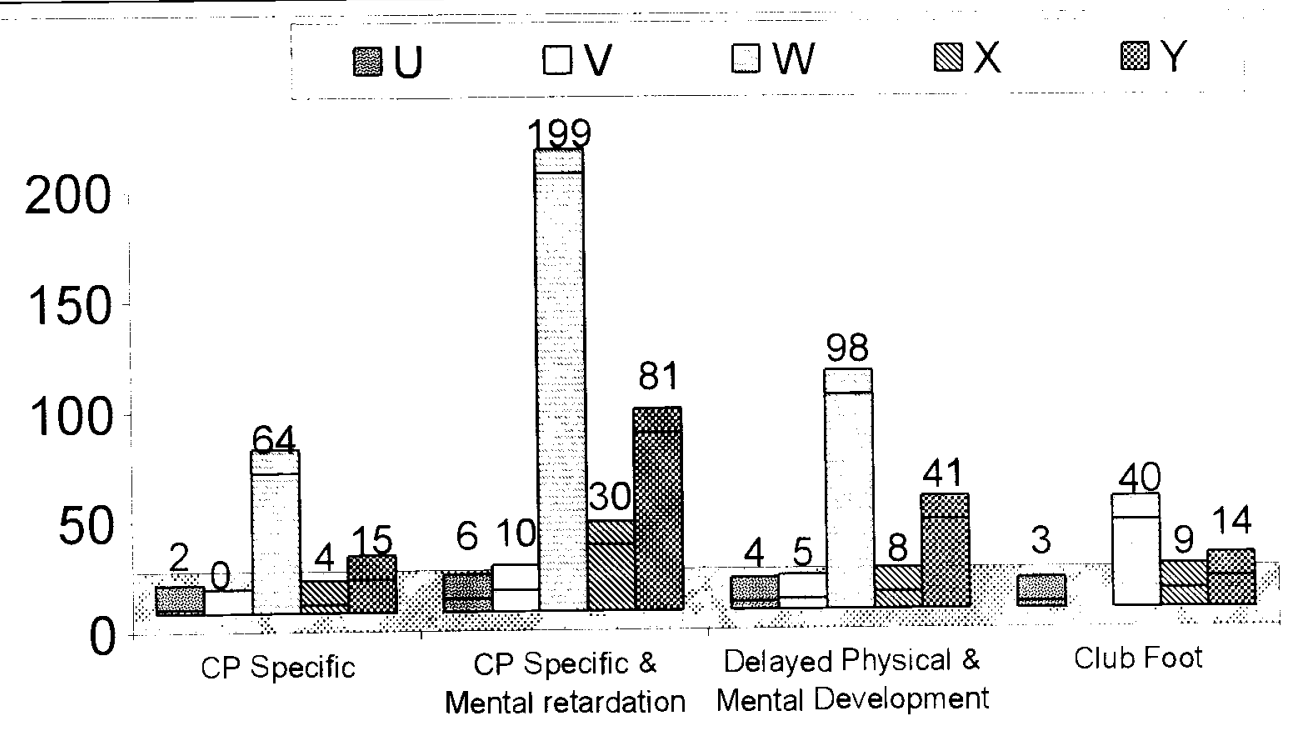

$\mathrm{U}=$ Patient's home a long distance from BHU \& Hospital roads Possible roads for vehicles, No vehicles available after $1 o^{\prime}$ clock.

$\mathrm{V}=$ Patient's home close to BHU but roads inaccessible to vehicles and mountainous.

$\mathrm{W}=$ Patient's home near reasonable roads with Pot holes some pubic transport. Fertile land,

agriculture, vegetables, and animals.

$\mathrm{X}=$ Patient's in an inaccessible location with town, poor transportation, Long distance from $\mathrm{BHU}$, and hard or no cultivation and little transport.

$\mathrm{Y}=$ Patient's home in Urban area, easy access to hospital \& BHU, no problem in obtaining food.

The study was mainly carried out in clinics in urban areas or in clinics near roads and fertile agricultural soil. This is reflected in the much higher number of patients coming form fertile and accessible rural areas or urban areas. A minority of patients studying came from inacessible areas which means the outreach programme should be extended to facilitate isolated communities and transport pregnant mothers when they are in distress. 


\section{TABLE 18}

Diagnosis and Location

\begin{tabular}{|c|c|c|c|c|c|c|c|c|c|}
\hline & \multicolumn{8}{|c|}{ DIAGNOSIS } & \multirow[b]{2}{*}{ Total } \\
\hline Location & CP Specific & $\%$ & $\begin{array}{l}\text { CP Specific \& } \\
\text { Mental Ret: }\end{array}$ & $\%$ & $\begin{array}{l}\text { Delayed Plysical \& } \\
\text { Mental Development }\end{array}$ & $\%$ & Club Foot & $\%$ & \\
\hline Urban & 17 & 13 & 67 & 51 & 34 & 26 & 13 & 10 & 131 \\
\hline Rural & 68 & 14 & 259 & 52 & 122 & 24 & 53 & 11 & 5012 \\
\hline Total & 85 & & 326 & & 156 & & 66 & & 633 \\
\hline
\end{tabular}

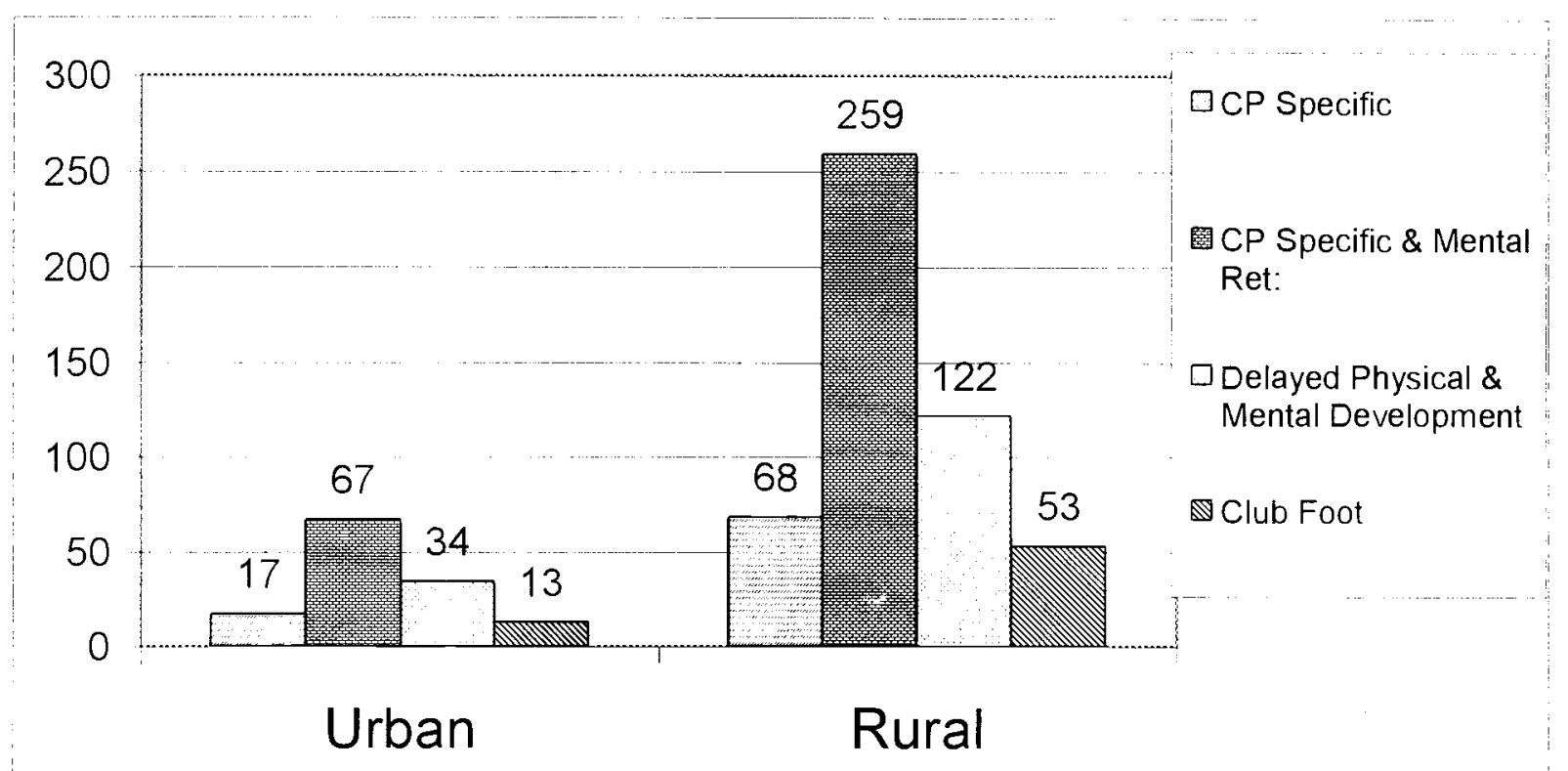




\section{TABLE 19}

Breakdown of Patients by Gender

\begin{tabular}{|c|c|c|c|c|c|c|c|c|c|}
\hline & \multicolumn{8}{|c|}{ DIAGNOSIS } & \\
\hline Sex & CP Specific & $\%$ & \begin{tabular}{|c|} 
CP Specific \& \\
Mental Ret:
\end{tabular} & $\%$ & $\begin{array}{l}\text { Delayed Physical \& } \\
\text { Mental Derolopment }\end{array}$ & $\%$ & Club Foot & $\%$ & Total \\
\hline Male & 60 & 15 & 214 & 52 & 85 & 21 & 52 & 13 & 411 \\
\hline Female & 25 & 11 & 112 & 50 & 71 & 32 & 14 & 6 & 222 \\
\hline Total & 85 & & 326 & & 156 & & 66 & & 633 \\
\hline
\end{tabular}

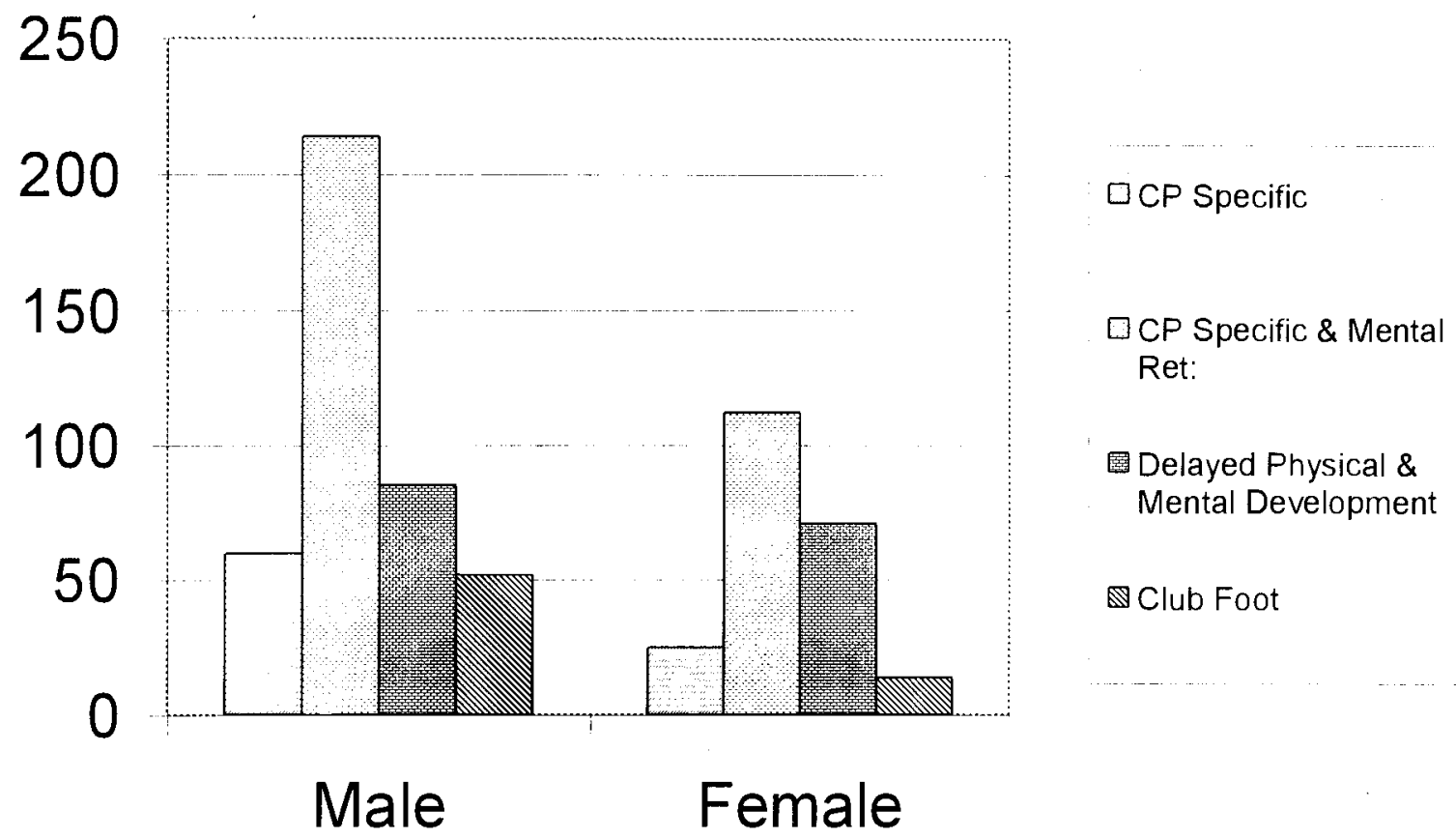

Significant here is the number of children with Cerebral Palsy specific and mental retardation which are more difficult for physiotherapists to treat. 


\section{TABLE 20}

Frequency Distribution Of Ages \& Diagnosis

\begin{tabular}{|c|c|c|c|c|c|c|c|c|c|}
\hline & \multicolumn{7}{|c|}{ DIAGNOSIS } & \\
\hline AGE & CP Specific & $\%$ & $\begin{array}{c}\text { CP Specific \& } \\
\text { Mental Ret: }\end{array}$ & $\begin{array}{c}\text { Delayed Plysical \& } \\
\text { Mental Development }\end{array}$ & $\%$ & Club Foot & $\%$ & Total \\
\hline$<5$ & 41 & 12 & 133 & 38 & 134 & 38 & 46 & 13 & 354 \\
$5-10$ & 36 & 16 & 153 & 68 & 18 & 8 & 19 & 8 & 226 \\
$10>$ & 8 & 15 & 40 & 75 & 4 & 8 & 1 & 2 & 53 \\
\hline Total & 85 & & 326 & & 156 & 66 & 633 \\
\hline
\end{tabular}

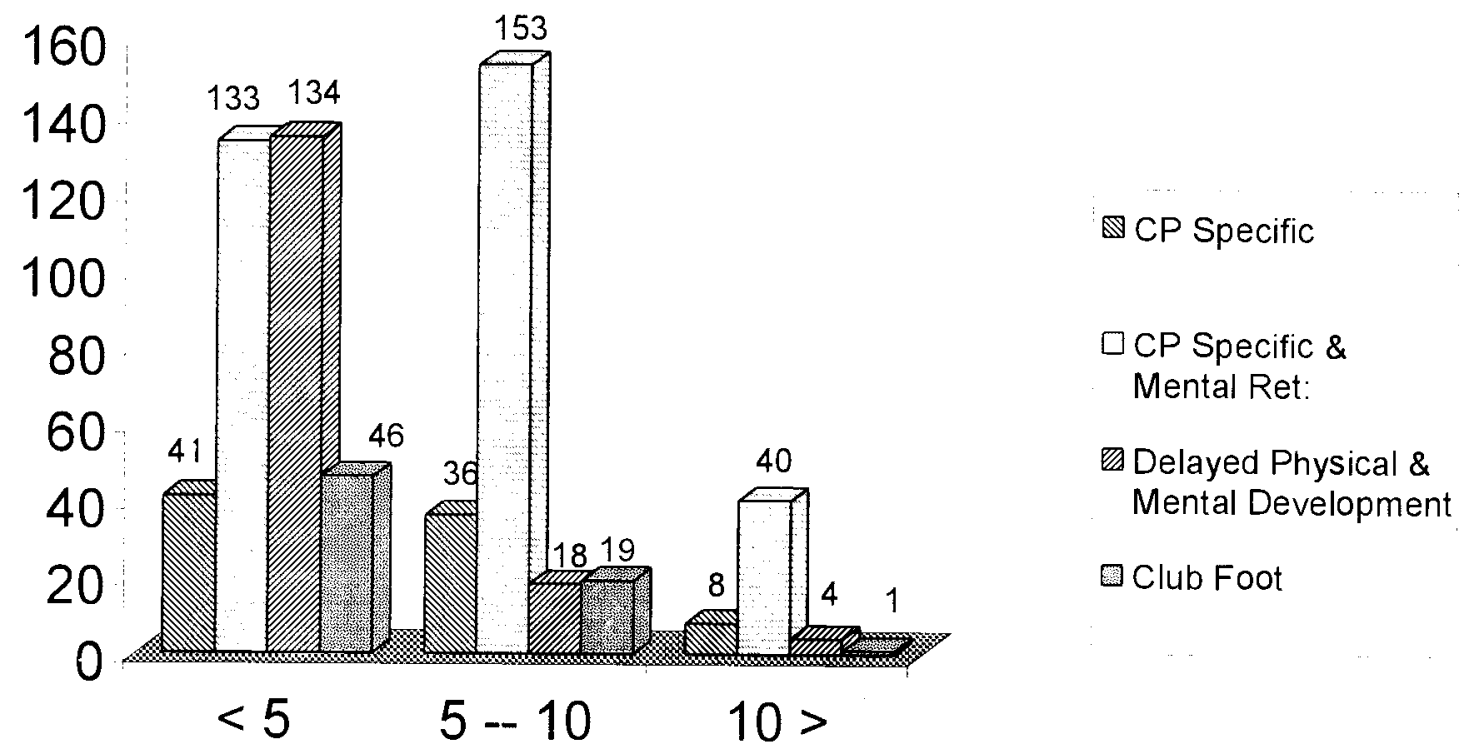

\section{AVERAGES}

Average Age of Disabled child $=5$

Average Age of Male $=5$

Average Age of Female $=4.5$

\section{PERCENTAGES}

$<5$ Years old $=56 \%$

$5-10$ Years old $=36 \%$

$>10$ Years old $=8 \%$

This table shows that $8 \%$ of children are over 10 years and have survived despite their disability. 


\section{TABLE 21}

Main Diagnosis With other Diseases

\begin{tabular}{|c|c|c|c|c|c|c|c|c|c|}
\hline \multirow[b]{2}{*}{ Diagnosis } & \multicolumn{8}{|c|}{ Diseases } & \multirow[b]{2}{*}{ Tota } \\
\hline & $\begin{array}{l}\text { Fever with } \\
\text { stiff neck }\end{array}$ & $\%$ & $\begin{array}{l}\text { High fever } \\
\text { with rashes }\end{array}$ & $\%$ & Jaundice & $\%$ & Others & $\%$ & \\
\hline CP Specific & 4 & 9 & 2 & 5 & 21 & 49 & 16 & 37 & 43 \\
\hline $\begin{array}{l}\text { CP Specific \& Mental } \\
\text { Ret: }\end{array}$ & 17 & 40 & 6 & 3 & 131 & 57 & $7 t$ & 32 & 228 \\
\hline $\begin{array}{l}\text { Delaycd Physical \& } \\
\text { Mental Development }\end{array}$ & 4 & 9 & 3 & 3 & 36 & 36 & 56 & 57 & 99 \\
\hline Club Foot & & 0 & & 0 & 7 & 47 & 8 & 53 & 15 \\
\hline Total & 25 & & 11 & & 195 & & 154 & & 385 \\
\hline
\end{tabular}

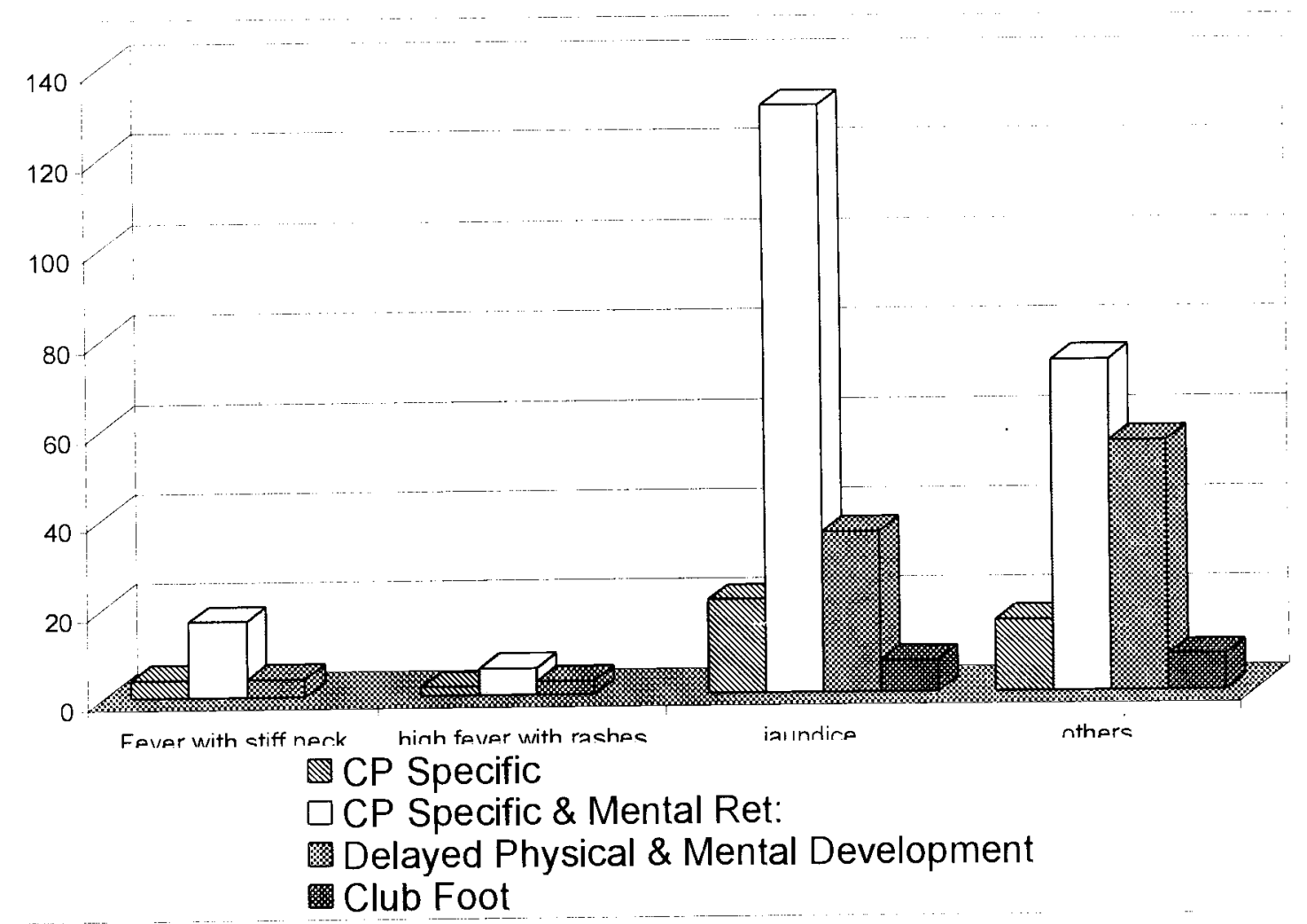




\section{TABLE 22}

Frequency Distribution Of Mother's Ages And Diagnosis

\begin{tabular}{|c|c|c|c|c|c|c|c|c|c|}
\hline & \multicolumn{8}{|c|}{ DIAGNOSIS } & \\
\hline Mother's ages & CP Specific & $\%$ & $\begin{array}{l}\text { CP Specific \& } \\
\text { Mental Ret: }\end{array}$ & $\%$ & $\begin{array}{l}\text { Delayed Physical \& } \\
\text { Mental Development }\end{array}$ & $\%$ & Club Foot & $\%$ & Total \\
\hline$<20$ & 3 & 43 & 2 & 29 & 2 & 29 & & () & 7 \\
\hline $20-30$ & 39 & 16 & 124 & 49 & 56 & 22 & 32 & 13 & 251 \\
\hline $30>$ & 43 & 11 & 200 & 53 & 98 & 26 & 34 & 9 & 375 \\
\hline Total & 85 & & 326 & & 156 & & 66 & & 633 \\
\hline
\end{tabular}

AVERAGES

Average Age of Mother $=35$

\section{$\underline{\text { PERCENTAGES }}$}

$<20$ Year's old $=1 \%$

20 - 30 Year's old $=40 \%$

$>30$ Year's old $=59 \%$

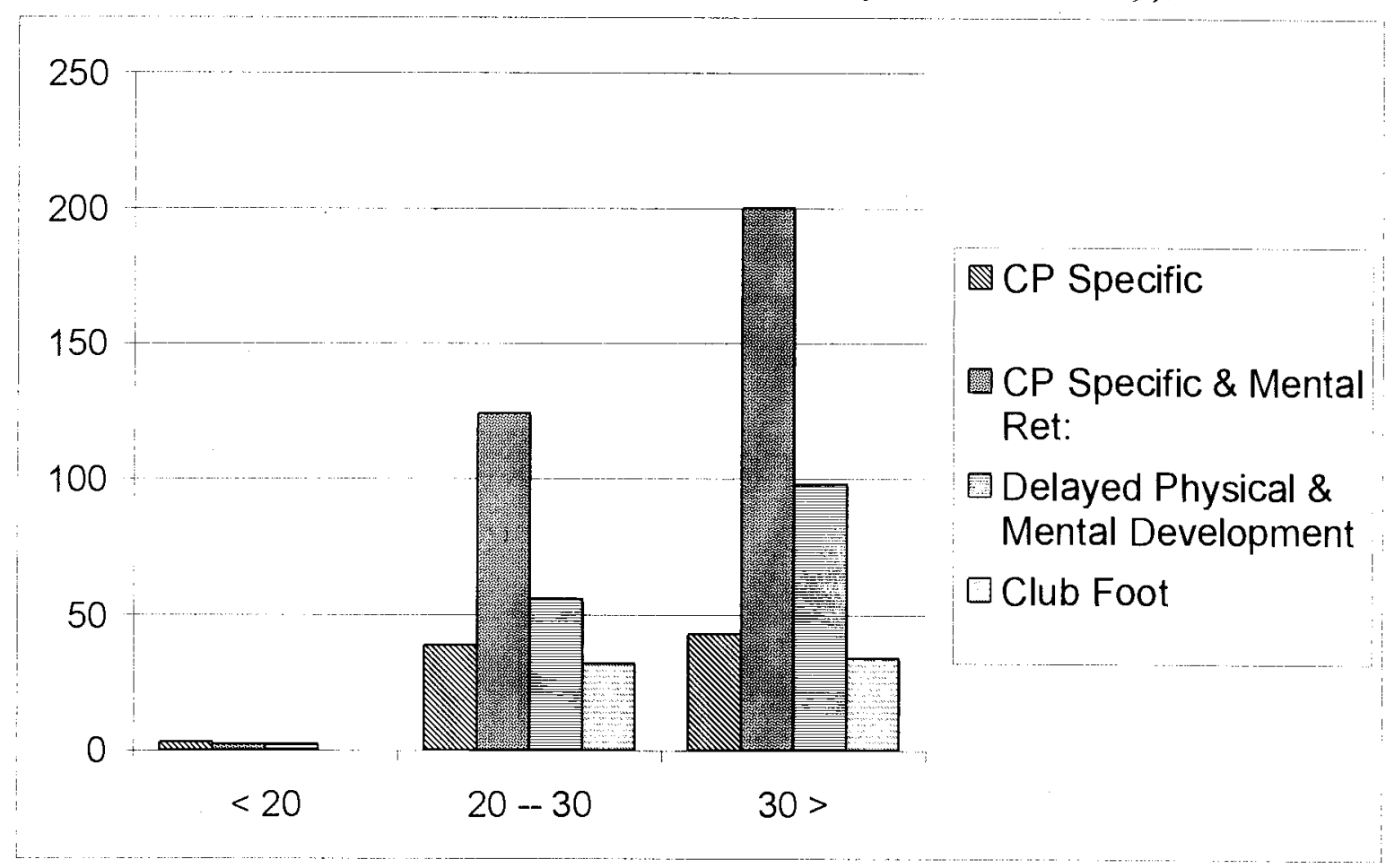




\section{TABLE 23}

\section{Diagnosis and Mother's Milk}

\begin{tabular}{|c|c|c|c|c|c|c|c|c|c|}
\hline & \multicolumn{8}{|c|}{ Diagnosis } & \multirow[b]{2}{*}{ Total } \\
\hline Mother Milk & CP Specific & $\%$ & $\begin{array}{l}\text { CP Specific \& } \\
\text { Mental Ret: }\end{array}$ & $\%$ & $\begin{array}{l}\text { Delayed Physical \& } \\
\text { Mental Development }\end{array}$ & $\%$ & Club Foot & $\%$ & \\
\hline \begin{tabular}{|l|} 
No Breast \\
Feeding
\end{tabular} & 1 & 25 & 3 & 75 & & 0 & & 0 & 4 \\
\hline Sufficient & 61 & 18 & 183 & 54 & 40 & 12 & 53 & 16 & 337 \\
\hline Not Sufficient & 23 & 8 & 140 & 48 & 116 & 40 & 13 & 4 & 292 \\
\hline Total & 85 & & 326 & & 156 & & 66 & & 633 \\
\hline
\end{tabular}

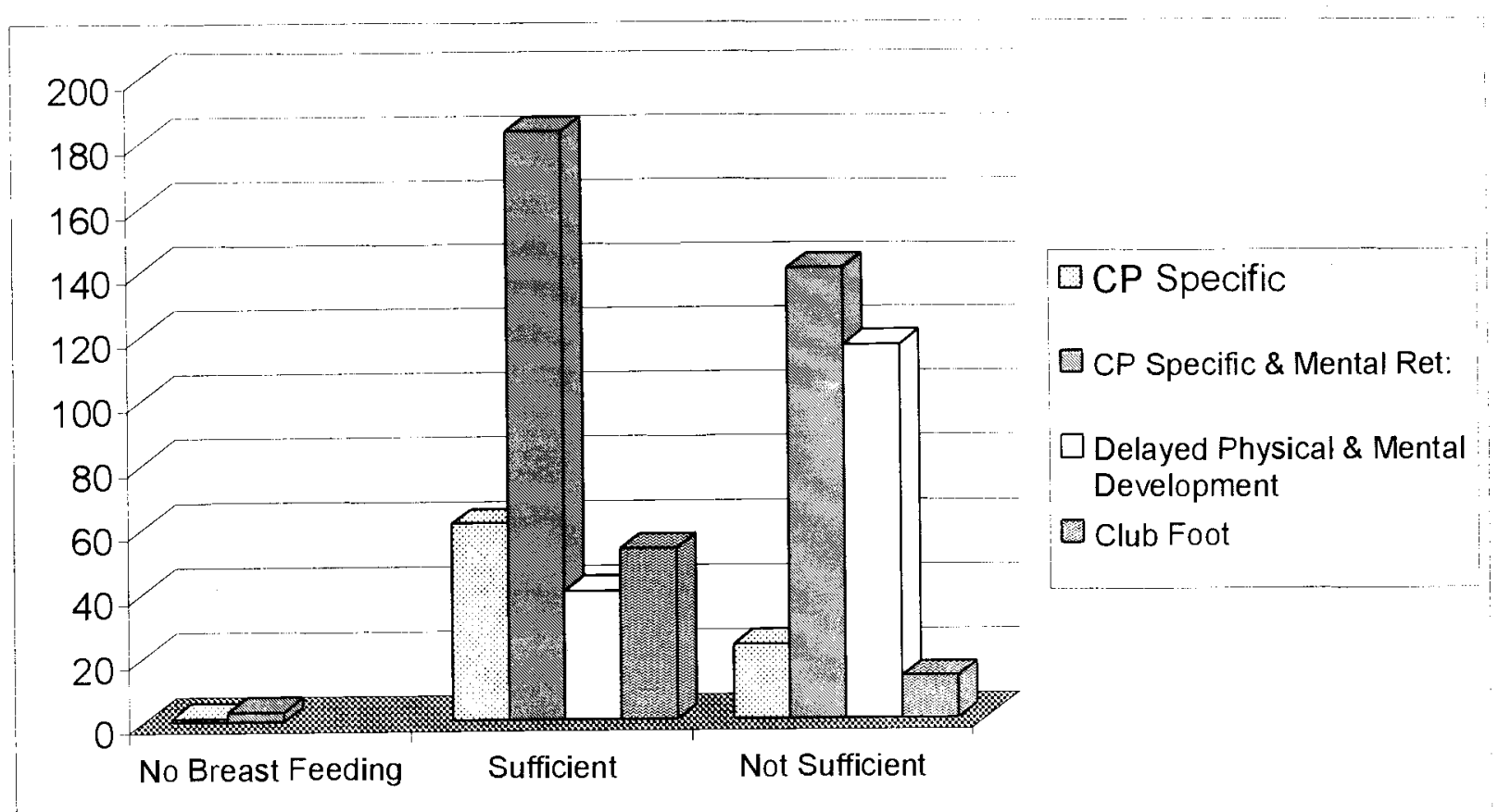

Insufficient breast-feeding is significant in Cerebral Palsy and mental retardation and delayed development. 


\section{TABLE 24}

Spacing Between Pregnancies

\begin{tabular}{|l|l|}
\hline Pregnancies & $\begin{array}{l}\text { Averags Spacing } \\
\text { (in months) }\end{array}$ \\
\hline Spacing b/w 1st and $2^{\text {nd }}$ & 21 \\
Spacing b/w 2nd and $3^{\text {rd }}$ & 21 \\
Spacing b/w 3rd and 4h & 21 \\
Spacing b/w 4th and $5^{\text {th }}$ & 22 \\
Spacing b/w 5th and $6^{\text {th }}$ & 20 \\
Spacing b/w 6th and 7th & 20 \\
Spacing b/w 7th and $8^{\text {th }}$ & 19 \\
Spacing b/w 8th and 9th & 20 \\
Spacing b/w 9th and 10th & 21 \\
Spacing b/w 10th and 11 & 23 \\
\hline
\end{tabular}

\section{NOTE}

Over all Average Spacing between Pregnancies $=21$ months.

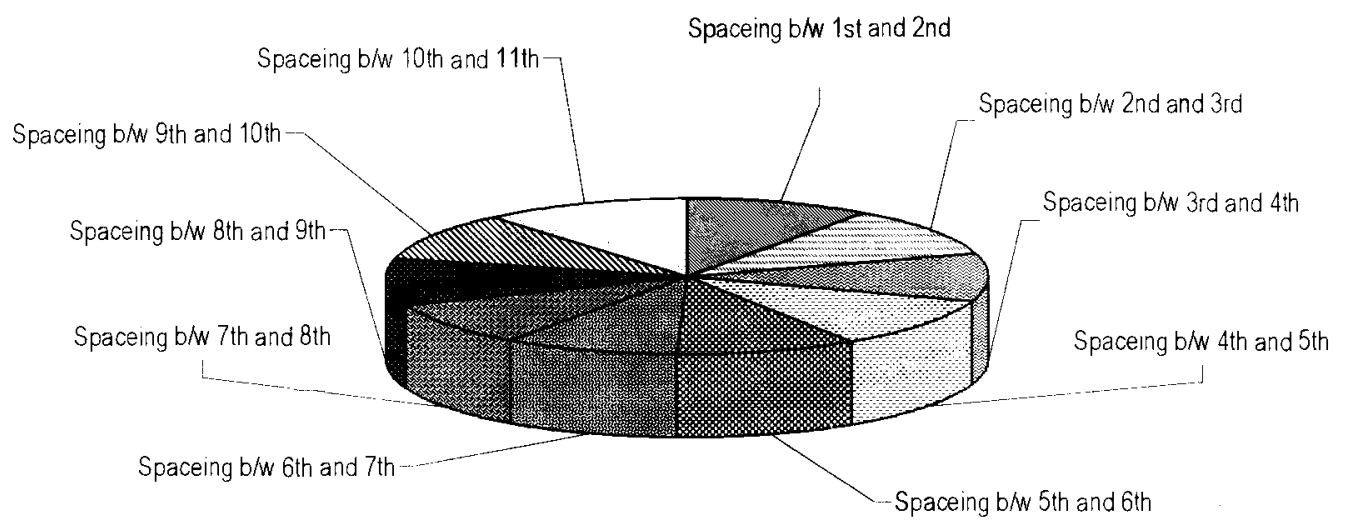




\section{TABLE 25}

Diagnosis and Ante-natal check-up

\begin{tabular}{|c|c|c|c|c|}
\hline & & Ante-n & heckup & \\
\hline & & Yes & No & Total \\
\hline Diagnosis & CP Specific & 19 & 65 & 84 \\
\hline & CP Specific \& Mental Ret: & 64 & 262 & 326 \\
\hline & Delayed Physical \& Mental Development & 52 & 104 & 156 \\
\hline & Club Foot & 6 & 60 & 66 \\
\hline Total & & $1+1$ & 491 & 632 \\
\hline
\end{tabular}

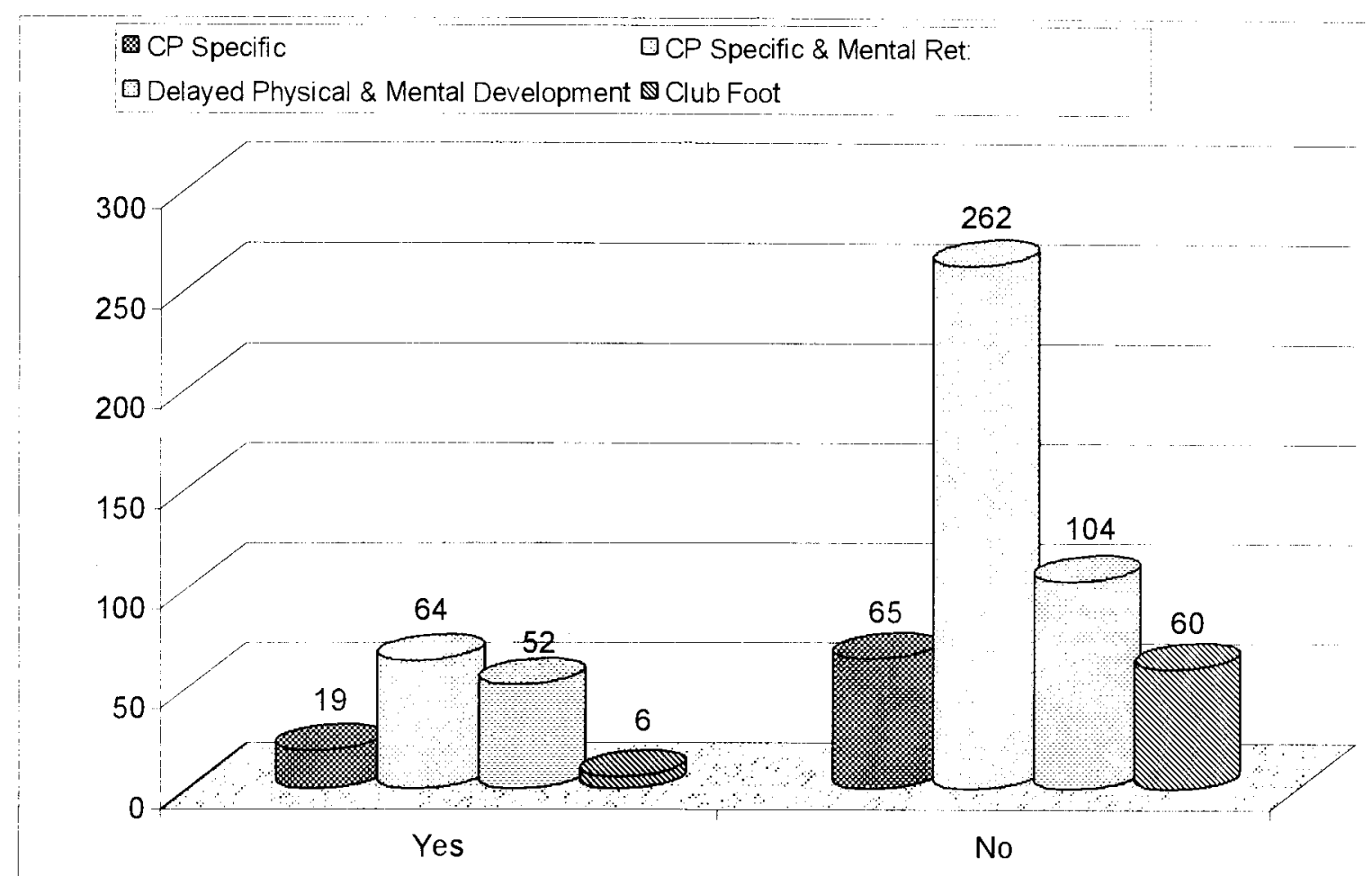

$22.4 \%$ of pregnant women had ante-natal check-ups, $77.6 \%$ did not. 


\section{TABLE 26}

\section{Diagnosis and Who Delivered Child}

\begin{tabular}{|c|c|c|c|c|c|c|}
\hline & & \multicolumn{4}{|c|}{ Diagnosis } & \multirow[b]{2}{*}{ Total } \\
\hline & & CP Specific & $\begin{array}{c}\text { CP Specific \& } \\
\text { Mental Ret: }\end{array}$ & $\begin{array}{l}\text { Delayed Physical \& } \\
\text { Mental Development }\end{array}$ & $\begin{array}{l}\text { Club } \\
\text { Foot }\end{array}$ & \\
\hline \multirow[t]{7}{*}{ Who Delivered } & Doctor & 8 & 25 & 20 & 2 & 55 \\
\hline & Nurse & 7 & 29 & 9 & 3 & 48 \\
\hline & Trained midwife & 1 & 2 & 3 & & 6 \\
\hline & Trained Dai & 2 & 5 & 4 & 1 & 12 \\
\hline & Un-trained Dai & 3 & 20 & 10 & 2 & 35 \\
\hline & Relative & 64 & 240 & 107 & 56 & +67 \\
\hline & Others & & 5 & 3 & 2 & 10 \\
\hline \multicolumn{2}{|l|}{ Total } & 85 & 326 & 156 & 66 & 633 \\
\hline
\end{tabular}

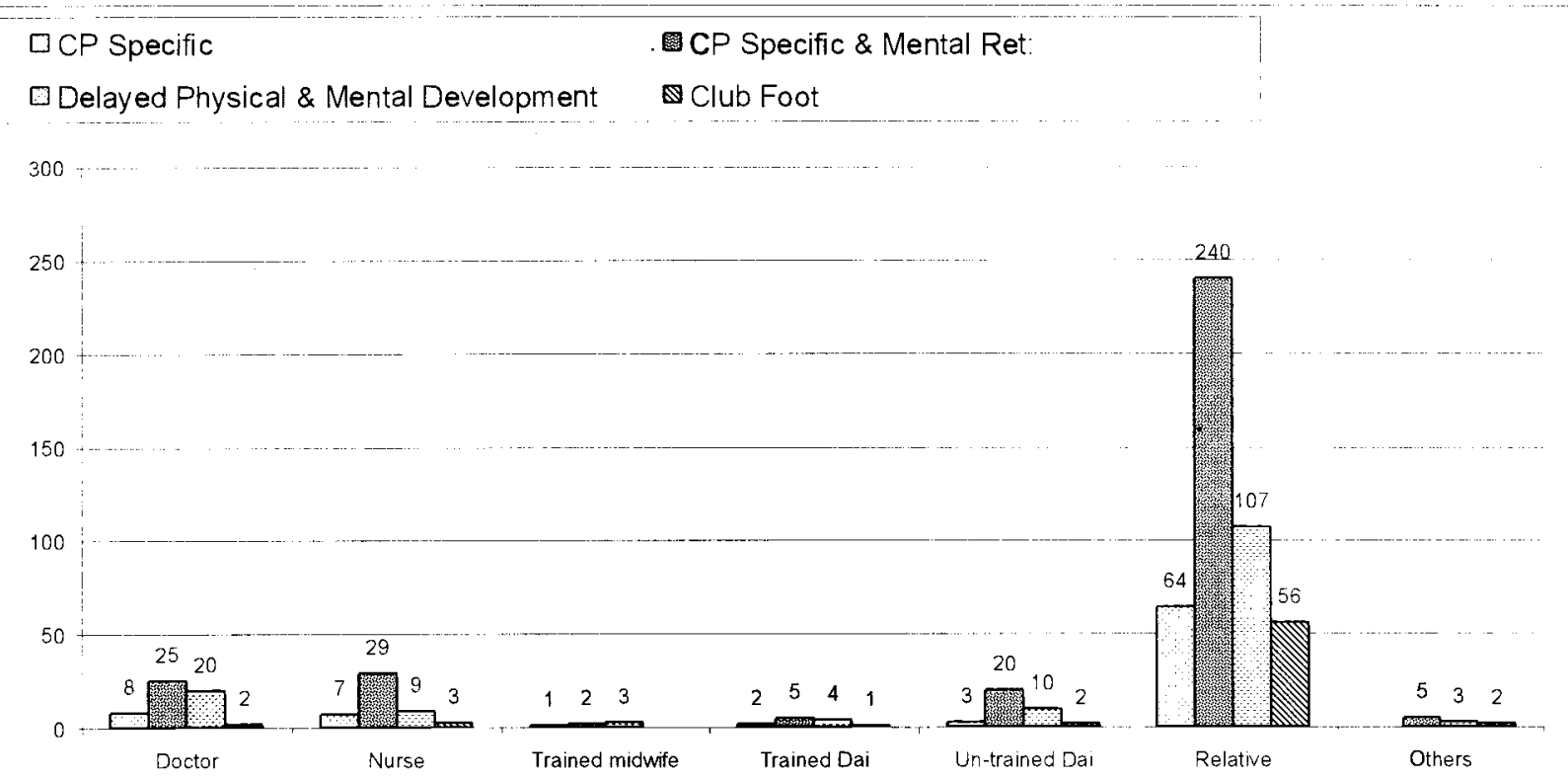

$73 \%$ of children in the study were delivered by relatives in the home. This shows the strong cultural tradition, women do not trust dais. Only in urban areas do the mothers use hospital facilities. 
TABLE 27

Frequency Distribution Of Nutrition

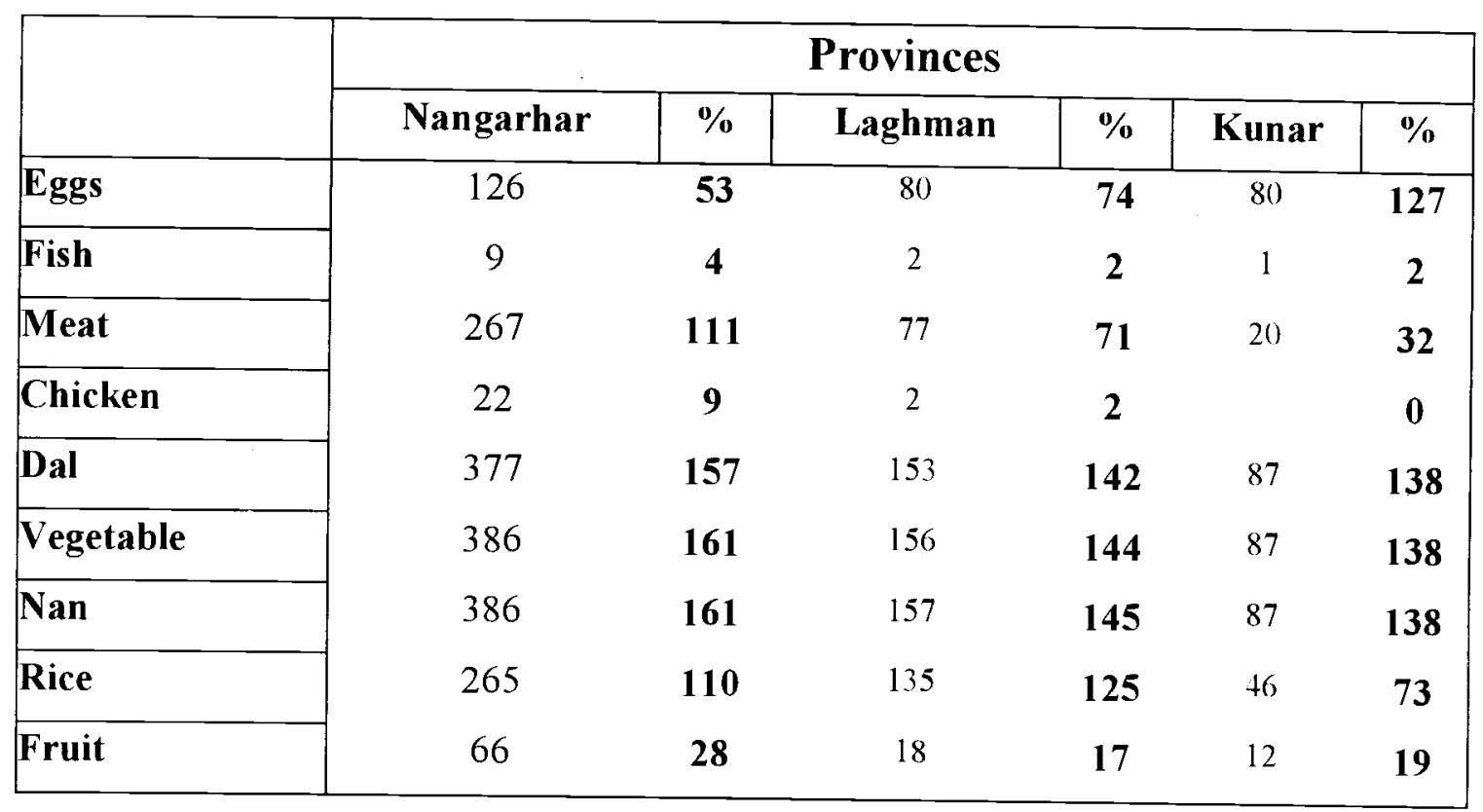

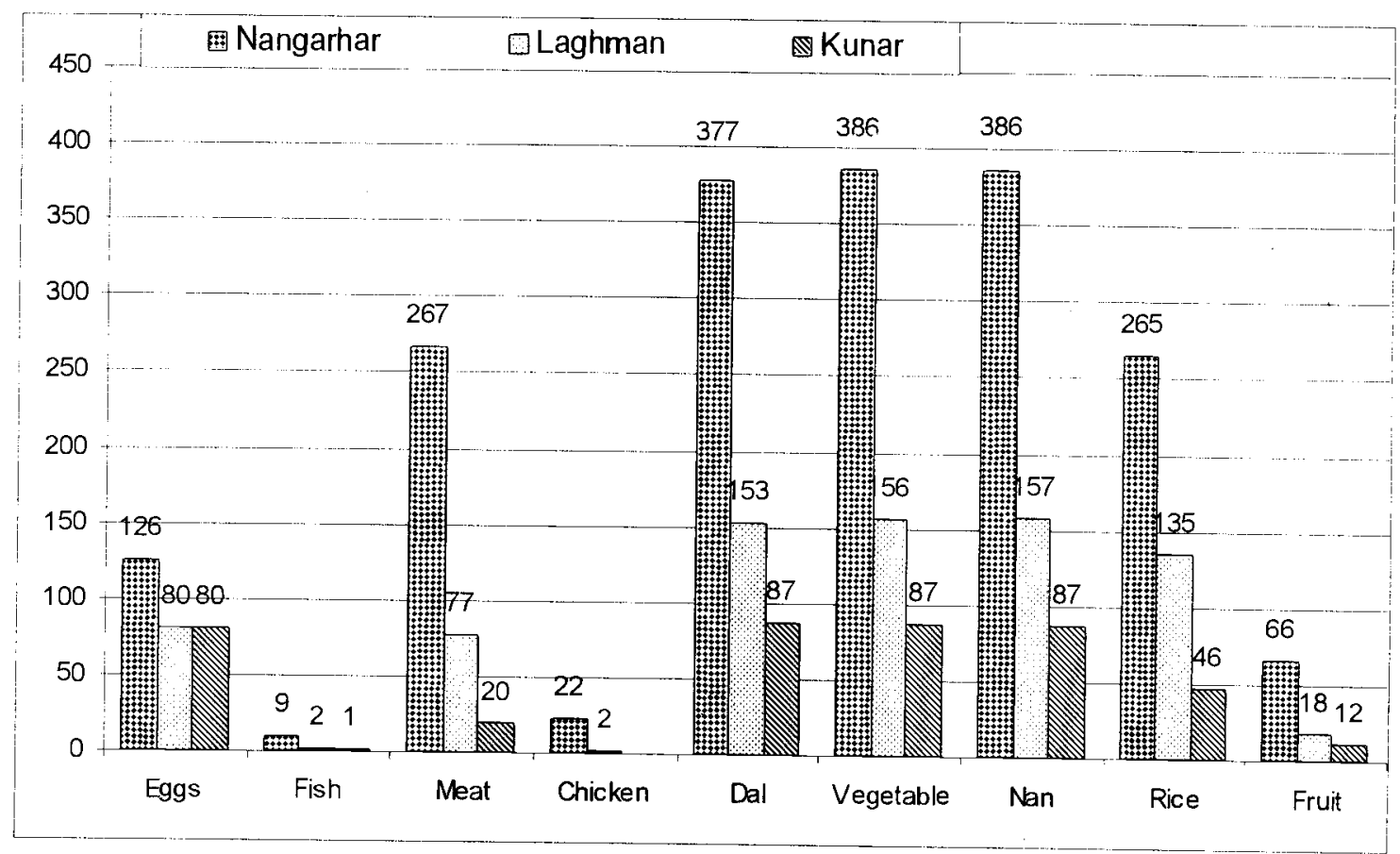

It would seem that a balanced diet of cheaper food (dal, vegetables and bread) is available to mothers in rural and urban areas. 


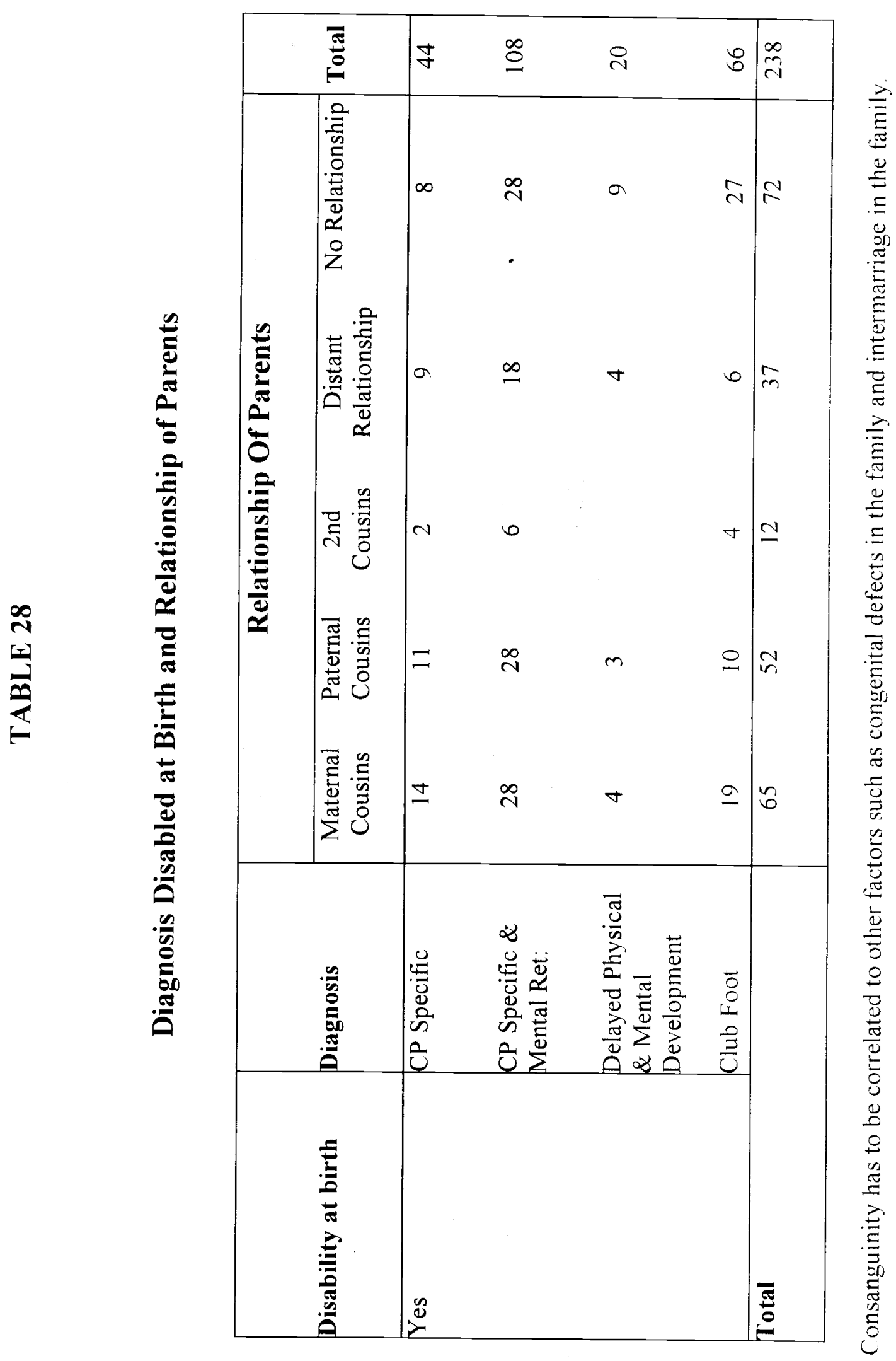




\section{AP PENDIX 2 \\ List of Research Papers}

1- $\quad$ Very Low Birth Weight

VLBW infants constitute more than one-quarter of all new cases of cerebral palsy. There is association between antenatal maternal infection and cerebral palsy in VLBW infants. The association with chorioamnionitis and spastic diplegia persisted when adjusted for maternal magnesium sulphate receipt, maternal betamethasone receipt, method of delivery (vaginal vs, abdominal), acidosis on the neonates initial arterial blood gas. systolic blood pressure $<30 \mathrm{mmHg}$ and the diagnosis of major neonatal neurosonographic abnormality.

TI: Intrauterine infection and the risk of cerebral palsy in VLBW infants

AU: $\quad$ O' Shea-TM; Klinepeter-KL; Meis-PJ; Dillard-RG

AD: Department of Pediatrics, Bowman Gray Sch Med Wake Forest Uni, Medical center Blvd, Winston-Salem, NC 27157, United States

SO: PAEDIATR-PERINAT-EPIDEMIOL. Pediatric-and-Perinatal-Epidemiology. $1998 ; 12 / 1(72-83)$

2- Gestational Age

This study aimed to evaluate the role of hypocarbia as a risk factor for mortality and for cerebral palsy in extremely VLBW infants. The analysed risk factors were birth weight, gestational age, maternal diseases and toxaemia, multiple pregnancy, respiratory distress syndrome, and at least two episodes of hypocarbia during the neonatal period.

AU: Salokorpi T. Rajantie I. Viitala J. Rita H. von Wendt L.

INST: Pediatric Neurology, Hospital for children and Adolescents, Helsinki University Central Hospital Finland.

Title: Does perinatal hypocarbia play a role in the pathogenesis of cerebral palsy?

SO: $\quad$ Acta Paediatrica. 88(5): 571-5, 1999 May.

3- Planter response profile at one year of life.

The planter reflex profile at 1 year of life in different categories of neurodevelopmental abnormalities, the planter responses sometimes present at one month, could be normal at one month and abnormal at 12 months.

AU: Zafeiriou DI. Tsikoulas IG. Kremenopoulos GM. Kontopoulos EE.

INST. First Pediatric Clinic, Aristotle University of Thessaloniki, Greece.

Title: Planter response profile of high-risk infants at one year of life.

SO: Journal of Child Neurology. 14(8):514-7, 1999 Aug.

4- Prospective evaluation of perinatal risk factors for cerebral palsy and delayed development in high risk infants. Prematurity, intrauterine infection and perinatal brain injury are the risk factors of $\mathrm{CP}$. We examined the perinatal predictors of CP \& delayed development (DD) in 184 high risk infants. 35 infants 
were diagnosed as CP \& DD at 12 months corrected age. Sepsis is also one of the cause of $\mathrm{CP}$.

AU: $\quad$ Kim JN. Namgung R. Chang W. Oh CH. SHIN JC. Park ES. Park CI. Park MS. Park KI. Lee C. Han DG.

INST. Department of Pediatrics, Yonsei University College of Medicine, Seoul, Korea.

Title: Prospective evaluation of perinatal risk factors for CP \& DD in high risk infants.

SO: Yonsei Medical Journal. 40(4): 363-70, 1999 Aug.

5- (Case Study) A patient with CP whose mother had a traffic accident.

A 16 year-old girl had spastic CP with triplegia and focal epilepsy. The patients past history included her mother's lower abdominal trauma caused by a traffic accident at the 7th month of gestation. In this patient, $\mathrm{CP}$ might be caused by an intrauterine DAI (diffuse axonal injury) when her mother was involved in the accident.

AU: Yamamoto T. Koeda T. Ishii S. Takeshita K.

INST. Gene Research Center, Tottori University, Yonago, Japan.

SO: Brain \& Development. 21(5): 334-6, 1999 Jul.

6- Low birth weight causing intraventricular hemorrhage in the first 6 postnatal hours.

The neurodevelopment outcome of VLBW infants experiencing early-onset intraventricular hemorrhage (IVH) occuring within the first 6 postnatal hours was compared with that of their peers without early-onset IVH at 3 years corrected age. The 440 surviving preterm infants (BW 600-1250 g) who had been enrolled in a multicenter, prospectively randomized controlled trial evaluating the efficacy of postnatal indomethacin to prevent IVH were evaluated with Stanford-Binet Intelligence Scale and neurological examinations at 3 years of age. The infants who experience the early onset of IVH are at high risk for both cognitive and motor handicaps at 3 years corrected age.

AU: Vohr B. Allan WC. Scott DT. Katz KH. Schneider KC. Makuch RW. Ment LR. INST: Dept of Pediatrics, Brown University School of Medicine, Providence, RI, USA.

Title: Early onset IVH in preterm neonates: incidence of neurodevelopmental handicap.

SO: Seminars in Perinatology. 23(3): 212-7, 1999 jun.

7- Maternal hypertension with pre-term infant, 24-32 weeks gestation, seem to protect against $\mathrm{CP}$ in pre-term infants without increasing the risk of cognitive impairments.

Information on maternal complications and medication was obtained and neonatal mortality and morbidities recorded. $\mathrm{CP}$ was not diagnosed in any infant of a hypertensive mother compared with 5 of the controls.

Maternal hypertension seems to protect against CP in preterm infants without increasing the risk of cognitive impairment. This was independent of the use of maternally administered magnnesium sulphate.

AU: $\quad$ Gray PH. O'Callaghan MJ. Mohay HA. Burns YR. King JF. 
INST: Dept of Neonatology, Mater Misericordiae Hospital, South Brisbane, Queensland, Australia.

Title: Maternal hypertension and neurodevelopmental outcome in very preterm infants.

SO: $\quad$ Archives of Disease in Childhood Fetal \& Neonatal Edition 79(2): F 88-93. 1998 Sep.

8- The role of asphyxia is smaller than was once believed but infection multiple pregnancies are risk factors.Electronic foetal monitoring are another observation during birth are hence unsatisfactory management guide.

AU: Matsuishi T. Yamashita Y. Ornitz E. Kuriya N. Murakami Y. Fukuda S. Hashmoto T. Yamashita F.

INST: Deptt of Pediatrics \& Child Health Kurume University School of Medicine Japan.

SO: Journal of Autism \& Developmental Disorders 29(2): 161-6, 1999 Apr.

9- $\quad$ Epidemiology of CP in England \& Scotland 1989.

1649 cases of CP, 2.1 per 1000 neonatal survival. The 550 severe ambulatory disability, 390 severe manual disability, 381 (23.1\%) severe learning disability, 146 (8.9\%) had severe visual disability and 12 at severe hearing disability.

AU: $\quad$ Pharoah-POD, Cooke-T; Johnson-MA; King-R; Mutch-L

AD: Dept of Public health University of Liverpool UK

SO: DEV-MED-CHILD_NEUROL. 33/12 (1048-1052) 1991, SEMIN-ORTHOP. 4/4 (205-214) 1989

10- Diet during pregnancy and the risk of $\mathrm{CP}$

278 children taking cereals, meat \& fish and the other taking cereal \& meat but no fish. This is the high risk factor in foetal brain development and the high meat intake is detrimental factor.

AU: Petridou-E; Koussouri-M; Toupadaki-N; Youroukos-S; Papavassiliou-A; Pantelakis-S; Olsen-J; Trichopoulos-D

AD: Dept of Hygiene \& Epidemiology, Athens University Medical School, Athens Greece.

SO: $\quad$ BR-J-NUTR. 1998; 79/5 (407-412)

11- Maternal infection and CP in infants of normal birth weight.

Maternal infection and the temperature exceeding 38 degree $\mathrm{C}$ (any form of infection) and increased hypertension and infectious diseases leads to severe spasticity. Maternal infection was also linked with low Apgar Scores, other evidence of hypertension and need for resuscitation, and neonatal seizures-signs commonly attributed to birth asphyxia.

AU: Grether-JK; Nelson-KB

AD: $\quad$ CBDMP, 1900 Powell st, Emeryville, CA 94608-1811, USA.

SO: J-AM-MED-ASSOC. Journal-of-the-Amercian-Medical-Association, 278/3 (207-211) 1997. 
12- How to prevent $\mathrm{CP}$ ante-nataly \& postnataly \& its aetiology

$\mathrm{CP}$ is by definition, incurable, epidemiology strives to elucidate causation as a necessary step towards prevention. So the recognized risk factors may be single or multiple and can occur at any stage from before conception to infancy. In developed countries the majority of aetiological paths are likely to commence before labour and delivery. The post-neonatally acquired brain damage has the most easily recognised and understood causes postnatally acquired cerebral palsy should be the most preventable.

AU: Blair-E; Stanley-FJ

AD: $\quad$ WA Cerebral Palsy Register, TVW TICHR, GPO BOX 855 West Pert WA 6872 Australia.

SO: MENT-RETARD-DEV-DISBIL-RES-REV. Mental-Retardation-and Developmental-Disabilities Research -Reviews. 3/2 (184-193) 1997

13- Strategies for prevention of $\mathrm{CP} \&$ low birth weight and prematurity

Premature infants who now survive in greater numbers than even before are at increased risk for motor and other neurologic didabilities. Risk is highest at the lowest extremes of birthweight and gestational age.

Maternal infection especially intrauterine infection is associated with preterm delivery, increased risk of cerebral palsy (CP) and neonatal brain imaging findings related to $C P$ risk.

AU: $\quad$ Nelson-KB; Grether-JK

AD; $\quad$ 7550, Wisconsin Av, Bethesda, MD 20892-9130, USA

SO; $\quad$ MENT-RETARD-DISABLE-RES-REV.

Mental-Retardation-and-Development-Disabilities-Research-Reviews $\quad 3 / 2$ (112-117) 1997

14- Mental Retardation \& Developmental Disabilities as by drug therapy, diazepam, dantrolene $\&$ baclofen, botulinium \& some uterus spasmolytic agent

AU: Cheney-PD; Palmer-FB

SO: MENT-RETARD-DEV-DISABIL-RES-REV. Mental-Retardation-andDevelopmental-Disabilities-Research-Reviews. $3 / 2$ (109-111) 1997

15- Case control study in Greece, To investigate the relation between series of maternal, antenatal, perinatal, socio-economic \& environmental variables and the occurance of $\mathrm{CP}$

AU: Petridou-E; Koussouri-M; Toupadaki-N; Pagavassiliou-A; Youroukos-S; Katsarou-E; Trichopoulos-D

AD: Harvard school of Public Health Dept of Epidemiology 677 Huntington Ave, Boston USA

SO: SCAND-J-SOC-MED. Scandinavian-Journal-of-Social-Medicine. 24/1 (14-26) 1996.

16- Ante-natal \& perinatal factors \& CP in VLBW infants. The weight $<1500 \mathrm{~g}$ gives VLBW.

Chorionitis followed by neonatal seizures occurred in 14\% of VLBW children with $\mathrm{CP}$ (in $25 \%$ with spastic diplegia) and preeclampsia was associated with decreased 
risk as was use of magnesium sulfate administered for preeclampsia or pre term labor.

AU: $\quad$ Grether-JK; Nelson-KB; Emery III-ES; Cummins-SK

AD: $\quad$ CBDMP 1900 Powell st, Emeryville, CA 94608-1811 USA

SO: J-Pediatr. Journal-of-Pediatrics. 128/3 (407-414) 1996

17- Early intervention for children with or at risk of cerebral palsy.

Quantitative \& qualitative analysis od well -conducted scientific studies of therapeutic early intervention for infants and yong children with or at risk of a motor handicap failed to find convincing evidence for the efficacy of physical therapy.

AU: Turnbull-JD Allen-MC; Alexander-GR

AD: $\quad$ Dept of Psychology ECRCD University of Edinburgh 7 George Sq Edinburgh UK Eudowood Division of Neonatal Medicine Dept of Pediatric The John Hopkins Hospital, Baltimore MD 21205 USA

SO: $\quad$ AM-J-DIS-CHILD. 147/1 (54-59) 1993 DEV-MED-CHILD-NEUROL. 34/3 (226232) 1992

18- The combination of children with epilepsy, CP \& mental retardation. History of neonatal convulsion \& history of epilepsy in close relatives. At two centres in Rome and Conegliano, Italy, 51 children with combined $\mathrm{CP}$ mental retardation \& Epilepsy, 31children with both CP \& mental retardation, and 48 with $\mathrm{CP}$ alone were examined \& identified.

AU: $\quad$ Arpino C. Curatolo P. Stazi MA. Pellegri A. Vlahov D.

INST: Pediatric Neurology Unit, University of Rome, Tor Vergata, Italy.

SO: Journal of Child Neurology. 14 (3): 15105, 1999 Mar.

19- CP who has signs of birth asphyxia, low Apgar-score \& low 6 intubation for ventilation \& initial blood $\mathrm{Hb}$, low, $<7$, and neonatal seizure Neuroprotective therapy offered to neonates with these early characteristics even if perfectly effective, would be unlikely to prevent most CP Most of these depressed infants with $\mathrm{CP}$ had nonasophyxial conditions that may have contributed to adverse neurological outcome.

AU: Nelson KB. Grether JK

INST: Neuroepidemiology Branch National Institute of Neurological Disordres \& Strokes, Bethesda MD, USA.

SO: $\quad$ Archives of Pediatrics \& Adolescent Medicine. 153(4): 393-8, 1999. Apr

20- Birth-weight $<2500 \mathrm{~g}$ needed resuscitation \& was risk factor for $\mathrm{CP}$ and when the birth weight was more than $2500 \mathrm{~g}$ they have intra-uterine hypoxia and birth at asphyxia and increased risk of $\mathrm{CP}$.

AU: $\quad$ Dite GS. Bell R. Reddihough DS. Bessell C. Brennecke S. Sheedy M.

INST: Dept of Child Development \& Rehabilitation, Royal Children's Hospital Melbourne, Victoria. Australia.

Title: Antenatal \& Perinatal antecedents of moderate and severe spastic CP.

SO: Australian \& New Zealand Journal of Obstetric \& Gynaecology. 38(4):37783, 1998. 
21- Premature rupture of membrane, respiratory distress syndrome, and monochorionic twin placenta. To delineate the perinatal risk factors of neurodevelopmental disabilities in very preterm birth applying Logistic analysis. This study was carried out in. France. The results were 167/171 (98\%) survivors were evaluated. 22 out of 167 examined infants (13\%) showed signs of CP \& 10 had severe $\mathrm{CP}$ or mental retatdation.

AU: Burguet A. Monnet E. Pauchard JY. Roth P. Fromentin C. Dalphin ML. Allemand H. Maillet R. Menget A.

INST: Reanimation Infantile Polyvalent, Center Hospitalo-Universitaire de Besancon France.

Title: Some risk factors for $\mathrm{CP}$ in very premature infants : importance of premature rupture of membranes and monochorionic twin placentation.

SO: Biology of the Neonate. 75(3):177-86, 1999 Mar.

22- Brain injury, infection during and before pregnancy leads to neonatal white matter damage $\&$ then $\mathrm{CP}$. There is relationship between prematurity \& infection (Infection \& Prematurity).

In this the hypothesis is that infection during or even before pregnancy remote from the fetal brain leads to Neonatal white matter damage (NWND) and its long term sequelae, including $\mathrm{CP}$.

AU: Dammann O. Leviton A.

INST: Dept of Neurology, Children Hospital Boston, MA 02115, USA

Title: Infection remote from the brain, neonatal white matter, and $\mathrm{CP}$ in the preterm infant.

SO: Seminars in Pediatric Neurology. 5(3):190-201, 1998 Sep.

23- The use of postural reaction in the 1 year of life to diagnose $\mathrm{CP}$.

To clarify the predictive value of the 7 more commonly used postural reactions (PR) in the 1 year of life for diagnosis of $\mathrm{CP}$. We prospectively examined 204 high risk infants of whom 58 developed CP, 22 had developmental retardation DR, \& 124 were normal at follow up at 3 years of age. We conclude that the examination of $\mathrm{PR}$ is a useful quantitative \& qualitative diagnostic screening tool for high risk infants from the 1 month of life.

AU: Zafeiriou DI. Tsikoulas IG. Kremenopoulos GM. Kontopoulos EE.

INST: Ist Pediatric Clinic, Aristotle University of Thessaloniki, Greece.

Title: Using postural reactions as a screening test to identify high risk infants for cerebral palsy.

SO: $\quad$ Brain and Development. 20(5):307-11,1998 Aug

24- VLBWchildren with prematurity, race, sex, septicemia have effects on the neonatal respectives. Antenatal, intrapartum, and neonatal events and therapies were compared between 72 singleton inborn VLBW children and 72 neurologically normal VLBW children matched by birth weight, gestational age, race, and sex via a retrospective case control study.

AU: Wilson-Costello D. Borawski E. Friedman H. Redline R. Fanaroff AA. Hack $\mathrm{M}$.

INST: Dept of Pediạtrics, Case Western Reserve University, Cleveland, Ohio, USA 
Title: Perinatal correlates of $\mathrm{CP}$ and other neurologic impairment among VLBW children.

SO: Pediatrics. 102(2Pt 1):315-22, 1998 Aug

25- Relation between short term interval pregnancy interval \& CP in LBW population \& neonatal brain injury. To investigate the relation of short interpregnancy interval and CP in LBW population \& brain injury in The newborn period. In the presence of strong explanatory power of neonatal brain injury, short interpregnancy interval maintains an independent risk for disabling CP. The LBW infants short interpregnancy interval appears to represent a significant risk for the development of disabiling $\mathrm{CP}$.

AU: Pinto-Martin JA. Cnaan A. Zhao H.

INST: University of Pennsylvania School of Nursing 19104, USA.

Title: Short interpregnancy interval and the risk of disabling CP in a LBW population.

SO: Journal of Pediatrics. 132(5): 818-21, 1998. May.

26- Preeclampsia \& CP among premature infants.

We investigate the relationship of preeclampsia to the development of infant $\mathrm{CP}$ (spastic quadriplegia, hemiplegia, or diplegia) at 2 years corrected age. The prevalence of $\mathrm{CP}$ in surviving infants from normotensive \& preeclamptic pregnancies was $13.4 \% \& 3.3 \%$ respectively.

AU: Spinillo A. Capuzzo E. Cavallini A. Stronati M. De Santolo A. Fazzi E.

INST: Dept of Obstt \& Gynae, IRCCS Policlinico San Matteo, Pavia Italy.

Title: Preeclampsia, preterm delivery and infant CP

SO: European Journal of Ostt \& Gnae, \& Reproductive Biology 77(2):151-5 , 1998 Apr.

27- Foetus associated with $\mathrm{CP}$ multiple gestation, Choriuamnionitis, maternal antibiotics, antepartum vaginal bleeding \& labor lasting less then 4 hours. The following factors are associated most strongly with an increased risk of $\mathrm{CP}$, multiply gestation, chrioamnionitis, maternal antibiotics, antepartum vaginal bleeding, and labor lasting less then 4 hours.

Preeclampsia and delivery without labor was associated with a decreased risk.

AU: O'Shea TM. Klinepeter KL. Dillard RG.

INST: Dept of Pediatrics, Bowman Gray School of Medicine, Wake Forest University Winston-Salem NC 27103, USA.

Title: Ante-natal events and the risk of CP in VLBW infants

SO: American Journal of Epidemiology. 147(4):362-9, $1998 \mathrm{Feb}$

28- Preterm infants are 8 times higher risk then term infants for ante-natal \& perinatal brain damage. Cesarean section and low Apgar Score were significant. Pregnancy complications, preterm birth did not apply the high risk of $\mathrm{CP}$

AU: $\quad$ Topp M. Langhoff-Roos J. Uldall P.

INST: Dept of Obstt \& Gynae, University of Copenhagen, Hvidovre Hospital Denmark.

Title: Preterm birth \& CP, mode of delivery and Apgar scores.

SO: $\quad$ Acta Obstetricia et Gynaecologica Scandinavica. 76(9):843-8.1997. Oct. 
29- Neurodevelopmental outcome of infants born at (24-26 gestation) these children have cognitive deficits. To assess the neurodevelopmental outcome of infants born 24-26 weeks gestation. Mean age at follow up was 32 months. The incidence of normal cognitive outcome was associated significantly with gestational age at birth $(28,47, \& 71 \%$ normal at $24.25 \& 26$ weeks respectively)

AU: Piecuch RE. Leonard CH. Cooper BA. Kilatrick SJ. Schlueter MA. Sola A.

INST: Dept of Pediatrics, University of California, San Francisco, USA

Title: Outcome of infants born at 24-26 weeks gestation Neurodevelopmental outcome.

SO: Obstetrics \& Gynecology. 90(5):809-14,1997 Nov.

30- Ante-natal factors are more common complex sequences and are more common as causes and those occuring perinatally or postnatally. Rubella, starvation, mercury poisoning any disease outbreak.

AU: Stanley FJ.

INST: TVW Telethon Institute for Child Health Research Perth Western Australia.

Title: Ante-natal determinants of motor disorders

SO: $\quad$ Acta Paediatrica. Supplement. 422:92-102, 1997 Jul

31- The piedictive Value of absent or abnormal spontaneous movement with the foetus, from 6-20 weeks and also fidgety movements upto the age of 2 years. Absence of fidgety movements in the foetus had $\mathrm{CP}$ or developmental retardation. AU: $\quad$ Prechtl HF. Einspieler C. Cioni G. Bos AF. Ferrari F. Sontheimer D.

INST: Dept of Physiology, Karl-Franzens-University, Graz, Austria.

Title: An early mark for neurological deficits after perinatal brain lesions.

SO: $\quad$ Lancet. 349(9062):1361-3, 19897 May

32- Comparing Asian \& Non Asian population and the prevalence between non-Asian \& Asian is 3.18 of 5.48 per 1000 . This was significant because of the first cousin marriages and the family head immediate close relatives with $\mathrm{CP}$. There was no consanguinity in non-Asian family.

AU: Sinha G. Corry P. Subesinghe D. Wild J. Levene MI.

INST: Dept of Pediatrics, Leeds General Infirmary , USA.

Title: Prevalence and type of $\mathrm{CP}$ in a British ethnic community : the role of consanguinity.

SO: Developmental Medicine \& Child Neurology. 39(4):259-62, 1997 Apr.

33- VLBW infants with mal-presentation and delivery method like breech. All risk factors for $\mathrm{CP}$ and mental retardation.

AU: Kato EH. Yamada H. Matsumoto Y. Hattori S. Makinoda S. Fujimoto S.

INST: Dept of Obstt \& Gynae, Hokkaido University School of Medicine Sapporo, Japan.

Title: Relation between perinatal factors and outcome of VLBW infants.

SO: Journal of Perinatal Medicine. 24(6):677-86, 1996. 
34- Pathophysiology of $\mathrm{CP}$

AU: Dzienkowski RC. Smith KK. Dillow KA. Yucha CB.

INST: U.S. Army Nurse Corp, Denver. CO, USA.

Title: $\mathrm{CP}$, a comprehensive review.

SO: $\quad$ Nurse Practitioner. 21(2):45-8, 51-4, 57-9, quiz 60-1, 1996 Feb.

35- The changing epidemiology from Liverpool, and increaed LBW from $81-89.50 \%$ of CP have LBW in comparison to $32 \%$ in 1960 . There are few cases of diplegia and increased in hemiplegia and increased severity of functional disabilities at ambulatory disabilities..

AU: $\quad$ Pharoah PO. Platt MJ. Cooke T.

INST: Dept of Public Health University of Liverpool.

Title: The changing epidemiology of $\mathrm{CP}$.

SO: Archives of Disease in Childhood Fetal \& Neonatal Edition. 75(3):F169-73. 1996

36- California VLBW, less than $1500 \mathrm{~g}$, associated with seizures, preeclampsia, chorionitis, \& fits and multigravida.

DU: Grether JK. Nelson KB. Emery ES $3^{\text {rd }}$. Cummins SK.

INST: California Birth Defects Monitoring Program, California Dept of Health Services, Emeryville 94608-1811, USA.

Title: Ante-natal \& perinatal factors \& CP in VLBW infants.

SO: Journal of Pediatrics. 128(3):407-14, 1996 Mar.

37- Urinary tract infection during pregnancy the risk was 4-5 times greater for the development of $\mathrm{CP}$.

AU: Polivka BJ. Nickel JT. Wilkins JR III.

INST: College of Nursing The Ohio State University, 1585 Neil Ave, Columbus, $\mathrm{OH} 43210$.

Title: UTI during pregnancy, a risk factor for $\mathrm{CP}$.

SO: JOGNN-Journal of Obstt \& Gynae \& Neonatal Nursing. 26(4):405-13, 1997 Jul-Aug.

38- Chi Square Test, Risk factors for Apgar Score, LBW, Premature \& pregnancy complication \& infection asphyxia, standard of midwifery.

AU: $\quad$ Murphy DJ. Sellers S. Mackenzie. Yudkin PL. Johnson AM.

INST: National Perinatal Epidemiology Unit, Radcliffe Infirmary, Oxford, UK.

Title: Case Control Study.

SO: $\quad$ Lancet. 346(8988): 1449-54, 1995.

39- Identification of childhood disability in Jamacia the ten question screen.

This is the first in a series of papers that report the testing of two instruments for the identification and assessment of childhood disability by community workers (CWs) in the third world countries. The ten question screen(TQ) was used as the main instrument to identify disability in a two stage population-based survey of 5478 children aged $2-9$ years in Clarendon, Jamaica. In the second stage, TQ positive and $8 \%$ of the screen negative controls were professionally assessed by a 
doctor and a psychologist using standard criteria based on the main classification system of the ICIDH.

AU: Marigold Thorburn, Patricia Desai, T. J. Paul. Louise Malcolm, Maureen Durkin \& Laslie,

INST: Dept of Social \& Preventive Medicine, University of West Indies, Mona, Jamaica, Gertrude Sergievsky Center, Columbia University, New York, USA.

SO: Belmont L. (1984) Final report of the international pilot study of severe childhood disability .Columbia university, New York.

Clarke, A. M.\& Clarke, A. D. B. (1974). Mental deficiency, London, Methuen.

Durkin, M. Davidson, L. Hasan, M. Khan, N. Thorburn, M. J.\& Zaman, S. 1990 Screening for childhood disabilities in community settings. In practical approaches to childhood disabilities in developing countries.

Ennever O. N. and standard, K L. 1982, Training primary health care workers for the Caribbean. World health Forum, 3, 156-8.

Feinstein, A. R. 1997, Clinical Biostatistics. St Louis, C.V.Mosby Co.

Frankenburg, W. and Dodds, J 1967, The Denver developmental screening test. Journal of Pediatrics, 71; 181-91.

Frankenburg W K , Chen, J and Thornton, S M 1988, Common pitfalls in the evaluation of developmental screening tests, Journal of Pediatrics, $113,1110-13$.

Fryers, T 1986, The epidemiology of severe intellectual impairment. The dynamics of prevalence.

Marfo, K. 1985, Childhood disabilities in developing countries. New York, Praegar.

O'Toole. B, 1987, Community based rehabilitation, problems and disabilities, European journal of special needs education, 2, 177-90.

Paul. T J, Desai, P . and Thorburn, M J 1990, The prevalence of childhood disability in claredon, Jamaica, West Indian Medical Journal, 39, 69-70.

Rehabilitation international 1981, childhood disability, its prevention and rehabilitation, Assignment children, 53/54, 43-75.

Thorburn, M J 1981, In Jamaica: Community aids for pre school disabled children, Assignment children, 53/54, 117-34.

Thorburn, M J 1991a, The disabled child in the Caribbean, a situation analysis, West Indian Medical Journal, 40, 172-7.

Thorburn, M J 1991b, A community approach to helping disabled children in Jamaica, International journal of mental health, 20,61-76.

Thorburn M J Desai, P and Durkin, M 1991, A comparison of efficacy of the key informant and community survey method in the identification of childhood disability in Jamaica, Annals of epidemiology, 1, 255-61.

Thorburn M J Desai, P and Davidson, L 1992a, categories, classes and criteria in childhood disability. Experience from a survey in Jamaica. Disability and Rehabilitation, 14 in press.

Who, 1980, International classification of impairments, disabilities and handicaps Geneva, WHO. 
40- MADDS- (Metropolitan Atlanta Developmental Disabilities Surveillance Program) Primary prevention of DD requires knowledge of the specific causes of these conditions. Postnatal causes account for $3 \%-15 \%$ of all developmental disabilities and often are preventable. Postnatal causes of DD in 1991-1996, bacterial meningitis, 30\%, child battering, $14 \%$ near drowning incident, motor vehicle, stroke, infection diseases \& injuries. Child battering includes the shaking baby syndrome, which is the second largest risk factor. Sickle cell anaemia, false hit by motor vehicle and otitis media, encaphalitis, brain tumour.

\section{References}

1- $\quad$ Lipikin PH. Epidemiology of the DD. In Capture AJ, Accardo PJ, eds. DD in infancy \& child hood. Baltimore, Maryland, 1991, 43-67.

2- McLaren J, Bryson SE. Review of recent epidemiological studies of mental retardation: prevalence, associated disorders and etiology. Am J Ment Retard 1987; 92:243-54.

3- Davidson J, Hyde ML, Alberti PW. Epidemiology of hearing impairment in childhood. Scand Audiol Suppl 1988; 30:13-20.

4- Drews CD, Yeargin-Allsopp M, Murphy CC, Decoufle P. Legal blindness among 10-year-old children in metropolitan Atlanta: prevalence, 1985 to 1987. Am J Public Health, 1992; 82: 1377-9.

5- $\quad$ Adams WG, Deaver KA, Cochi SL, et al. Decline of childhood Haemophilus influenzae type $b$ (Hib) disease in Hib vaccine era. JAMA 1993;269:221-6.

6- $\quad$ Pegelow CH, Adams RJ, McKie V, et al. Risk of recurrent stroke in patients with sickle cell disease treated with erythrocyte transfusions. J Pediatr 1995;126:896-9.

7- Shah PM. Prevention of mental handicaps in children in primary health care. Bull world Health Organ 1991;69:779-89.

41- Prevalence of cerebral palsy among 10-year-old children in metropolitan Atlanta, USA.

204 children identified of 10-years of age with CP. It was higher in black children than white and higher in boys and $75 \%$ of the children had one of the other 4 disabilities. (visual, hearing, mental retardation \& epilepsy)

\section{References}

Boyle CA, Yeargin-Allsopp M, Doernberg NS, Holmgreen P, Murphy CC, Schendel DE. Prevalence of developmental disabilities in children 3-10 years of age: April 19, 1996. MMWR 1996, 45 (No. SS-2):1-14.

Boyle CA, Decoufle P. Yeargin-Allsopp M. Prevalence \& health impact of DD in US children. Pediatrics 1994:93:399-403.

Murphy CC, Yeargin-Allsopp M, Decoufle P, Drews CD. Prevalence of CP among 10-year-old children in metropolitan Atlanta, 1985 through 1987. Journal of Pediatrics, 1993;123:S13-S20.

Boyle CA, Decoufle P, Holmgreen P. Contribution of DD to childhood mortality in the US: Paediatric and perinatal Epidemiology 1994;8:411-422. Yeargin-Allsopp M, Murphy CC, Oakley GP, Sikes RK. A multiple source method for studying the prevalence of DD in children: the metropolitan Atlanta DD study. Pediatrics 1992:89:624-630. 
42- $\quad$ Evaluation by exercise testing of the child with $C P$.

$\mathrm{CP}$ is classified as a static encephalopathy. Children with $\mathrm{CP}$ have distinctly subnormal values for peak anaerobic power and muscular endurance of the upper \& lower limbs. A multidisciplinary (kinetic, kinematics \& electromyography) approach is an important noninvasive tool for studying some of the underlying mechanisms responsible for abnormal gait and elevated energy costs.

AU: Unnithan-VB; Clfford-C; Bar-Or-O

INST: Dept of Movement Science \& Physical Education, University of Liverpool, England

SO: $\quad$ Sports Med. 1998 Oct; 26(4) : 239-51

43- Neurosensory outcome \& growth at 3 years in extremely LBW infants, follow-up results from the Swedish national prospective study. 633 extremely LBW infants born alive in the 2-y period 1990-92 with a birth weight of $<$ or $=1000 \mathrm{~g} \&$ gestational age of $>$ or $=23$ completed weeks was conducted regarding neurosensory outcome \& growth. 98\% surviving infants at the median age of 36 months, the mean height, weight and head of the circumference were lower than the reference values.

AU: Finnstrom-O; Otterblad-Olausson-P; Sedin-G; Serenius-F; Sevenningen-N; Thiringer-K; Tunell-R; Wesstorm-G.

INST: Dept of Paediatrics University Hospitals of Linkoping, Sweden

SO: $\quad$ Acta-Paediatr. 1998 Oct; 87(10):1055-60.

44- Using postural reactions as a screening test to identify high risk infants for $\mathrm{CP}$ : a prospective study. To clarify the predictive value of the 7 more commonly used postural reactions in the $1^{\text {st }}$ year of life for the diagnosis of $\mathrm{CP}$, and follow-up at 3 $y$. Abnormalities of 5 or more from the $1^{\text {st }}$ month of life were correlated with spastic CP while 5 or 6 abnormal PR were also correlated with athetoid CP.

AU: Zafeiriou-DI; Tsikoulas-IG; Kremenopoulos-GM; Kontopoulos-EE

INST: $1^{\text {st }}$ Pediatric Clinic Aristotle University of Thessaloniki, Greece.

SO: Brain-Dev. 1998 Aug; 20(5) : 307-11.

45- Neurodevelopment of surviving infants at age $2 \mathrm{y}$ with a BW less than $2000 \mathrm{~g}$ and cared for in neonatal intensive care units (NICU)-results from a population based longitudinal study in Taiwan.The assessments included neurological, growth and general health. The incidence of abnormal neurodevelopmental outcome remained high in the graduates of NICU at $2 \mathrm{y}$ of age, compared to normai controls.

AU: Wang-ST; Wang-CJ; Huang-CC; Lin-CH

INST: Dept of Public Health, College of Medicine, National Cheng Kung University, Tainan, Taiwan.

SO: $\quad$ Public-Health. 1998 Sep; 112 (5) : 331-6

46- Comparison of 2 outcome measures for infants with CP \& infants with delays.

The purpose of this study was to compare the Gross Motor Function Measure (GMFM) \& the Peabody Developmental Gross Motor Scale (PDMS-GM). For the 6 
months period, mean PDMS-GM age-equivalent scores increased 3.8 months \& mean scaled scores increased 35 points for infants with $\mathrm{CP}$.

AU: Kolobe-TH; Palisano-RJ; Stratford-PW

INST: Hahnemann University Philadelphía, PA, USA.

SO: $\quad$ Phys-Ther. 1998 Oct; 78(10) : 1062-72.

47- Nursery Neurobiologic Risk Score \& outcome at 18 months.

The aim of this study was to confirm the PV of the nursery neurobiologic risk score. Prospectively 121 infants were followed at 18 months. Sensitivity. specificity, positive \& negative predictive values for any disability were $81,54,49$, $\& 84 \%$ for a score $>$ or $=5 \& 56,71 \& 78 \%$ for a score $>$ OR $=8$.

AU: $\quad$ Lefebvre-F; Gregoire-MC; Dubois-J; Glorieus-J.

INST: Dept of Pediatrics, Hospital Ste-Justine, Universite de Montreal, Quebec, Canada.

SO: $\quad$ Acta-Paediatr. $1998 \mathrm{Jul} ; 87(7)$ : 751-7.

48- Classification of developmental delays.

A child suspected to have delays should always be assessed in each of the major streams of development. The 5 main domains, pathophysiology, impairment, functional limitation, disability \& societal limitation. An etiology domain is added.

AU: Peterson-MC; Kube-DA; Palmer-FB.

INST: Dept of Pediatrics, Boling Center for DD, University of Tennessee, Memphis, College of Medicine, USA.

SO: $\quad$ Semin-Pediatr-Neurol. 1998 Mar; 5(1) : 2-14.

49- Ante-natal methylmercury exposure \& children : neurologic, developmental, and behavioral research.Predatory fish and sea mammals have the highest levels of $\mathrm{MeHg}$. Ante-natal poisoning with high dose $\mathrm{MeHg}$ causes mental retardation \& $\mathrm{CP}$. AU: Myers-GJ; Davidson-PW

INST: Dept of Neurology, University of Rochester School of Medicine \& Dentistry, New York 14642, USA.

SO: $\quad$ Environ-Health-Perspect. 1998 Jun; 106 Suppl 3: 841-7.

50- Impaired visual perceptual performance on an object recognition task in children with cerebral visual Impairment VPA \& grating acuity were studied with CPI. In 22 children, Recognition performance on this subset of drawings was impaired in 16 children $72.7 \%$ but was unrelated to visual acuity.

AU: Stiers-P; De-Cock-P; Vandenbussche-E.

INST: Centrum voor Ontwikkelingsstoornissen, Universitaire Ziekenhuizen, Belgium.

SO: $\quad$ Neuropediatrics. 1998 Apr; $29(2): 80-8$

51- The vulnerable preschool child: the impact of biomedical \& social risks on neurodevelopmental function. The scope of preschool children with biological risk \& social disadvantages is large \& includes over 1 million $28 \%$ newborns per year. Currently in 1996, $7 \%$ of children are born with LBW, 1\% with VLBW, 20\% have alcohol exposure, and 10\% have other drug exposure. 
AU: $\quad$ Msall-ME; Bier-JA; LaGasse-L; Tremont-M; Lester-B

INST: Dept of Pediatrics, Brown University of Medicine, Providence RI, USA.

SO: $\quad$ Semin-Pediatr-Neurol. 1998 Mar; 5(1) : 51-61.

52- A quantitative review of mortality \& DD in extremely premature newborns.

Since 1970 reporting on both mortality \& disability in infants born at or before 26 weeks, gestation, with a birth weight of $800 \mathrm{~g}$ or less. Survival averaged $41 \%$ for extremely immature infants \& $30 \%$ for ES infants and it increased with time.

AU: $\quad$ Lorenz-JM; Wooliever-DE; Jetton-JR; Paneth-N

INST: Dept of pediatrics \& human Development. College of Human Medicine. Michigan State University, East Lansing USA.

SO: $\quad$ Arch-Pediatr-Adolesc-Med. 1998 May; 152(5) :425-35

53- Children with sensorimotor deficits: a special risk group.

4874 acute burn admissions, 66 children were identified with preexisting sensorimotor deficits. The with sensorimotor deficit are more prone to burn injury from both their physical impairment and poorly supervised environments.

AU: Ramirez-RJ; Behrends-LG; Blakeney-P; Herndon-DN

INST: Shriners Burns Institute, Galveston, TX 77550, USA

SO: j-Burn-Care-Rehabil. 1998 Mar-Apr; 19(2) : 124-7.

54- Health \& Developmental outcomes at 18 months in very preterm infants with bronchopulmonary dysplasia. A total of 217 infants born in a tertiary care center at 24-28 weeks gestation in 1987-92. No differences were found in weight, height, head circumference, or total numbers of days of rehospitalizations for any causes, or in rate of rehospitalizations to the intensive care unit, persistent respiratory problems, $\mathrm{CP}$, or sensory impairment.

AU: Gregoire-MC; Lfebvre-F; Glorieux-J

INST: Universite de Montreal, Hospital ste-Justine \& Universite de Montreal, Montreal, Canada.

SO: $\quad$ Pediatrics. 1998 May; 101(5) : 856-60.

55- Increased survival \& deteriorating developmental outcome in 23-25 week old gestation infants. A comparison study between 1984-9 \& 1990-4. Between 1984 \& 1989 (cohort 1) \& 1990-4 (cohort 2) the rate of survival to discharge increased significantly from $27 \%$ to $42 \%$ and the rate of disability in survivors increased from $38 \%$ to $68 \%$; most of this increase was in mild disability.

AU: $\quad$ Emsley-HC; Wardle-SP; Sims-DG; Chiswick-ML; D'Souza-SW

INST: Dept of Child Health, University of Manchester, St Mary's Hospital

SO: $\quad$ Arch-Dis-Child-Fetal-Neonatal-Ed. 1998 Mar; 78(2) : F99-104.

56- Before viability: a geographically based outcome study of infants weighing $500 \mathrm{~g}$ or less at birth. This was a 12 years historical cohort follow-up study of all infants born in this gestational age \& birth weight category 1983 \& 1994 .

AU: $\quad$ Sauve-RS; Robertson-C; Etches-P; Byrne-PJ; Dayer-Zamora-V

INST: Dept of Pediatrics, University of Calgary, Calgary, Alberta, Canada.

SO: Pediatrics. 1998 Mar; 101 (3 pt 1) : 438-45. 
57- Neurologic outcomes for infants weighing less than $1000 \mathrm{~g}$ at birth $u t \quad 10$; infants with birth weight of less than $1000 \mathrm{~g}$ from 1981-86, the diagnosis wer normal in $71, \mathrm{CP}$ in 13 , mental retardation in 11 , borderline intellige 1111, spinal palsy due to birth injury in 1 .

AU: Futagi-Y; Suzuki-Y, Goto-M

INST: Division of Pediatric Neurology, Osaka Medical Center \& Researin I diuti: for Maternal \& Child Health

SO: $\quad$ No-To-Hattatsu.1998 Jan; 30 (1): 56-60.

58- The value of scoring system for hypoxic ischaemic encephatipath. neurodevelopmental outcome. This was done at the age of lyear. 45 intant, . bo developed hypoxic ischaemic encephalopathy after birth. 23 (58\%) of the winte: were normal \& $17(42 \%)$ were abnormal, 16 with CP \& 1 with develo snt tia delay.

AU: Thompson-CM; Puterman-AS; Linley-LL; Hann-FM; van-der-it t- Liv Molteno-CD; Malan

INST: Dept of Paediatrics \& Child Health, University of Cape Town. South Afrira. SO: $\quad$ Acta-Paediatr. 1997 Jul; 86(7) : 757-61

59- Neurodevelopmental outcome in babies with a low Apgar score from Zmis bw: 165 infants were examined with a NNE \& 142 with Bayley Scale of Infant Development (BSID) at 1 y of age. 23 infants had CP, 10 had a motor attlay or developmental delay, \& 4 were mentally retarded.

AU: Wolf-MJ; Wolf-B; Bijleveld-C; Beunen-G; Casaer-P

INST: Children's Rehabilitation Unit, Mpilo Central Hospital, Buiawayo. Zimbabwe.

SO: $\quad$ Dev-Med-Child-Neurol. 1997 Dec, 39 (12) : 821-6.

60- Survival \& developmental disability in infants with BW of 501-800 g during 19791994.

513 infants with BW of $501-800 \mathrm{~g}$ at $1 \mathrm{y}$ of age. A total of $209 / 216(97 \%)$ of survivors were examined. This analysis suggests that the increasing survival of extremely LBW neonates since the late 1970 s has not resulted in an increased rate of major developmental problems identifiable at $1 \mathrm{y}$ of age.

AU: O'Shea-TM; Klinepeter-KL; Goldstein-DJ; Jackson-BW; Dillard-RG

INST: Dept of Pediatrics, Bowman Gray School of Medicine of Wake Forest University, Winston- Salem, North Carolina, USA.

SO: $\quad$ Pediatrics. 1997 Dec; 100 (6) : 982-6

61- Outcome of infants born at 24-26 weeks gestation. Neurodevelopmental outcome. 138 nonanomalous infants born after pregnancies of $24-26$ weeks gestation between 1990-94. 94 infants survived \& 86 were followed for follow-up for outcome.

AU: $\quad$ Piecuch-RE; Leonard-CH; Cooper-BA; Kilpatrick-SJ; Schlueter-MA; Sola-A

INST: Dept of Pediatrics, University of California, San Francisco, USA.

SO: Obstet-Gynecol. 1997 Nov; 90 (5) : 809-14. 
62- Outcome at 2 y of children 23-27 weeks gestation born in Victoria in 1991-92.

This was a cohort study \& the results of 401 livebirths 23-27 weeks in 1992-92, 225 $(56.1 \%)$ survived to 2 years of age. The survival rate for those $24-26$ weeks was $57.4 \%(143 / 249)$, a statistically significant increase on the regional survival rate of $30.1 \%(95 / 316)$ in $1985-87$.

AU: Victorian Infant Collaborative Study Group

SO: J-Paediatr-Child-Health. 1997 Apr; 33(2) : 161-5

63- A follow-up study of infants $<$ or $=2000 \mathrm{~g} \mathrm{BW}$ treated in central Queensland.

Among 482 infants of $B W<$ or $=2000 \mathrm{~g}$ treated in the period under review. 393 survived \& 8 were known to died subsequently. Of the remaining 385 children. $288(74.8 \%)$ were able to be found in good health. A total 36 infants were found to have significantly disabilities.

AU: Mercer-HP; Roper-PC

INST: Mater Misericordiae Hospital Rockhamptor, Australia.

SO: J-Paediatr-Child-Health . 1997 Apr; 33 (2) : 98-101

64- Relationship between MR images \& clinical findings in neuronal migration disorders.

39 patients (23 males, 16 females; mean age 6.1y) with neuronal migration disorders, the diagnosis were $C P$ in 23 cases, mental retardation in 4 , west syndrome in 4, Fukuyama type congenital muscular dystrophy in 6.

AU: Onuma-A; Kobayashi-Y; Iinuma-K

INST: Division of Pediatric Neurology, Takuto Rehabilitation Center for Disabled Children, Sendai.

SO: $\quad$ No-To-Hattatsu. 1997 Jul; 29(4) : 285-90

65- Infarcts in the vascular distribution of the middle cerebral artery in preterm nd full term infants.

AU: de-Vries-LS; Groenendaal -F; Eken-P; van-Haastert-IC; Rademaker-KJ; Meiners-LC

INST: Dept of Neonatology, Wilhelmina Childrens Hospital, Utrecht, The Netherlands.

SO: $\quad$ Neuropediatrics. 1997 Apr; 28 (2) : 88-96

66- Surveillance of developmental disabilities with an emphasis on special studies.

AU: Boyle-CA

INST: Developmental Disabilities Branch, Centers for Disease Control and Prevention, Atlanta, Georgia 30333, USA.

SO: $\quad$ Reprod-Toxicol. 1997 Mar-Jun; 11 (2-3): 271-4

67- Randomized study of the effect of antenatal dexamethasone on growth and development of premature children at the corrected age of 2 years.

AU: $\quad$ Salokorpi-T; Sajaniemi-N; Hallback-H; Kari-A; Rita-H; von-Wendt-L

IST: Dept of pediatric Neurology, Children's Castle Hospital, Helsinki, Finland.

SO: $\quad$ Acta-Paediatr. 1997 Mar; 86 (3) : 294-8 
68- An early marker for neurological deficits after perinatal brain lesions.

AU: Prechtl-HF; Einspieler-C; Cioni-G; Bos-AF; Ferrari-F; Sontheimer-D

INST: Dept of Physiology, Karl-Franzens-University, Graz, Austria.

SO: $\quad$ Lancet. 1997 May 10; 349 (9062) : 1361-3

69- Equivalence reliability of the functional independence measure for children (WeeFIM) administration methods.

AU: $\quad$ Sperle-PA; Ottenbacher-KJ; Braun-SL; Lane-SJ; Nochajski-S

INST: University of New York at Buffalo, Buffalo, New York, USA.

SO: $\quad$ Am-J-Occup-Ther. 1997 Jan; 51 (1) : 35-41

70- Neurodevelopmental outcome of extremely LBW infants in Maryland.

AU: Blitz-RK; Wachtel-RC; Blackmon-L; Berenson-Howard-J

INST: Developmental Pediatric Associates, Scottsdale, Arizona, USA.

SO: $\quad$ Md-Med-J. 1997 Jan; 46 (1) : 18-24

71- Extremely LBW children and their peers. A comparison of school -age outcomes.

AU: Halsey-CL; Collin-MF; Anderson-CL

INST: Loyola University Medical Center, Maywood, 11, USA.

SO: $\quad$ Arch-pediatr-Adolesc-Med. 1996 Aug; 150 (8) : 790-4

72- Development of a regional cohort of VLBW children at six years: cognitive abilities are associated with neurological disability \& social background.

AU: Dammann-O; Walther-H; Allers-B; Schroder- M; Drescher-J; Lutz-D; Veelken-N; Schulte-FJ

INST: Neuroepidemiology Unit, Children's Hospital, Boston, MA 02115 USA.

SO: $\quad$ Dev-Med-Child-Neurol. 1996 Feb; 38 (2) : 97-106

73- Surgery and the tiny baby : sensorineural outcome at 5 years of age.

AU: The Victorian Infant Collaborative Study Group.

SO: J-Paediatr-Child-Health. 1996 Apr; 32 (2) : 167-72

74- MRI features of cerebral lesions and cognitive functions in preterm spastic diplegic children.

AU: Fedrizzi-E; Inverno-M; Bruzzone-MG; Botteon-G; Saletti-V; Farinotti-M

INST: Dept of Developmental Neurology, Instituto Neurologico Nazionale C. Besta, Milan, Italy.

SO: $\quad$ Pediatr-Neurol. 1996 Oct, 15 (3) : 207-12

75- The infant neurodevelopmental assessment : a clinical interpretive manual for CAT-CLAMS in the first two years of life,

AU: Capute-AJ; Accardo-PJ

INST: Johns Hopkins University School of Medicine, Baltimore MDm USA.

SO: $\quad$ Curr-Probl-Pediatr. 1996 Sep; 26 (8) : 279-306

76- Ranitidine therapy for esophagitis in children with developmental disabilities.

AU: Kaufman-SS; Loseke-CA; Young-RJ; Perry-DA 
INST: Joint Section of Pediatric Gastroenterology, Creighton University, Omaha, NE 68114, USA.

SO: $\quad$ Clin-Pediatr-Phila. 1996 Sep; 35 (9) : 451-6

77- Fundoplication in children : experience with 106 cases.

AU: Spillane-AJ; Currie-B; Shi-E

INST: Dept of Surgery, Prince of-Wales Children's Hospital, Randwick, New South Wales, Australia.

SO: $\quad$ Aust-N-Z-J-Surg. $1996 \mathrm{Nov} ; 66$ (11) : 753-6

78- Ante-natal magnesium sulfate exposure and the risk for $\mathrm{CP}$ or mental retardation among VLBW children aged 3 to 5 years.

AU: Schendel-DE; Berg-CJ; Yeargin-Allsopp-M; Boyle-CA; Decoufle-P

INST: Developmental Disabilities Branch, Division of Birth Defects \& Developmental Disabilities, National Center for Environmental Health, Centers for Disease Control \& Prevention, GA, USA.

SO: $\quad$ JAMA. $1996 \operatorname{Dec} 11 ; 276(22): 1805-10$

79- Magnetic resonance imaging in children with neonatal asphyxia : correlation with developmental sequele.

AU: Yokochi-K; Fujimoto-S

INST: Dept of Pediatric Neurology, Ohzora-no-iye Hospital, Japan.

SO: $\quad$ Acta-Paediatr. 1996 Jan; 85 (1) : 88-95

80- Measurement of growth in children with developmental disabilities.

AU: Stevenson-RD

INST: University of Virginia School of Medicine, Kluge Children's Rehabilitation Center \& Research Institute, Charlottesville, 22903, USA.

SO: $\quad$ Dev-Med-Child-Neurol. $1996 \mathrm{Sep} ; 38(9): 855-60$.

81- Neurodevelopmental outcome at age 2 years amongst VLBW infants: results from a district general Hospital.

AU: Sethi-VD; Macfarlane-PI

INST: Dept of Community Pediatrics, Rotherham Priority Health Trust, South Yorkshire.

SO: $\quad$ Public-Health. 1996 Jul; 110 (4) : 211-4.

82- Unilateral cerebral aplasia.

AU: Boltshauser-E; Steinlin-M; Martin-E; Deonna-T

INST: Dept of pediatrics, Universities of Zuerich, Switzerland.

SO: $\quad$ Neuropediatrics. 1996 Feb; 27 (1):50-3

83- Fine motor outcomes in preschool children who receive occupational therapy services.

AU: Case-Smith-J

INST: Division of Occupational Therapy, Ohio State University, Columbus 43210, USA. 
SO: Am-J-Occup-Ther. 1996 Jan; 50 (1) : 52-61

84- Postnatal causes of developmental disabilities in children aged 3-10 years Atlanta, Georgia, 1991.

SO: $\quad$ MMWR-Morb-Mortal-Wkly-Rep. 1996 Feb 16; 45 (6) : 130-4

85- Prevalence of selected developmental disabilities in children 3-10 years of age : the Metropolitan. Atlanta Developmental Disabilities Surveillance Program, 1991.

AU: Boyle-CA; Yeargin-Allsopp-M; Doernberg-NS; Holmgreen-P; Murphy-cc; Schendel-DE.

INST: Division of Birth Defects \& Developmental Disabilities National Center for Environmental Health.

SO: $\quad$ Mor-Mortal-Wkly-Rep-CDC-Surveill-Summ. 1996 Apr 19; 45 (2) : 1-14.

86- Pain in persons with cerebral palsy.

AU: Schwartz-L; Engel-JM: Jensen-MP

INST: Dept of Rehabilitation Medicine, University of Washington School of Medicine, Seattle 98195-6490, USA.

SO: $\quad$ Arch-Phys-Med-Rehabil. 1999 Oct; 80 (10) : 1243-6

87- Health \& educational outcomes of children who experienced severe neonatal medical complications.

AU: Boyce-GC; Smith-TB; Casto-G.

INST: Early Intervention Reseaech Institute, Utah State University, USA.

SO: J-Genet-Psychol. 1999 Sep; 160 (3) : 261-9.

88- Brain lesions in preterm : origin, consequences \& compensation.

AU: $\quad$ Krageloh-Mann-I; Toft-P; Lunding-J; Andresen-J; Pryds-O; Lou-HC.

INST: Dept of Child Neurology, Children's Hospital University of Tubingen, Germany.

SO: $\quad$ Acta-Paediatr. 1999 Aug; 88 (8) : 897-908.

89- Intact survival in extremely LBW infants after delivery room resuscitation.

AU; $\quad$ Finer-NN; Tarin-T; Vacher-YE; Barrington-K; Bejar-R.

INST: Division of Neonatology, Dept of Pediatrics, University of California, San Diego, California 92103-8774, USA.

SO: $\quad$ Pediatrics. 1999 Oct; 104 (4) : e40.

90- Prospective evaluation of perinatal risk factors for cerebral palsy and delayed development in high risk infants.

AU: $\quad$ Kim-JN; Namgung-R; Chang-W; Oh-CH; Shin-JC; Park-ES; Park-Cl; Park-MS; Park-KI; Lee-C; Han-DG.

INST: Dept of Pediatrics, Yonsei University College of Medicine, Seoul, Korea.

SO: $\quad$ Yonsei-Med-J. 1999 Aug; 40 (4) : 363-70.

91- Population -based study of infants born at less than 28 weeks' gestation in New South Wales, Australia, in 1992-3. 
AU: $\quad$ Sutton-L; Bajuk-B.

INST: New Neonatal Intensive Care Units' Data Collection (NICUS). Sydney, Australia.

SO: Paediatr-Perinat-Epidemiol. 1999 Jul; 13 (3) : 288-301.

92- Mental health of families caring for people with developmental disabilities : the present situation and strategies for improvement.

AU: Horiguchi-T; Kaga-M; Uno-A; Inagaki-M; Akiyama-C.

INST: National Institute of Mental Health, National Center of Neurology \& Psychiatry, Chiba.

SO: $\quad$ No-To-Hattatsu. $1999 \mathrm{Jul}$; 31 (4) : 349-54.

93- Health status of a population of infants born before 26 weeks gestation derived from routine data collected between $21 \& 27$ months post-delivery.

AU: Bohin-S; Draper-ES; Field-DJ.

INST: Dept of Child Health, University of Leicester, Leicester Royal Infirmary, UK.

SO: $\quad$ Early-Hum-Dev. 1999 May; 55 (1) : 9-18.

94- Outcome measures for pediatric rehabilitation : use of the Functional Independence Measures for children (WeeFIM) . A pilot study in Chinese children with neurodevelopmental disabilities.

AU: $\quad$ Yung-A; Wong-V; Yeung-R; Yeun-SM; Ng-SL; Tse-SF; Wong-E; Chan-A.

INST: Dept of Pediatrics, University of Hong Kong, Queen Mary Hospital.

SO: Pediatr-Rehabil. 1999 Jan-Mar; 3 (1) : 21-8

95- Pulmonary hemorrhage : clinical course and outcomes among VLBW infants.

AU: Tomaszewska-M; Stork-E; Minich-NM; Friedman-H; Berlin-S; Hack-M

INST: Deptt of Pediatrics, Case Western Reserve University, Cleveland, Ohio, USA.

SO: $\quad$ Arch-pediatr-Adolesc-Med. 1999 Jul; $153(7): 715-21$

96- The neurologically impaired child and alleged malpractice at birth.

AU: Nelson-KB

INST: Neuroepidemiology Branch, National Institute of Neurological Disarders \& Stroke, Bethesda, Maryland, USA.

SO: Neurol-Clin. 1999 May; 17 (2) : 283-93.

97- Long-term outcome of infants at the margin of viability.

AU: LeBlanc-MH; Graves-GR; Rawson-TW; Moffitt-J

INST: Dept of Pediatrics, University of Mississippi Medical Center, Jackson 39216, USA.

SO: J-Miss-State-Med-Assoc. 1999 Apr: 40 (4) : 111-4

98- The descriptive epidemiology of infantile spasms among Atlanta children.

AU: Trevathan-E; Murphy-CC; Yeargin-Allsopp-M 
INST: Pediatric Epilepsy Center, Department of Neurology, Washington University School of Medicine, St. Louis Children's Hospital, Missouri 63110, USA.

SO: $\quad$ Epilepsia. 1999 Jun; 40 (6) : 748-51.

99- Clinical significance of planter grasp response in infants.

AU: $\quad$ Futagi-Y; Suzuki-Y; Goto-M

INST: Division of Pediatric Neurology, Osaka Medical Center \& Research Institute for Maternal \& Child Health, Izumi, Japan.

SO: Pediatr-Neurol. 1999 Feb; 20 (2) : 111-5

100- A study on incidence of developmental disabilities in Higashi-Osaka City, Japan. (1988-1992).

AU: $\quad$ Irie-N

INST: Dept of Pediatrics, Higashi-Osaka City Rehabilitation Center, Japan.

SO: $\quad$ No-To-Hattatsu. 1999 Jan; 31 (1) : 32-7

101- Prevalence and characteristics of children with serious hearing impairment in metropolitan Atlanta, 1991-1993.

AU: Van-Naarden-K; Decoufle-P; Caldwell-K

INST: Developmental Disabilities Branch, Division of Birth Defects \& Developmental Prevention, Atlanta, Georgia, USA.

SO: $\quad$ Pediatrics. 1999 Mar; 103 (3) : 570-5

102- Prognostic value of flash visual evoked potentials in preterm infants.

AU: Shepherd-AJ; Saunders-KJ; McCulloch-DL; Dutton-GN

INST: Dept of Child Health, Royal Hospital for Sick Children, Yorkhill, Glasgow, Scotland.

SO: $\quad$ Dev-Med-Child-Neurol. 1999 Jan; 41 (1) : 9-15

103- Evaluating research in developmental disabilities : a conceptual framework for reviewing treatment outcomes.

AU: $\quad$ Butler-C; Chambers-H; Goldstein-M; Harris-S; Leach-J; Campbell-S; AdamsR: Darrah-J

INST: Treatment Outcome Committee, Amercian Academy for Cerebral Palsy \& Developmental Medicine, Rosemont, IL, USA.

SO: $\quad$ Dev-Med-Child-Neurol. 1999 Jan; 41 (1) : 55-9

104- Consideration of the use of health status, functional outcome, and quality-of-life to monitor Neonatal intensive care practice.

AU: Hack-M

INST: Rainbows Babies \& Children's Hospital, Division of Neonatology, Cleveland, Ohio, USA.

SO: $\quad$ Pediatrics 1999 Jan; 103 (1 Suppl E) : 319-28.

105- Pain in persons with cerebral palsy.

AU: Schwarts-L; Engel-JM; Jensen-MP. 
INST: Dept of Rehabilitation Medicine, University of Washington School of Medicine, Seattle USA.

SO: $\quad$ Arch-Phys-Med-Rehabil. 1999 Oct; 80 (10) : 1243-6

106- Health and educational outcomes of children who experienced severe neonatal medical complications.

AU: Boyce-GC; Smith-TB; Casto-G

INST: Early Intervention Research Institute, Utah State University, USA.

SO: J-genet-Psychol. 1999 Sep; 160 (3) : $261-9$

107- Brain lesions in preterms: origin, consequences and compensation.

AU: Krageloh-Mann-I; Toft-P; Lunding-J; Andresen-J; Pryds-O; Lou-HC

INST: Dept of Child Neurology, Children's Hospital University of Tubingen, Germany.

SO: $\quad$ Acta-Paediatr. 1999 Aug; 88 (8) : 897-908

108- Intact survival in extremely LBW infants after delivery room resuscitation.

AU: $\quad$ Finer-NN; Tarin-T; Vaucher-YE; Barrington-K; Bejar-R

INST: Division of Neonatology, Department of Pediatrics, University of California, San Diego, California, USA.

SO: $\quad$ Pediatrics. 1999 Oct; 104 (4) : e40.

109- Prospective evaluation of perinatal risk factors for cerebral palsy and delayed development in high Risk infants.

AU: $\quad$ Kim-JN; Namgung-R; Chang-W; Oh-CH; Shin-JC; Park-ES; Park-CI; Park-MS; Park-KI; Lee-C; Han-DG

INST: Dept of Pediatrics, Yonsei University College of Medicine, Seoul, Korea.

SO: $\quad$ Yonsei-Med-J. 1999 Aug; 40 (4) : 363-70.

110- Population-based study of infants born at less than 28 weeks' gestation in New South Wales, Australia, in 1992-3. New South Wales Neonatal Intensive Care Unit Study Group,

AU: $\quad$ Sutton-L; Bajuk-B

INST: NSW Neonatal Intensive Care Units' Data Collection (NICUS), Sydney, Australia.

SO: Paediatr-Perinat-Epidemiol. 1999 Jul; 13 (3) : 288-301

111- Mental health of families caring for people with developmental disabilities: the present situation and strategies for improvement.

AU: $\quad$ Horiguchi-T; Kaga-M; Uno-A; Inagaki-M; Akiyama-C

INST: National Institute of Mental Health, National Center of Neurology and Psychiatry, Chiba.

SO: $\quad$ No-To-Hattatsu. 1999 Jul; 31 (4) : 349-54

112- Correlation between neonatal cranial ultrasound, MRI in infancy and neurodevelopmental outcome in infants with a large intraventricular hemorrhage with or without unilateral parenchymal involvement. 
AU: de-Vries-LS; Rademaker-KJ; Groenendaal-F; Eken-P; van-Haastert-IC; Vandertop-WP; Gooskens-R; Meiners-LC.

INST: Dept of Neonatology, Wilhelmina Children' Hospital, Utrecht, The Netherlands.

SO: $\quad$ Neuropediatrics. 1998 Aug; 29 (4) : 180-8

113- Adverse outcome after multiple pregnancy

AU: Petterson-B; Blair-E; Watson-L; Stanley-F

INST: Dept of Anatomy and Human Biology, University of Western Australia, Nedlands, Australia.

SO: Bailliers-Clin-Obstet-Gynaecol. 1998 Mar; 12 (1) : 1-17.

114- Increasing medical student's self-perceived skill and comfort in examining persons with severe developmental disabilities: the use of standardized patients who are nonverbal due to $\mathrm{CP}$.

AU: $\quad$ Eddey-GE; Robey-KL; McConnell-JA

INST: Matheny Hospital, Peapack, NJ 07977 USA.

SO: $\quad$ Acad-Med. 1998 Oct; 73 (10 Suppl) : S106-8

115- Case management and supported employment : a good fit

AU: Gilson-SF

INST: School of Social Work, Virginia Commonwealth University, Richmond 23284, USA.

SO: $\quad$ J-Case-Manag. 1998 Spring; 7 (1) : 10-7

116- Psychological findings in preterm children related to neurologic status and MRI.

AU: $\quad$ Olsen-P; Vainionpaa-L; Paakko-E; Korkman-M; Pyhtinen-J; Jarvelin-MR

INST: Dept of Pediatrics, University of Oulu, Oulu, Finland.

SO: Pediatrics. 1998 Aug; 102 (2 pt 1) : 329-36

117- Visual-motor, visual-perceptual, and fine motor outcomes in VLBW children at 5 years.

AU: Amiel-Tison-C; Stewart-A; Gosselin-J.

SO: $\quad$ Dev-Med-Child-Neurol. 1998 Jul; 40 (7) : 500-2.

118- Correlation of brain CT findings and developmental outcome in patients with spastic cerebral palsy.

AU: Park-ES; Park-CI; Lee-JK; Yim-SY.

INST: Dept of Rehabilitation Medicine, Yonsei University College of Medicine, Seoul, Korea.

SO: $\quad$ Yonsei-Med-J. 1998 Apr; 39 (2) : 103-8.

119- Acquired spinal cord lesion associated with os odontoidem causing deterioration in dystonic CP.

AU: Amess-P; Chong-WK; Kirkham-FJ

INST: Neuroscience's Unit, Institute of Child Health (UCL) \& Great Ormond Street Hospital London,UK. 
SO: $\quad$ Dev-Med-Child-Neurol. 1998 Mar; 40 (3) : 195-8.

120- The Worster-Drought syndrome : a severe test of pediatric neurodisability services.

AU: $\quad$ Neville-B

INST: Institute of Child Health, (UCL) London, The Wolfson Center, Mecklenburgh Square, UK.

SO: $\quad$ Dev-Med-Child-Neurol. 1997 Nov; 39 (11) : 782-4

121- Intraventricular hemorrhage and long-term outcome in the premature infant.

AU: Wildrick-D

INST: Southern Illinois University School of Medicine, Springfield, 62794-1614. USA.

SO: J-Neurosci-Nurs. 1997 Oct; 29 (5) : 281-9

122- The neurologically impaired child and alleged malpractice at birth.

AU: Nelson KB.

INST: Neuroepidemiology Branch, National Institute of Neurological Disorders and Stroke, Bethesda, Maryland, USA.

SO: Neurologic Clinics. 17 (2) : 283-93, 1999 May.

123- Risk factors for cerebral palsy : a case-control study in Greece.

AU: Petridou E. Koussouri M. Toupadaki N. Papavassiliou A. Youroukos S. Katsarou E. Trichopoulos D.

INST: Dept of Hygiene \& Epidemiology, Athens University Medical School, Greece.

SO: $\quad$ Scandinavian Journal of Social Medicine. 24 (1) : 14-26, 1996 Mar.

124- A South Australian study of pregnancy and birth risk factors associated with cerebral palsy.

AU: Jonas-O; Stern-LM; Macharper-T

INST: Epidemiology Branch, South Australian Health Commission, 11 Hindmarsh Square, Adelaide Citi Center, Adelaide SA 5000, SA, Australia.

SO: $\quad$ INT-J-REHABIL-RES. 12/2 (159-166) 1989

125- Significance of ante-natal, perinatal \& postnatal factors in the development of AGA preterm infants at 5-7 years.

AU: Largo-RH; Pfister-D; Molinari-L; Kundu-S; Lipp-A; Duc-G

INST: Universitats - Kinderspital Zurich, $\mathrm{CH}-8032$ Zurich, Switzerland.

SO: $\quad$ Dev-Med-Child-Neurol. 31/4 (440-456) 1989.

126- Epidemiology of cerebral palsy in England \& Scotland, 1984-9.

AU: Pharoah_POD; Cooke-T; Johnson-MA; King-R; Mutch-L.

INST: ASID U. Pediat. / Perinat. Epidemiol. Dept of Public Health, University of Liverpool, Liverpool

L69 3GB, UK. 
SO: $\quad$ ARCH-DIS-CHILD-FETAL-NEONAT-ED. Archives-of -Diseases-in Childhood: Fetal-and-Neonatal-Edition. 1998; 79/1 (F21-F25)

127- Does pregnancy bacterial vaginosis increase a mother's risk of having a preterm infant with $\mathrm{CP}$.

AU: Dammann-O; Leviton-A

INST: Neuroepidemiology Unit, Children's Hospital, 300 Longwood Avenue, Boston, USA.

SO: Dev-Med-Child-Neurol. Developmental-Medicine-and-Child-Neurology. 1997; 39/12

$(836-840)$

128- A neuromotor screening test for high-risk infants in a hospital or community setting.

AU: Magasiner-VA; Molteno-CD; Lachman-P; Thompson-C; Buccimazza-SS; Burger-EJ

INST: Neonatal Medicine H46-OMB, Groote Schuur Hospital, Observatory, South Africa.

SO: $\quad$ Pediatr-Phys-Ther. Pediatric-Physical-Therapy. 9/4 (166-172) 1997.

129- Amniotic fluid infection \& CP : Focus on the fetus.

AU: $\quad$ Eschenbach-DA

INST: Dept of Obstetrics \& Gynecology, University of Washington, USA.

SO: J-AM-MED-ASSOC. Journal-of-the-American-Medical-Association. 278/3 (247-248) 97.

130- Placental lesions associated with neurologic impairment and CP in VLBW infants.

AU: Redline RW, Wilson-Costello D, Borawski E, Fanaroff AA, Hack M.

INST: Dept of Pathology, Case Western University and University Hospitals of Cleveland, Ohio 44106, USA.

SO: $\quad$ Archives of Pathology \& Laboratory Medicine. 122 (12): 1091-8, Dec 1998.

131- Psychological findings in preterm children related to neurologic status and magnetic resonance imaging.

AU: Olsen P. Vainionpaa L. Paakko E. Korkman M. Pyhtinen J. Jarvelin MR.

INST: Dept of Pediatrics, University of Oulu, Oulu, Finland.

SO: $\quad$ Pediatrics. 102 (2Pt 1) : 329-36, 1998 Aug.

132- Etiology, timing of insult, and neuropathology of CP evaluated with MRI.

AU: Jaw TS. Jong YJ. Sheu RS. Liu GC. Chou iMS. Yang RC.

INST: Dept of Radiology, Kaohsiung Medical College, Taiwan.

SO: Journal of the Formosan Medical Association. 97(4): 239-46, 1998 Apr.

133- Preeclampsia \& $\mathrm{CP}$ : are they related?

AU: Collins M. Paneth N.

INST: Dept of Epidemiology, College of Human Medicine, Michigan State University, East Lansing USA.

SO: Developmental Medicine \& Child Neurology. 40(3): 207-11, 1998 Mar. 
134- Antenatal onset of hemorrhagic and/or ischaemic lesions in preterm infants: prevalence and associated obstetric variables.

AU: de Vries LS. Eken P. Groenendaal F. Rademaker KJ. Hoogervorst B. Bruinse HW.

INST: Dept of Neonatology. Wilhelmina Children's Hospital, Utrecht, The Netherlands.

SO: $\quad$ Archieves of Disease in Childhood Fetal \& Neonatal Edition. 78(1): F51-6. Jan 98.

135- Clinical antecedents of neurologic and audiologic abnormalities in survivors of neonatal extracorporeal membrane oxygenation

AU: Graziani LJ. Baumgart S. Desai S. Stanley C. Gringlas M. Spitzer AR.

INST: Dept of Pediatrics, Thomas Jefferson University, Jefferson Medical College, Philadelphia, USA.

SO: Journal of Child Neurology. 12(7):415-22, 1997 Oct.

136- Causes of Cerebral Palsy

SO: MADDS- (Metropolitan Atlanta Developmental Disabilities Surveillance Program)

137- Changes in the Gross Motor Function Measure in children with different types of cerebral palsy: an eight-month follow-up study

AU: Trahan-J, Malouin-F

SO: $\quad$ Pediatr Phys Ther 1999 Spring, 11 (1) : 12-7

138- Patterns of development exhibited by infants with cerebral palsy

AU: Jelsma-J, Iliff-P, Kelly-L

SO: $\quad$ Pediatr Phys Ther 1999 Spring, 11 (1) 2-11

139- Postnatal Causes of Developmental Disabilities in Children Aged 3-10 yearsAtlanta, Georgia, 1991

Feb 16, 1996/45(06); 130-134

140- Prevalence of selected Developmental Disabilities in Children 3-10 years of Age: the Metropolitan Atlanta Developmental Disabilities Surveillance Program, 1991 April 19, 1996/45 (SS-2); 1-14 


\section{AP P E N D I X 3 \\ Questionaire Part 1}

\section{CHILD}

1 Diagnosis

(1) C.P Specific
(a) Hemiplegia
(b) Quadraplegia
(c) Diplegia
(d) Cerebellar Alaxia
(e) Athetoid

Degree

Degree

(2) C.P Specifi

Degree

(1) Severe

Degree

(1) Severe

(1) Severe

Degree

(1) Severe

\begin{tabular}{|l|l|l|l|l|l|}
\hline Province & District & Town & Village & S.No of child & Sex \\
\hline & & & & & \\
\hline
\end{tabular}

2 Identification Code

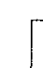

\begin{tabular}{|l|l|l|l|}
\multicolumn{1}{c|}{ Date } & \multicolumn{1}{l}{ Month } & \multicolumn{1}{l}{ Year } & \multicolumn{1}{l}{ Time } \\
\hline & & & \\
\hline
\end{tabular}

4 Name of Interviewer

5 Interviewers Profession

6 Name of the Disabled Child

\begin{tabular}{|c|c|c|c|c|c|}
\hline Doctor & Nurse & Midwife & Social Worker & Physiotherapist & Others \\
\hline & & & & & \\
\hline
\end{tabular}

7 Fathers name

8 Age

9 Age seeking help / diagnosis

10 Urban [ ] rural [ ]

11 Current address of the disabled child

Province

District

Village

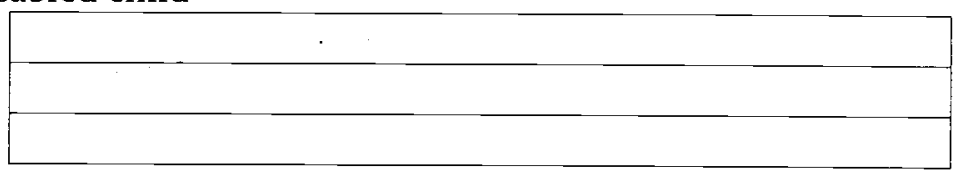

12 Length of time living this address

13 Address of near relative provides?

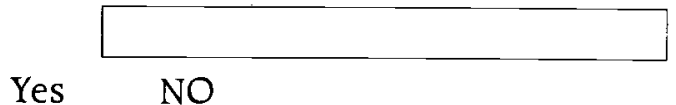

If Yes then write the address:
14 Terrain
$\mathrm{U}$
V
W X
Y
Z 
15 Ethnic Groups
(a) Pashtoon
(b) Tajik
(C) Pashie

16 No.of brothers \& sisters

Brothers

Sisters

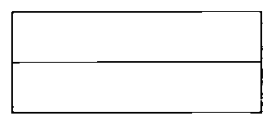

17 Placement of the child in the family

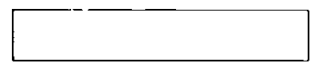

18 Compared with other children, did the child have any serious delay in Rolling with head control Yes No Sitting with head control. Yes No
If Yes
(a) Slight
(b) Moderate
(c) Severe

19 Compared with other children does the child have difficulty in Vision?

$\begin{array}{lll}\text { Day-time } & \text { Yes } & \text { No } \\ \text { Night-time } & \text { Yes } & \text { No }\end{array}$

20 Does the child appear to have difficulty in hearing? Yes No
If Yes
(a) Unilateral
(b) Bilateral
(c) Partial
(d) Total

21 A-Does the child have difficulty in walking and standing compare other children with their e? age?
If Yes
1) Slightly Difficulty
2) Moderate Difficulty
3) Severe Difficulty

Yes

No

B- Does the child have weakness with passive movements

$\begin{array}{lll}\text { With Arm } & \text { Yes } & \text { No } \\ \text { With Leg } & \text { Yes } & \text { No }\end{array}$

Does the child have Sposticity with passive movements

$\begin{array}{lll}\text { With Arm } & \text { Yes } & \text { No } \\ \text { With Leg } & \text { Yes } & \text { No }\end{array}$

22 Does the child learn to do things like other children his/her age? Yes No
If Yes
(a) Some
(b) Many

23 Does the child speak at all?

Yes No

Can he/she make himself/herself understood in words/Sound? Yes No
If Yes
(a) Word
(b) Sound

Can he/she say any recognisable words?

Yes No 
24 For 3 - to - 9 Years old:

Is the child's speech different in any way than the normal? Yes No

Clear enough to be understood by other than his/her immediate family?

$$
\text { Yes No }
$$

25 For all children

Can he/she name at least one object (for example, an animal, a toy, a cup, a spoon)

Yes

No

26 Babinski's sign

$$
\text { Yes No }
$$

27 Do you know the cause of disability?

Accident Trauma

Disease

Medicine

High Fever

Convulsion

Others

28 Disability Status since diagnosis

Improving

Increasing

Same

29 Psychological Behaviour

Aggressive

Submissive

Normal

30 Convulsions

$\begin{array}{lc} & \text { (A) Petit -mal } \\ \text { Weeks } & \text { Months Years }\end{array}$

(B) Grand-mal

(C) Coma

Frequency

Duration

Seconds Minutes

31 A- Please indicate if mothers milk was sufficient during the $1^{\text {st }}$ years of life?

1.No breast feeding 2.Sufficient

3.More than sufficient 4.Not sufficient

B- If they use other sources

1.Animal milk

2.Liquid food \& milk

3. Formula milk

4. Not milk, only liquid food.

32 Did the child suffer from any other following diseases?

1.Fever with stiff neck? 2.High Fever with rashes

3. Jaundice

4.Others 
33 For under 5 year old. Head circumference (

$34 \quad$ Nutrition status
1) Malnutrition
Yes
No
2) Under normal weight

Arm circumference ( Weight ( )

35 Was the child Vaccinated (Triple vaccine).

Yes

No

36 Did the chid get Polio vaccine?

Ist vaccine

2nd vaccine

3rd vaccine

37

B.C.G Yes

NO

$\begin{array}{ll}\text { Yes } & \text { No } \\ \text { Yes } & \text { No } \\ \text { Yes } & \text { No } \\ \text { Yes } & \text { No }\end{array}$

\section{Questionaire Part 1}

\section{CHILD}

1 Diagnosis

(1) Delayed Physical and Mental development

2 Family History of Delayed Physical and Mental development.
(1) Malnutrition
(2) Preterm
Yes No
Yes No

3 Physical status
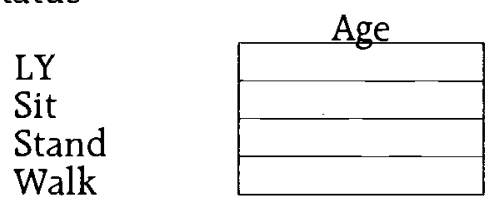

4 Physical status in Walk?
(a) Stairs
(b) Run

5 Social-Mental development Chart
(1) Age
(2) Level

6 Identification Code

\begin{tabular}{|l|l|l|l|l|l|}
\hline Province & District & Town & Village & S.No of child & Sex \\
\hline & & & & & \\
\hline
\end{tabular}

7 Date of Interview

\begin{tabular}{|l|l|l|l|}
\hline Date & Month Year Time \\
\hline
\end{tabular}

8 Name of Interviewer

9 Interviewers Profession

Doctor

10 Name of the Disabled Child 
11 Fathers name

12 Age

13 Age seeking help / diagnosis

14 Urban [ ] rural [ ]

15 Current address of the disabled child

Province

District

Village

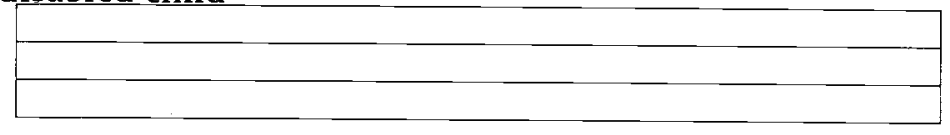

16 Length of time living this address

17 Address of near relative provides?

Yes NO

If Yes then write the address:

18 Terrain

U

V

W

$\mathrm{X}$

Y

Z

19 Ethnic Groups

(A) Pashtoon

(B) Tajik

(C) Pashie

20 No.of brothers \& sisters Brothers

Sisters

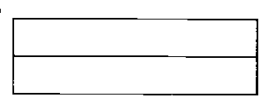

21 Placement of the child in the family

22 Compared with other children, did the child have any serious delay in

Rolling with head

Sitting with head

$\begin{array}{ll}\text { Yes } & \text { No } \\ \text { Yes } & \text { No }\end{array}$
If Yes
(a) Slight
(b) Moderate
(c) Severe

23 Compared with other children does the child have difficulty in Vision?

$\begin{array}{lll}\text { Day-time } & \text { Yes } & \text { No } \\ \text { Night- } & \text { Yes } & \text { No }\end{array}$

24 Does the child appear to have difficulty in hearing? Yes No
If Yes
(a) Unilateral
(b) Bilateral
(c) Partial
(d) Total

25 A-Does the child have difficulty in walking and standing compare other children with their age?
If Yes
Yes
No
2) Moderate Difficulty
3) Severe Difficulty

B- Does the child have weakness with passive movements

\begin{tabular}{|c|c|}
\hline With Arm & Yes \\
\hline
\end{tabular}

Does the child have Sposticity with passive

$\begin{array}{lll}\text { With Arm } & \text { Yes } & \text { No } \\ \text { With Leg } & \text { Yes } & \text { No }\end{array}$

26 Does the child learn to do things like other children his/her age?

$$
\text { Yes No }
$$



If Yes
(a) Some
(b) Many

27 Does the child speak at all?

Yes No

Can he/she make himself/herself understood in words/Sound? Yes

No

If Yes $\quad \begin{array}{ll}\text { (a) Word } & \text { (b) Sound }\end{array}$

Can he/she say any recognisable words? Yes No

28 For 3 - to - 9 Years old:

Is the child's speech different in any way than the normal? Yes No

Clear enough to be understood by other than his/her immediate family?

29 For all children

$$
\text { Yes No }
$$

Can he/she name at least one object (for example, an animal, a toy, a cup. a spoon)

30 Babinski's sign Yes No

31 Do you know the cause of disability? No

Accident Trauma

Disease

Medicine

High

Convulsio

Others

32 Disability Status since diagnosis

Improving

Increasing

Same

33 Psychological Behaviour

Aggressiv

Submissive

Normal

34 Convulsions Frequency Weeks

(a) Petit-mal

Months Years

(b) Grand-mal

(C) Coma

Duration Seconds

Minutes

35 A- Please indicates if mother's milk was sufficient during the $1^{\text {st }}$ years of life?

1.No breast feeding 2.Sufficient

3.More than sufficient 4 .Not sufficient

B- If they use other sources

1.Animal milk

2.Liquid food \& milk

3. Formula milk

4. Not milk, only liquid food.

36 Did the child suffer from any other following diseases?

1.Fever with stiff neck? 2.High Fever with rashes

3.

4.Others

37 For under 5 year old.

38 Nutriton status

Head circumference ( Height (
Arm circumference (

Weight ( ' ) 
$\begin{array}{lll}\text { 1) Malnutrition } & \text { Yes } & \text { No } \\ \text { 2) Under normal weight } & \text { Yes } & \text { No }\end{array}$

39 Was the child Vaccinated (Triple vaccine).

Yes

No

40 Did the chid get Polio vaccine?

Ist vaccine

2nd vaccine

3 rd vaccine

Yes No

Yes No

Yes No

Yes No

41 B.C.G Yes NO

\section{Questionaire Part 1}

\section{CHILD}

1 Diagnosis

2 Unilateral

3 Bilateral

4 Family history of Club Foot

5 Type Group 1

Group 2

6 Diagnosis

7 Unilateral

8 Bilateral

9 Family history of Congenital Dislocation of HIP?

Yes No

10 Type Group 1 [ ]

Group 2 I ]

11 Identification Code

\begin{tabular}{|c|c|c|c|c|c|}
\hline Province & District & Town & Village & S.No of child & Sex \\
\hline & & & & & \\
\hline
\end{tabular}

12 Date of Interview

\begin{tabular}{|l|l|l|l|}
\hline Date & Month & Year & Time \\
\hline
\end{tabular}

13 Name of Interviewer

14 Interviewers Profession

\begin{tabular}{|c|c|c|c|c|c|}
\hline Doctor & Nurse & Midwife & Social Worker & Physiotherapist & Others \\
\hline
\end{tabular}

15. Name of the Disabled Child

16 Fathers name 
17 Age

18 Age seeking help / diagnosis

19 Urban [ ] rural [ ]

20 Current address of the disabled child

Province

District

Village

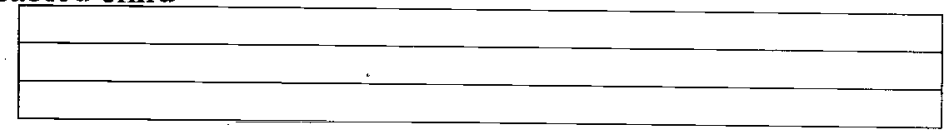

21 Length of time living this address

22 Address of near relative provides?

Yes NO

If Yes then write the address:

23 Terrain

U

V

$\mathbf{W}$

$\mathbf{X}$

$\mathbf{Y}$

$\mathbf{Z}$

24 Ethnic Groups

(A) Pashtoon

(B) Tajik

(C) Pashie

25 No.of brothers \& sisters

Brothers

Sisters

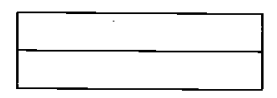

26 Placement of the child in the family

27 Compared with other children, did the child have any serious delay in
Rolling with head control
Sitting with head control.
Yes
No
No
If Yes
(a) Slight
(b) Moderate
(c) Severe

28 Compared with other children does the child have difficulty in Vision?
Day-time
Night-time
Yes
No
No

29 Does the child appear to have difficulty in hearing?

Yes No
If Yes
(a) Unilateral
(b) Bilateral
(c) Partial
(d) Total

30 A-Does the child have difficulty in walking and standing compare other children with their age?
If Yes
1) Slightly Difficulty
No
2) Moderate Difficulty
3) Severe Difficulty

B- Does the child have weakness with passive movements

$\begin{array}{lll}\text { With Arm } & \text { Yes } & \text { No } \\ \text { With Leg } & \text { Yes } & \text { No }\end{array}$

Does the child have Sposticity with passive movements
With Arm
With Leg
$\begin{array}{ll}\text { Yes } & \text { No } \\ \text { Yes } & \text { No }\end{array}$

31 Does the child learn to do things like other children his/her age?
If Yes
(a) Some
Yes
(b) Many

No

Does the child speak at all?

Yes No 
Can he/she make himself/herself understood in words/Sound?

Yes

No

If Yes $\quad$ (a) Word $\quad$ (b) Sound

Can he/she say any recognisable words?

Yes No

33 For 3 - to - 9 Years old:

Is the child's speech different in any way than the normal?

Yes

No

Clear enough to be understood by other than his/her immediate family?

34 For all children

$$
\text { Yes No }
$$

Can he/she name at least one object (for example, an animal, a toy, a cup, a spoon)

35 Babinski's sign

Yes

No

36 Do you know the cause of disability?

No

Accident Trauma

Disease

Medicine

High Fever

Convulsio

Others

37 Disability Status since diagnosis

Improving

Increasing

Same

38 Psychological Behaviour

Aggressive

Submissive

Normal

39 Convulsions

Frequency Weeks

(a) Petit -mal

Months

(b) Grand-mal

(c) Coma

Duration

Seconds

Minutes

40 A-Please indicate if mothers milk was sufficient during the $1^{\text {st }}$ years of life?

1.No breast feeding 2.Sufficient

3.More than sufficient 4.Not sufficient

B- If they use other sources

1.Animal milk

2.Liquid food \& milk

3. Formula milk

4. Not milk, only liquid food.

41 Did the child suffer from any other following diseases?

1.Fever with stiff neck? 2.High Fever with rashes

3. Jaundice

4.Others

42 For under 5 year old. Head circumference (

43 Nutrition status

Height ( )

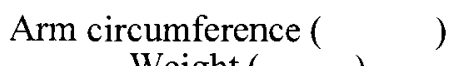

1) Malnutrition

2) Under normal weight Yes No 
44 Was the child Vaccinated (Triple vaccine)

Yes

45 Did the chid get Polio vaccine?

Ist vaccine

2nd vaccine

3 rd vaccine

46 B.C.G Yes

NO

No

$\begin{array}{ll}\text { Yes } & \text { No } \\ \text { Yes } & \text { No } \\ \text { Yes } & \text { No } \\ \text { Yes } & \text { No }\end{array}$




\section{Questionaire Part 2}

\section{MATERNAL HEALTH}

MOTHER:

1. Identification code: Province District Village

2. Mother's name:

3. Childs Name:

4. Serial Number of Child:

5. Age:

6. Education status: Primary School

Secondary School

University

Nil

7. Occupation:

8. Previous pregnancies in number

Primigravida

Spontaneous abortion(s) No. [ ]

Live births No.

Still births No.

Total pregnancies no.

9. Spacing between pregnancies in months :

Between $1^{\text {st }}$ and $2^{\text {nd }}$ months
Between $2^{\text {nd }}$ and $3^{\text {rd }}$ months
Between $3^{\text {rd }}$ and $4^{\text {th }}$ months
Between $4^{\text {th }}$ and $5^{\text {th }} \quad$ months




$\begin{array}{ll}\text { Between } 5^{\text {th }} \text { and } 6^{\text {th }} & \text { months } \\ \text { Between } 6^{\text {th }} \text { and } 7^{\text {th }} & \text { months } \\ \text { Between } 7^{\text {th }} \text { and } 8^{\text {th }} & \text { months } \\ \text { Between } 8^{\text {th }} \text { and } 9^{\text {th }} \text { months } & \text { months }\end{array}$

10. Any other children in the family with disabilities..... No [ ] Yes [ ] If yes write Type of disability

11. Family History of disabilities No [ ] Yes [ ]

If yes mention:

a. type of disabilities:

12. What was the relationship of the parents of the disabled child before marriage
1. Do not know
2. Maternal Cousins
3. Paternal Cousins
4. $2^{\text {nd }}$ Cousins
5.Distant Relationship
6. No Relationship

13. Did the mother have Tetanus Vaccination?
1. Yes
2. No
3. Don't know/remember

14. Did the mother get antenatal check-up ?
1. Yes
2. No
3. Don't know/remember

15. If yes by whom?
1. Doctor
2. TBA
3. Nurse
4. Others [ ]

16. If yes, how often?
1. Regularly
2. Irregularly
3. Don't remember [ ]

17. When the child was delivered ?
1. Pre-mature 2. Full term
3. Post-mature
4. Don't know

18. What was the presentation of the child at the time of delivery?
1. Breech
2. Cephalic
3. Don't know/remember

19. (a) Where was the child diagnosed as having disability?
1. Hospital /Maternity home
2. Home
3. Private clinic
4. Rehab centre

a. Who delivered the child ? 

1. Doctor
2. Nurse
3. LHV
4. Trained
midwife
6. Un-trained Dai
7. Relative(s)
8. Others

20. How the child was delivered ?
1. Caesarean
2. Vaccum Extraction
3. Forceps/other instruments
4. Normal delivery
5. Do not know.

21. Ante-natal (Conception until labour)

- P.E.T

- A.P.H

- Threatened abortion

- Fever with Rash

- Diabetes

- Epilepsy

- Exposure to X-rays (Greater than 5 times)

- Sickle cell

- Anaemia

- Psychological stress

- Trauma

-Acute Illness

- Essential Hypertension

- Tuberculosis

- Asthma

-Malaria

-Typhoid

-Hyper-emesis gravidarum

Any Infection

$\begin{array}{ll}\text { Yes [ ] } & \text { No [ ] } \\ \text { Yes [ ] } & \text { No [ ] } \\ \text { Yes [ ] } & \text { No [ ] } \\ \text { Yes [ ] } & \text { No [ ] } \\ \text { Yes [ ] } & \text { No [ ] } \\ \text { Yes [ ] } & \text { No [ ] } \\ \text { Yes [ ] } & \text { No [ ] } \\ \text { Yes [ ] } & \text { No [ ] } \\ \text { Yes [ ] } & \text { No [ ] } \\ \text { Yes [ ] } & \text { No [ ] } \\ \text { Yes [ ] } & \text { No [ ] } \\ \text { Yes [ ] } & \text { No [ ] } \\ \text { Yes [ ] } & \text { No [ ] } \\ \text { Yes [ ] } & \text { No [ ] } \\ \text { Yes [ ] } & \text { No [ ] } \\ \text { Yes [ } & \text { No [ } \\ \text { Yes } & \text { No } \\ \text { Yes } & \text { No }\end{array}$


Rubella

Toxoplasmosis

Herpes simplex

Antibiotics

Malnutrition

Urinary Tract infection

Neo-natal Sepsis

\section{Perinatal}

Anoxia

(Problem with umbilical cord)

Premature (less than 32 weeks)

Forceps delivery

Low Birth weight

(less than 2500 grams)

Low APGAR

Respiratory distress syndrome

Rh Factor

Too fast delivery

Too slow delivery

Trauma to head during delivery

Severe Asthma

Absence of ante-natal care

Head Shape Micro Cephalic

Hydro Cephalic

Head Shape
Yes [ ]

No [ ]

Yes [ ]

No [ ]

Yes [ ]

No [ ]

Yes [ ]

No [ ]

Yes [ ]

No [ ]

Yes [ ]

No [ ]

Yes [ ]

No [ ]

Yes [ ]

No [ ]

Yes [ ]

No [ ]

Yes [ ]

No [ ]

Yes [ ]

No [ ]

Yes [ ]

No [ ]

Yes [ ]

No [ ]

Yes [ ]

No [ ]

Yes [ ]

No [ ]

Yes [ ]

No [ ]

Yes [ ]

No [ ]

Yes [ ]

No [ ]

Yes [ ]

No [ ]

Yes [ ]

No [

Yes [ ]

No [ ]

Yes [ ] 
22. Was the disability present at birth

Yes [ ]

No [ ]

23. If not present when was it noticed?

Days

Months

Years

Post Natal

Bacterial Meningitis

Yes [ ]

No [ ]

Child Battering

Yes [ ]

No [ ]

Child shaking

Yes [ ]

No [ ]

Motor / bus / vehicle Accident

Yes [ ]

No [ ]

Accident Pedestrian

Yes [ ]

No [ ]

Fever with stiff neck

Yes [ ]

No [ ]

High Fever

Yes [ ]

No [ ]

Heat Stroke

Yes [ ]

No [ ]

Fall

Yes [ ]

No [ ]

Sickle Cell Anaemia

Yes [ ]

No [ ]

Near drowning

Yes [ ]

No [ ]

- Age when child was diagnosed

NUTRITION

24. What is the weekly menu of food normally taken at home.
a) Eggs
Weekly
b) Fish
Weekly
c) Meat
[ ]
Weekly
d) Chicken
Weekly
e) Dal
[
Weekly
f) Vegetable
Weekly 

g) Nan
$\left[\begin{array}{ll}1 & 3\end{array}\right.$
Weekly
h) Rice
[
Weekly
i) Fruit
[
Weekly

25. Please indicate where did you

1. Urban 2. Rural

lived during pregnancy of the disabled child

26. FATHER:

1. Age:

2. Occupation:

3. Net income of the family per month (I.D.) (Rs?)

i) Less than 1000

ii) Greater than 1000

4. Family History of any disability Yes [ ] No [ ]

If yes mention type of disability And relation

$1^{\text {st }}$ Generation [ ]

$2^{\text {nd }}$ Generation [ ]

$3^{\text {td }}$ Generation [ ]
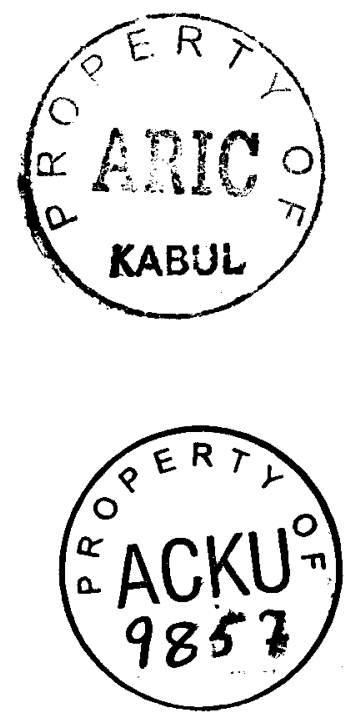
